Portland State University

PDXScholar

\title{
Analysis and Prediction of the Water Temperature of the McKenzie River, Oregon Using the Equilibrium Temperature Approach
}

R. Peder Hansen

Portland State University

Follow this and additional works at: https://pdxscholar.library.pdx.edu/open_access_etds

Part of the Civil Engineering Commons, and the Environmental Engineering Commons Let us know how access to this document benefits you.

\section{Recommended Citation}

Hansen, R. Peder, "Analysis and Prediction of the Water Temperature of the McKenzie River, Oregon Using the Equilibrium Temperature Approach" (1986). Dissertations and Theses. Paper 3610.

https://doi.org/10.15760/etd.5494

This Thesis is brought to you for free and open access. It has been accepted for inclusion in Dissertations and Theses by an authorized administrator of PDXScholar. Please contact us if we can make this document more accessible: pdxscholar@pdx.edu. 
AN ABSTRACT OF THE THESIS OF R. Peder Hansen for the Master of Science in Engineering: Civil presented June 20, 1986.

Title: Analysis and Prediction of the Water Temperature of the McKenzie River, Oregon, Using the Equilibrium Temperature Approach.

APPROVED BY MEMBERS OF THE THESIS COMMITTEE:

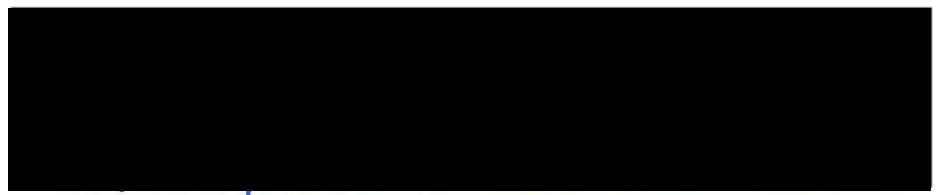

Roy W. Kpch, Chairman

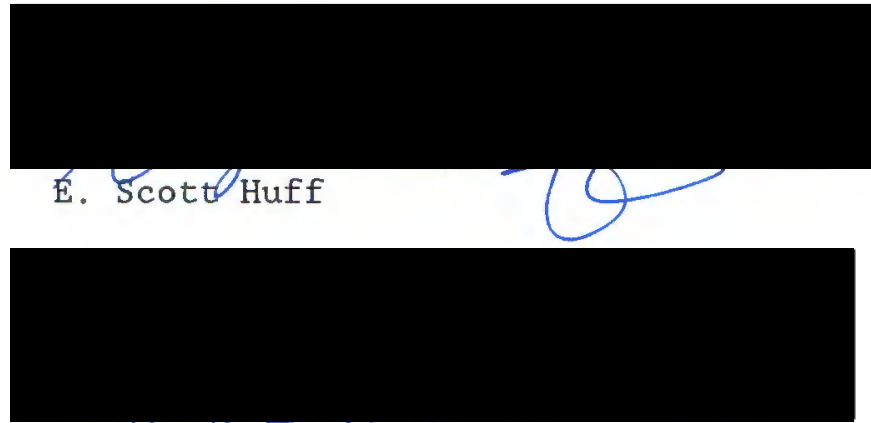

Graig AU Spolek

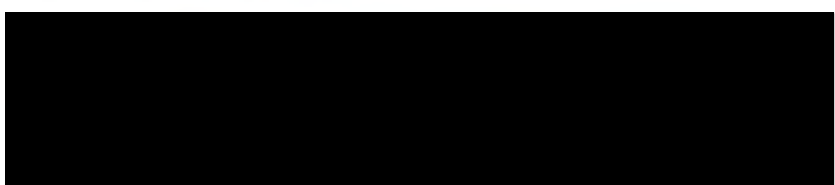

Richard R. Petersen

A one dimensional, steady flow, unsteady temperature model is used to evaluate the effects of two U.S. Army Corps of Engineers (COE) dams and resulting reservoirs on hourly water temperatures of the mainstem McKenzie River from Delta Park (RM 62.1) to Leaburg Dam (RM 38.8). Both COE projects are on tributaries to the McKenzie River and at present have only bottom withdrawl capabilities. 
Water temperatures were simulated using the equilibrium temperature approach with air temperature used to estimate equilibrium temperature and also using computed hourly equilibrium temperature. Results obtained using computed equilibrium temperatures were less satisfactory than results using air temperature to estimate equilibrium temperature. The much larger diel fluctuation of hourly equilibrium temperature as compared to air temperature accounts for this apparent contradiction.

A heat exchange parameter, HEP, was introduced during calibration to account for the additional surface area of a stream effectively available for heat transfer created by a multitude of riffles. Use of this parameter improved model results by increasing simulated daily maximums and diel fluctuations. Calibration produced a HEP value of 2.5 for the McKenzie River.

The model had a mean accuracy of near zero with a mean absolute deviation (MAD) of less than $0.4^{\circ} \mathrm{C}$ at Finn Rock (RM 54.2). A mean error of $0.6{ }^{\circ} \mathrm{C}$ and $\mathrm{MAD}$ of over $0.6{ }^{\circ} \mathrm{C}$ at Leaburg Dam (RM 38.8) indicates that accuracy decreased downstream from Finn Rock.

COE reservoir effects were examined for a one week period in each of the months of July, August, and September, 1984. COE reservoirs had a cooling effect at Finn Rock during all three periods. Cooling effects were found at Leaburg Dam during August and September with no effects found in July. The overall result of COE reservoirs during these periods was a decrease in mean water temperature and a decrease in diel fluctuation at Finn Rock, but an increase in diel fluctuation at Leaburg Dam. 
ANALYSIS AND PREDICTION OF THE WATER TEMPERATURE OF THE MCKENZIE RIVER, OREGON USING THE EQUILIBRIUM TEMPERATURE APPROACH

\author{
by \\ R. PEDER HANSEN
}

A thesis submitted in partial fulfillment of the requirements for the degree of

\author{
MASTER OF SCIENCE \\ in \\ CIVIL ENGINEERING
}

Portland state University 
TO THE OFFICE OF GRADUATE STUDIES AND RESEARCH:

The members of the Committee approve the thesis of R. Peder Hansen presented June 20, 1986.

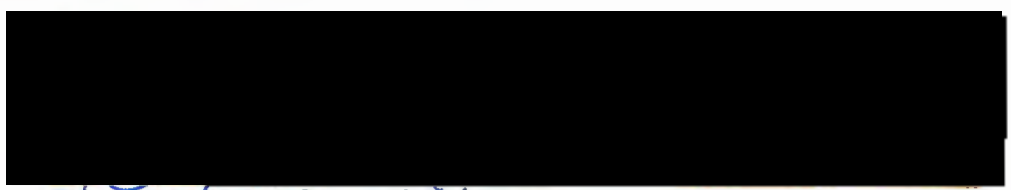

$$
\text { Roy w, Koch, Chairman }
$$
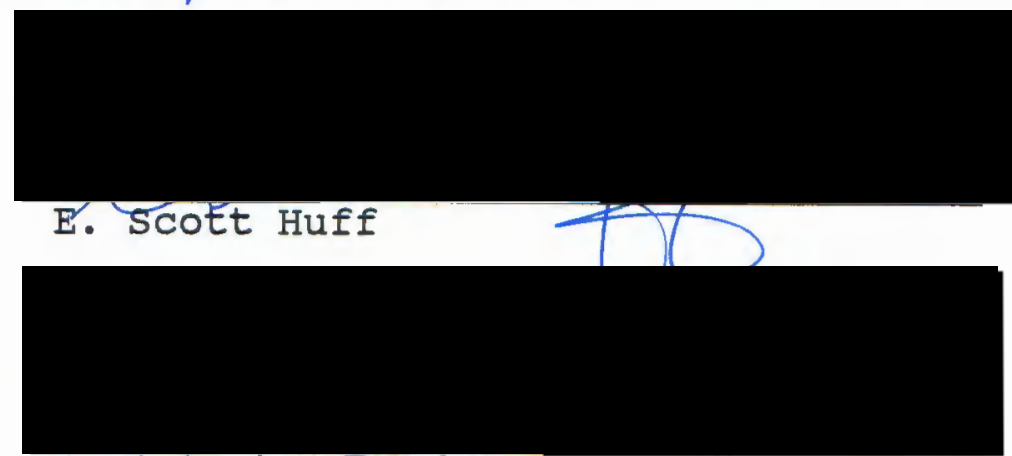

Graig/ A./ Spolek

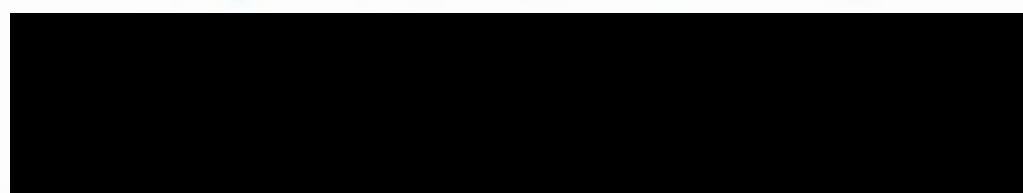

Richard R. Petersen

APPROVED:

Franz N. Rad, Head, Department of Civil Engineering 


\section{ACKNOWLEDGEMENTS}

First and foremost, I would like to thank my wife, Deb, for her patience, encouragement, and support throughout my graduate studies, and my daughter, Heather, for the inspiration to keep going when things got tough.

Secondly, I would like to thank my colleagues of the U.S. Geological Survey, Water Resources Division, Portland, Oregon and especially Tony Laenen for the opportunity to perform this research and discuss various aspects of it.

Next, I would like to thank Dr. Tom Morse of the U.S. Army Corps of Engineers, Portland District, for many valuable discussions regarding temperature modeling.

I would also like to thank Dr. Roy Koch for his instruction in the area of water resources engineering and his valuable criticism of initial drafts of this manuscript.

Finally, I would like to thank my family for their unwavering support and encouragement, not only during graduate school, but also throughout my life. 
TABLE OF CONTENTS

PAGE

ACKNOWLEDGEMENTS . . . . . . . . . . . . . . . . . . . . . . . iii

LIST OF TABLES . . . . . . . . . . . . . . . . . . . . . . . . vi vi

LIST OF FIGURES . . . . . . . . . . . . . . . . . . . . . . . . . vii

LIST OF SYMBOLS USED . . . . . . . . . . . . . . . . . . . . . . . $\mathrm{x}$

CHAPTER

I INTRODUCTION . . . . . . . . . . . . . . . . 1

The research stategy . . . . . . . . . . . . 2

Scope . . . . . . . . . . . . . . . . . 4

II BACKGROUND . . . . . . . . . . . . . . . . . . . 6

Temperature modeling in rivers . . . . . . . . 7

Heat transfer in water . . . . . . . . . . . . 8

Heat transport in water.... . . . . . . . 9

III AIR/WATER INTERFACE HEAT EXCHANGE . . . . . . . . . . 12

Components . . . . . . . . . . . . . . . . . . . . 12

Solar radiation... . . . . . . . . . . . 14

Atmospheric radiation . . . . . . . . . . 15

Back radiation . . . . . . . . . . . . . 17

Evaporation . . . . . . . . . . . . . . . . 18

Conduction/convection . . . . . . . . . . . 19

Equilbrium temperature concept . . . . . . . . . 21 
CHAPTER

PAGE

IV

MODEL DESCRIPTION . . . . . . . . . . . . . . . . . . 27

Model equation . . . . . . . . . . . . . 27

Data requirements . . . . . . . . . . . . . . 31

Parameters . . . . . . . . . . . . . 32

V APPLICATION TO THE MCKENZIE RIVER . . . . . . . . . . 37

Physical setting . . . . . . . . . . . . . . 37

Geography/geology . . . . . . . . . . . 37

Climate... . . . . . . . . . . . . 39

Riverine description . . . . . . . . . . . . . 40

Reservoirs . . . . . . . . . . . . . . . . 42

Data network . . . . . . . . . . . . 43

Existing long-term stations . . . . . . . . . 43

Additional sites . . . . . . . . . . . . . 45

Field surveys . . . . . . . . . . . . . . . 46

Model segmentation . . . . . . . . . . . . . 47

Calibration . . . . . . . . . . . . . . 53

Calculated equilibrium temperature . . . . . 54

Topwidth parameter . . . . . . . . . . 60

Validation . . . . . . . . . . . . . . 64

Sensitivity . . . . . . . . . . . . . . . . . . . 70

Accuracy . . . . . . . . . . . . . . 73

Analysis of effects.............. . . 75

VI SUMMARY, CONCLUSIONS, AND RECOMMENDATIONS . . . . . . 87

Summary . . . . . . . . . . . . . . . . . . . . 87

Conclusions . . . . . . . . . . . . . . . . . . . . 88

Recommendations . . . . . . . . . . . . . 89

REFERENCES CITED . . . . . . . . . . . . . . . . . . . . . . . . . 91

APPENDIX . . . . . . . . . . . . . . . . . . . . . . . . . . . 94 


\section{LIST OF TABLES}

TABLE

PAGE

I Selected meteorological normals (1951-1980), means and extremes for Eugene, Oregon, 1942-1984 . . . . . . . 39

II Period of record for each variable at long-term stations . . . . . . . . . . . . . . . . . 44

III Comparative statistics between equilibrium, air, and water temperatures for the period June 22 , to September 24,1984 . . . . . . . . . . . . . . 59

IV Sensitivity analysis summary for selected parameters and variables... . . . . . . . . . . . . 71

V Model accuracy . . . . . . . . . . . . . . 74

VI With- and without-reservoir comparisons . . . . . . . . 84 


\section{LIST OF FIGURES}

FIGURE

PAGE

3.1 Components of heat transfer at a water surface . . . . . 13

3.2 Schematic of river cross section used to determine the part of the water surface to be shaded by bank vegetation. From Jobson and Keefer, 1979 . . . . . 16

3.3a Comparison of water temperatures in Pigeon Creek to mean monthly air temperatures at Evansville, Indiana. From Jobson, 1980a . . . . . . . . . . . . . . 24

3.3b Comparison of monthly mean water temperatures of the

Kansas River at Topeka to monthly mean air

temperatures at Topeka, Kansas. From Jobson, 1980a . 25

4.1 Schematic of a longitudinal section of a river with fluid parcels delineated to illustrate the dispersive process. From Jobson, 1980a . . . . . . . . . . 30

4.2 Example model input data set . . . . . . . . . . . . . 33

4.3a Example model output, header page . . . . . . . . . . 34

4.3b Example model output, data table . . . . . . . . . . . 35

5.1 Map showing McKenzie River basin with data recorder sites... . . . . . . . . . . . . . . 38

5.2 Water temperature cross-sections at selected locations on the McKenzie River . . . . . . . . . . . . . . . 48 
5.3 Comparison of recorded water temperatures of the downstream end of Leaburg power canal, the McKenzie River at Leaburg, and the McKenzie River at Leaburg Dam . . 50

5.4 Schematic of model segmentation for the McKenzie River . 52

5.5a Comparison of modeled versus recorded water temperatures at Finn Rock for the initial model run using air temperature to estimate equilibrium temperature . . . 55

5.5b Comparison of modeled versus recorded water temperatures at Leaburg Dam for the initial model run using air temperature to estimate equilibrium temperature . . . 56

5.6a Comparison of modeled versus recorded water temperatures at Finn Rock using calculated equilibrium temperatures 57 5.6b Comparison of modeled versus recorded water temperatures at Leaburg Dam using calculated equilibrium temperatures . . . . . . . . . . . . . . . . . . 58

5.7a Comparison of modeled versus recorded water temperatures at Finn Rock after final calibration using air temperature to estimate equilibrium temperature and a HEP value of 2.5 . . . . . . . . . . . . . . 62

5.7b Comparison of modeled versus recorded water temperatures at Leaburg Dam after final calibration using air temperature to estimate equilibrium temperature and a HEP value of 2.5 . . . . . . . . . . . . . . 63

5.8a Comparison of calibrated model versus recorded water temperatures at Finn Rock for the period July 11-17, 
5.8b Comparison of calibrated model versus recorded water temperatures at Leaburg Dam for the period July 11-17, 1984 . . . . . . . . . . . . . . . 66

5.9a Comparison of calibrated model versus recorded water

temperatures at Finn Rock for the period

September $1-7,1984$. . . . . . . . . . . . . . 67

5.9b Comparison of calibrated model versus recorded water

temperatures at Leaburg Dam for the period

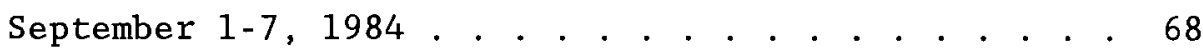

5.10 Graph showing recorded water temperatures at selected

stations for he period August 1-7, 1984 . . . . . . 69

5.11a Comparison of with- and without-reservoir simulations at

Finn Rock for the period July 11-17, 1984 . . . . . 78

5.11b Comparison of with- and without-reservoir simulations at

Leaburg Dam for the period July 11-17, 1984 . . . . . 79

5.12a Comparison of with- and without-reservoir simulations at

Finn Rock for the period August 1-7, 1984. . . . . 80

$5.12 \mathrm{~b}$ Comparison of with-and without-reservoir simulations at

Leaburg Dam for the period August 1-7, 1984. . . . . 81

5.13a Comparison of with-and without-reservoir simulations at

Finn Rock for the period September 1-7, 1984 . . . . 82

5.13b Comparison of with- and without-reservoir simulations at

Leaburg Dam for the period September 1-7, 1984 . . . 83 


\section{LIST OF SYMBOLS USED}

SYMBOL

DEFINITION
A = horizontal cross-sectional area of channel
B $=$ Bowen ratio
C $=$ coefficient
$c_{p}=$ specific heat of water
DQ = flow rate of water between parcels
$\mathrm{DQQ}=\mathrm{DQ} / \mathrm{Q}$
$\mathrm{Dx}=$ longitudinal dispersion coefficient
$\mathrm{E}=$ evaporation rate
$\mathbf{e}_{\mathbf{a}}=$ vapor pressure of air above the water
$\mathbf{e}_{\mathbf{0}}=$ saturation vapor pressure $=$ air at a temperature equal to that of the water surface
$\mathrm{H}=$ net heat exchange per unit area of air-water interface
$\mathrm{Ha}=$ incoming long-wave (atmospheric) radiation
Har $=$ reflected component of $\mathrm{Ha}$
$\mathrm{Hbr}=$ long-wave back radiation from a water body
Hc $=$ conductive (sensible) heat transfer
$\mathrm{He}=$ evaporative heat transfer
$\mathrm{Hs}=$ incoming short-wave (solar) radiation
Hsn $=$ net absorbed solar radiation
$\mathrm{Hsr}=$ reflected component of $\mathrm{Hs}$
$\mathrm{K}=$ exchange coefficient or parcel index number
$\mathrm{L}=$ latent heat of vaporization
$\mathrm{N}=$ mass transfer coefficient in the windspeed function 


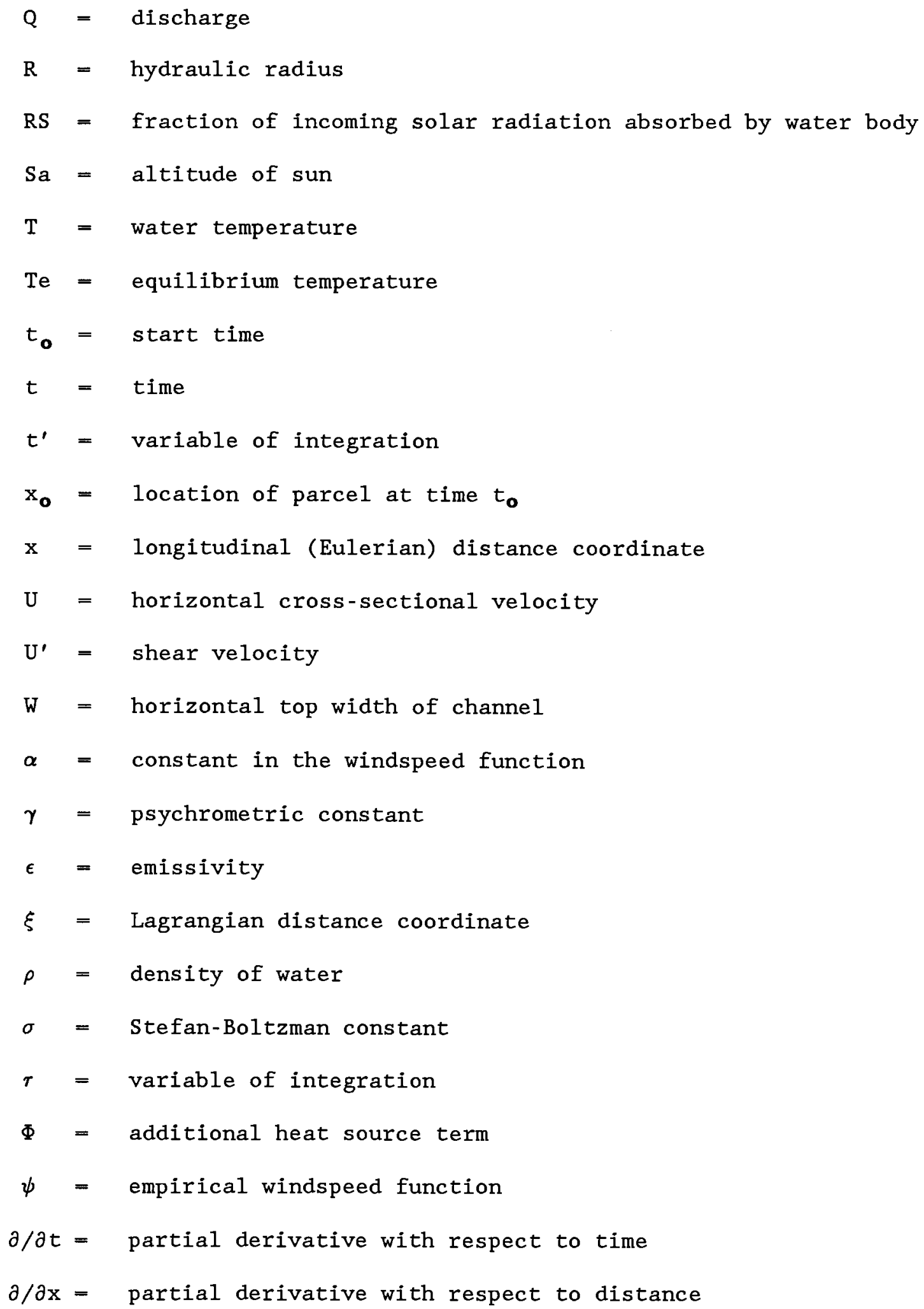


CHAPTER I

\section{INTRODUCTION}

Water temperature is an important water quality variable, since the rates of most chemical and biological reactions are temperature dependent, e.g., dissolved oxygen (D.O.) solubility decreases as temperature increases, and fish metabolism increases with temperature. Water temperature has a direct influence on the quality of water for domestic supplies, fisheries, waste assimilation, industrial and agricultural use. Because of its importance, modeling water temperature has become a necessary part of any study determining the effects of anthropogenic activity on natural rivers.

Man's effect on the water temperature in a drainage basin can be determined by measuring and comparing temperatures before and after significant basin changes, i.e., logging, agricultural development, or dam construction. This method requires stream temperature data before and after the activity, preferably at the same location. Temperature record preceding major activity is seldom available, or if available, is usually short. Correlation between sites can be used to extend short records, but estimation errors could easily mask minor changes in water temperature caused by anthropogenic effects.

Another approach would be to use a mathematical model to simulate pre- and post activity conditions. Models allow the flexibility of estimating effects before the activity is carried out. The ability to evaluate project impacts before construction or land use changes occur 
makes the model approach desirable to decision makers. Even though models may have high predictive value, they should not be used without caveats. Most models require calibration. Prediction outside the range of calibration is questionable and has no firm basis for error assessment.

The U. S. Army Corps of Engineers (COE) has constructed dams on two tributaries of the McKenzie River east of Eugene, Oregon. The effects of releases from these dams on water temperatures of the mainstem Mckenzie River below the tributary confluences have not been fully determined. The subject of this thesis is the quantification of the effects of these COE reservoirs on the water temperature of the mainstem McKenzie River using a mathematical model.

\section{THE RESEARCH STRATEGY}

A research strategy is a plan for a systematic inquiry into a subject in order to discover, or check, facts. The logical place to begin such an inquiry is with a definition of what is to be examined (water temperature) and the tool to be used (mathematical model). Temperature is a measure of the thermal (heat) energy of a body. A model is a representation of a system, and a mathematical model is a type of model whereby system behavior is represented by equations. Thus, a mathematical model of water temperature is a representation of the thermodynamics of a water system, e.g. a stream. Basically the model consists of two components. The first component evaluates heat transfer and the second, heat transport. 
The accuracy of a water temperature model is dependent upon its ability to evaluate the energy exchange between the water and the surrounding media, and the transport of that thermal energy to a particular location. A major component of the energy exchange process is atmospheric heat exchange. This depends on the meteorological variables of solar (shortwave) and atmospheric (longwave) radiation, air temperature, windspeed, and vapor pressure.

For most applications, the data necessary to compute the complete energy exchange is not available. In these instances, simplified expressions estimating heat exchange must be used. One such simplified expression makes use of the equilibrium temperature concept. The equilibrium temperature is the water temperature at which the net heat exchange between water and atmosphere is zero. The expression takes the form:

$$
H=-K\left(T-T_{e}\right)
$$

where $\mathrm{H}$ is the net heat exchange per unit area of air-water interface, $\mathrm{K}$ is an exchange coefficient, $T$ is the water temperature and $T_{e}$ is the equilibrium temperature. The development of this equation will be presented in detail later.

A simplified temperature model developed by Jobson (1980a) using equation 1.1 was used successfully to evaluate the effects of a COE reservoir on the North Santiam River near Salem, Oregon (Laenen and Hansen, 1985). The North Santiam River is similar in character to the McKenzie River. The major difference in the basins is the location of the reservoirs. On the North Santiam River, the reservoir is located on the mainstem whereas COE reservoirs in the McKenzie basin are on 
tributaries to the mainstem. Also, Laenen and Hansen used atmospheric data from outside the basin and had only four temperature recorders to cover 42.7 miles of river and a major tributary. A much more comprehensive data collection network was employed on the McKenzie River.

Jobson's simplified model requires a minimum of meteorological data, using only equilibrium temperature and windspeed. According to Jobson (1980a, p. 27) "... air temperature can be substituted for equilibrium temperature for most practical applications to predict water temperatures to within \pm 1 or $2{ }^{\circ} \mathrm{C} . "$ Air temperature was collected within the basin on the McKenzie River to give an estimate of the equilibrium temperature. In addition, atmospheric data necessary to compute the equilibrium temperature were collected for a short period (June 22 to September 24,1984$)$. The computation of the actual equilibrium temperature should yield better modeling results than when air temperature is used as an estimate. If a relation can be established between the computed equilibrium temperature and air temperature, then this relation can be used to improve air temperature as an estimate of equilibrium temperature and should improve the accuracy of the temperature model.

\section{SCOPE}

This thesis documents the calibration, verification, and validation of a one dimensional, unsteady temperature, steady, non-uniform flow model. The temperature model uses the equilibrium temperature approach. When sufficient data are available, the equilibrium temperature is calculated directly. Otherwise, air temperature is used to estimate equilibrium temperature. A comparison between model results 
using calculated and estimated equilibrium temperature values is made. A heat exchange parameter is introduced during calibration to improve model accuracy. The validated model is then used to determine the effects of COE reservoirs on the mainstem McKenzie River under present operating policy for selected periods in 1983 and 1984. Finally, recommendations for future analysis and applications are given. 
CHAPTER II

\section{BACKGROUND}

Modeling of water temperatures has generated a plethora of literature over the past 15 to 20 years. This was mainly due to increased concern for the environment and new awareness of the effects of water temperature changes on the nations streams. An increased need for cooling facilities due to tremendous growth in the demand for electricity spawned an influx of new ideas and approaches to water temperature modeling. Much early effort was spent on trying to learn more about the physics of heat transfer at the air-water interface. The late 1960's and early $1970^{\prime}$ s saw many studies investigating the thermal loading (addition of water with temperatures significantly above or below natural stream temperatures) of streams (Edinger and Geyer, 1965; Dingman et al, 1968; Jobson, 1973; Paily et a1, 1974; Hills and Viskanta, 1976; Jackman and Yotsukura, 1977) Other authors investigated the theoretical aspects of water temperature modeling (Edinger et al, 1968; Edinger, 1970; Dingman, 1972; Yotsukura et a1, 1973; and Noble, 1981) as well as practical applications (Brown, 1969; Morse, 1970, 1972; Brocard and Harleman, 1976; Jobson, 1980a, 1980b; Stang, 1982; Laenen and Hansen, 1985).

Despite many advances, the behavior of many natural phenomena still defy complete description. A trend toward simplistic modeling approaches has come about due to a scarcity of, or expense in collecting, field data. 
The approach taken in this thesis, the equilibrium temperature approach, is classified as a simplistic approach. Before describing the equilibrium temperature approach, some basic types of water temperature models and concepts of heat transfer and transport in water are given.

\section{TEMPERATURE MODELING IN RIVERS}

Temperature modeling in rivers can be roughly delineated into three categories: 1) models using conservation of energy or heat budget analysis (physically based and completely deterministic), 2) models having a deterministic component from 1 above, but also including a random component (stochastic), and 3) models based on statistical analysis of past data at the same location (harmonic analysis) or nearby locations (correlation analysis). Data availability, project purpose, and desired accuracy dictate which model type to use for a specific application.

Models in category 1 are the most pervasive and are detailed further. Models in category 2 can be used for forecasting possible future scenarios (McMichael and Hunter, 1972), but will not be presented in further detail. Models in category 3 can be used for data record extension or to fill in missing data (Moore, 1967). Category 3 models can also be used to examine pre- and post-activity effects (Kothandaraman, 1971) if sufficient pre- and post-project data are available. These models also will not be described in more detail.

While all three types of models can be used for simulation purposes, not all three can be used if changes in a system are sought. 
Empirical formulae (category 3) should only be used within the limits of the conditions under which they were established. Models with a stochastic component can be used to give probable ranges of system changes. Physically based models, because they are based on the physics of a system, can be used under any range of conditions. They are best for cases requiring both prediction and changes in the system. The model used in this thesis is a mathematical physically based model.

A physically based model relies on the determination of the most significant processes and representation of their contribution with mathematical expressions. The relevant components of heat transfer and transport required for this study are now presented.

\section{HEAT TRANSFER IN WATER}

The total heat budget for a water body includes the effects of atmospheric heat exchange at the air-water interface, surface and subsurface inflows and outflows (including precipitation and groundwater), heat transfer through the streambed, and heat generated by chemical-biological reactions. For most practical purposes, the dominant heat transfer process of natural water bodies is atmospheric heat exchange. This primary process is covered in detail in a later chapter.

Even though the energy-budget equation adequately describes the heat exchange at the air-water interface, it is not suitable for describing heat transport. This is the topic of the next section. 
HEAT TRANSPORT IN WATER

A stream, the body of water under consideration here, is in constant motion. For this reason, it is not enough to examine only the heat transfer components of the system, but also how the heat, once transferred, is transported downstream.

Downstream transport takes place in two forms, advection and dispersion, with advection the dominant mechanism in streams. Advection is the longitudinal (assuming one-dimensional) translation due to velocity. Dispersion is translation due to molecular and turbulent mixing. Turbulence is by far the more important dispersion mechanism in natural systems.

Historically, the transport in streams has been approached in the Eulerian sense. Applying the principal of conservation of thermal energy to a one-dimensional open channel, the governing equation is

$$
\frac{\partial \mathrm{T}}{\partial \mathrm{t}}+\mathrm{U} \frac{\partial \mathrm{T}}{\partial \mathrm{x}}=\mathrm{Dx} \frac{\partial^{2} \mathrm{~T}}{\partial \mathrm{x}^{2}}+\frac{\mathrm{H} \mathrm{W}}{\mathrm{A} \mathrm{C}_{\mathbf{p}} \rho}
$$

in which $\mathrm{T}$ = average cross-sectional water temperature; $t=t i m e ; U=$ cross-sectional average velocity in the $\mathrm{x}$ direction; $\mathrm{x}=$ longitudinal coordinate; $\mathrm{Dx}=$ longitudinal dispersion coefficient; $\mathrm{H}=$ net rate of heat exchange at the water surface per unit area; $W=$ top width of the channel; $A=$ horizontal cross-sectional area of the channel; $c_{\mathbf{p}}=$ specific heat of water at constant pressure; and $\rho=$ density of water. In the Eulerian formulation, one conceptually sits at a point and observes what is going by. Except for the simple case of constant $U$ and $\mathrm{Dx}$, the resulting convective-diffusion equation is mathematically complex and solutions contain an undesirably large amount of numerical 
dispersion (Jobson, 1980a). Generally, both the mathematical complexity and numerical dispersion are the results of attempts to accurately simulate the advective term of the equation (second term, left hand side). These sentiments are echoed by Pinder and Shapiro (1979) when they noted that:

While considerable effort has been expended in the development of numerical schemes for the accurate solution of the transport equation, no existing methodology is entirely satisfactory. Standard numerical approaches based on finite differences, finite elements, and other weighted residual methods characteristically trade off numerical dispersion for numerical diffusion. It is well known that the source of the difficulty resides in the fact that for convective-dominated transport the governing equation behaves as a first-order hyperbolic equation rather than as a second-order parabolic equation. Thus numerical methods developed for parabolic equations are not entirely satisfactory.

A second approach utilizes the Lagrangian formulation. In the Lagrangian framework, an individual fluid parcel is followed while keeping track of the factors which change its temperature. This is not just a change of variable but a different formulation of the problem. Applying the thermal continuity equation, the Lagrangian equivalent of equation 2.1 is:

$$
\frac{\partial T}{\partial t}=D x \frac{\partial^{2} \mathrm{~T}}{\partial \xi^{2}}+\frac{\mathrm{HW}}{\mathrm{A} C_{\mathbf{p} \rho} \rho}
$$

and $\xi=$ Lagrangian distance coordinate. $\xi$ is related to $\mathrm{x}$ by the expression:

$$
\xi=\mathrm{x}-\mathrm{x}_{\mathbf{0}}-\int_{\mathrm{t}_{\mathbf{0}}}^{\mathrm{t}} \mathrm{u} \mathrm{d} \tau
$$

where $\mathrm{x}_{0}=$ location of parcel at time $t_{0}$ and $r$ is the variable of integration. Note that the advection term does not appear in equation 2.2. In the Lagrangian formulation, longitudinal dispersion can be 
veiwed as caused by the difference in velocity between points in the cross-section. It is mainly a correction factor to account for treating a three dimensional problem by use of a one-dimensional equation (Jobson, 1980a). Transforming the Lagrangian solution back to a Eulerian (fixed) coordinate system is somewhat involved, but straightforward (Jobson, 1980a) and is accomplished by tracking the location of each parcel using equation 2.3 with $\xi=0$.

According to Jobson (1980c), "The Eulerian reference frame was adapted as standard long before the advent of the digital computer, probably because of the bookkeeping problems associated with solutions in the more natural Lagrangian reference frame." The Lagrangian solution scheme is simple to understand in the physical sense, and provides accurate, stable solutions. For these reasons, the Lagrangian formulation is the one used in the temperature model presented here. 


\section{AIR-WATER INTERFACE HEAT EXCHANGE}

The principal heat transfer process in natural water bodies is atmospheric heat exchange. The net heat exchange at the air-water interface can be expressed as:

$$
\mathrm{H}=\mathrm{Hs}-\mathrm{Hsr}+\mathrm{Ha}-\mathrm{Har}-\mathrm{Hbr} \pm \mathrm{He} \pm \mathrm{Hc}
$$

where $\mathrm{H}=$ rate of net heat exchange per unit area of water surface; Hs = incoming short wave (solar) radiation; Hsr = solar radiation reflected from the water surface; Ha = long wave (atmospheric) radiation; Har = atmospheric radiation reflected from the water surface; Hbr = long wave back radiation from the water body; He = evaporative heat transfer; and $\mathrm{Hc}=$ conductive/convective (sensible) heat transfer. The Hs, Hsr, Ha, and Har terms are water temperature independent, while the $\mathrm{Hbr}$, He, and Hc terms are water temperature dependent. Figure 3.1 schematically illustrates the air-water interface heat exchange components.

\section{COMPONENTS}

Each component of the air-water interface heat exchange equation will now be examined in detail. The instrumentation, calculation procedures, and/or empirical formulae required for computation of each component is presented. 


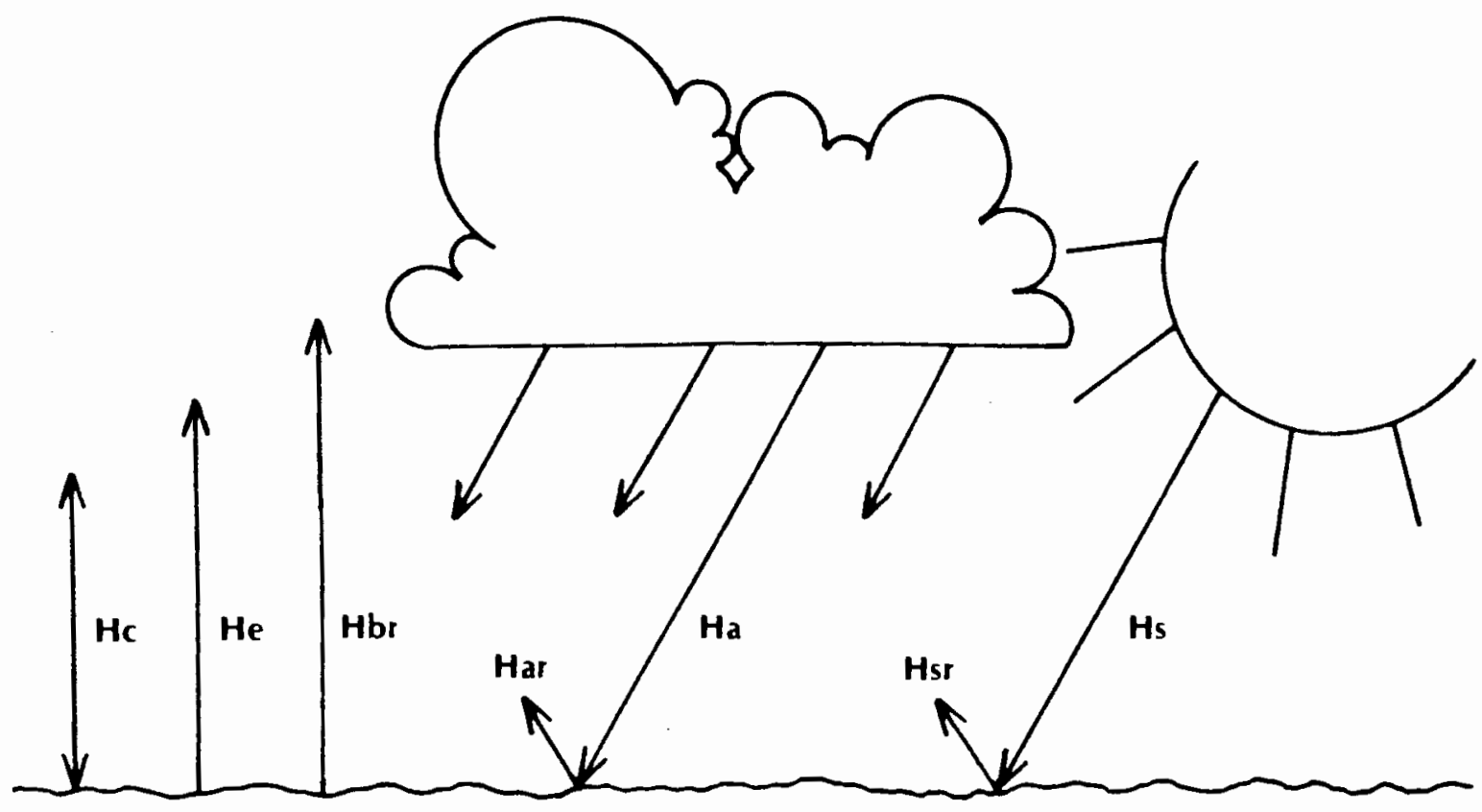

$H_{5}=$ Short wave solar radiation

$\mathrm{Ha}=$ Long wave atmospheric radiation

Hsr = Reflected solar radiation

Har = Reflected atmospheric radiation

Water remperature independent terms

$\mathrm{Hbr}=$ Long wave back radiation

$\mathrm{HC}=$ Conductive heal transler

W'ater

$\mathrm{He}=$ Evaporative heal transfer temperature dependent terms

Figure 3.1 Components of heat transfer at a water surface. 


\section{Solar radiation}

The source of all solar radiation is the sun. Incoming solar radiation can be measured directly using a pyranometer. However, objects between the sun and the water surface (e.g. clouds, vegetation) can intercept much of the solar radiation. In addition, not all incident solar radiation is absorbed by the water, some is reflected. The fraction of the measured solar radiation actually absorbed by the water is related to time of day, time of year and amount of exposed (unshaded) stream surface area.

A procedure to estimate the part of the measured solar radiation actually absorbed by the water can be found in Jobson and Keefer, (1979), and is summarized here. First, the portion of the measured solar radiation that is absorbed if none of the water surface is shaded is calculated. This shade-free absorption can be computed using an expression proposed by Anderson (1954, p.85);

$$
\mathrm{RS}=1-1.18 * \mathrm{Sa}^{-0.77}
$$

where RS is the decimal fraction of the incoming solar radiation absorbed by the water and $\mathrm{Sa}$ is the altitude of the sun in degrees. Then, the shade-free absorption is reduced to account for shading of the water due to trees and banks. It can be assumed that the shaded portion of the water surface absorbs 20 percent of the measured radiation and the unshaded portion absorbs RS times the measured radiation. The part of the water surface shaded at any time of day is determined from the geometric relation between the elevation and azimuth of the sun, the azimuth of 
the stream reach, the water surface width, the bank width and the effective barrier height. The physical relation between these terms is illustrated in figure 3.2.

The above procedure can be summarized by the equation:

$$
\text { Hsn }=\text { Hs }[\text { RS (fraction surface unshaded) + }
$$

0.2 (fraction surface shaded)]

and Hsn is the net absorbed solar radiation. Hsn is also equal to Hs Hsr from equation 3.1. The units used are heat (calories, BTU's) per unit area $\left(\mathrm{cm}^{2}, \mathrm{ft}^{2}\right)$ per time (hour, day).

Theoretically, a pyranometer submerged just below the water surface should produce the same results as equation 3.3 for an open reach. Since pyranometers are not submersible and keeping the instrument at the proper depth is difficult, this approach is not feasible for any practical application at present.

When direct measurements are not available, empirical relations using other observable meteorological data (e.g. cloud cover) must be employed. Edinger and Geyer (1965), Ryan and Stolzenbach (1972), and the Tennessee Valley Authority (1972), present various empirical relations for solar as well as atmospheric radiation. For the purposes of this study, incoming solar radiation is measured using an Epply Precision Spectral Pyranometer. The reflected component is calculated using the method described above.

\section{Atmospheric radiation}

Atmospheric radiation is the thermal radiation primarily due to water vapor, carbon dioxide, and ozone components of the atmosphere (Ryan and Stolzenbach, 1972). In many cases, it is second in magnitude only to the longwave radiation from the water surface itself. 


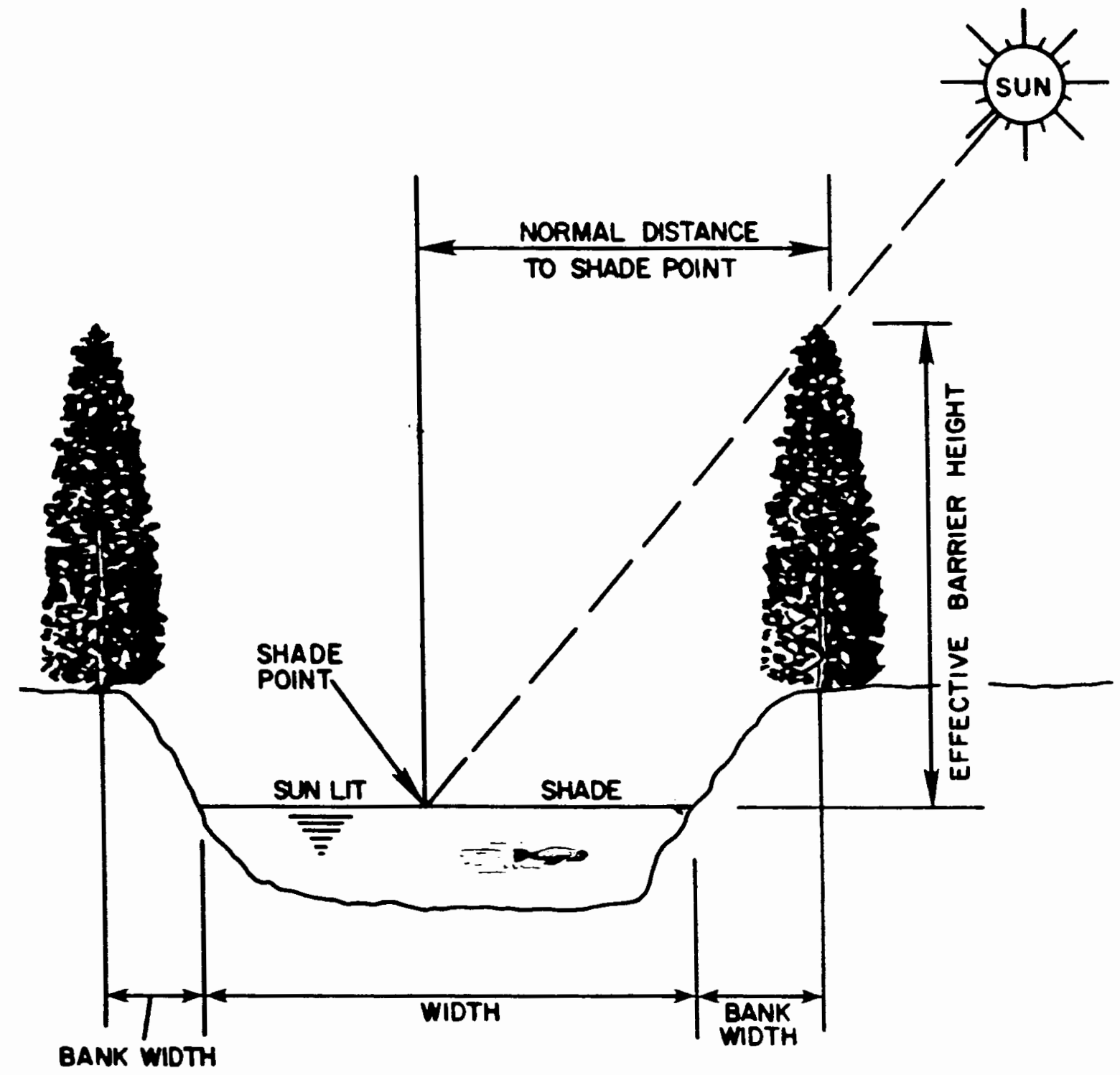

Figure 3.2 Schematic of river cross-section used to determine the part of the water surface to be shaded by bank vegetation. From Jobson and Keefer, 1979. 
Atmospheric radiation is measured using a pyrgeometer (Fritschen and Gay, 1979). Incoming (incident) atmospheric radiation is measured using the instrument upright while the reflected component can be measured by inverting the pyrgeometer. The traditional assumption is that three percent of the measured atmospheric radiation is reflected (Anderson, 1954, p. 98). Therefore, the atmospheric radiation absorbed at the air-water interface is 0.97 times the measured incoming radiation.

As mentioned previously, when direct measurement is not possible, empirical relations based on other observable meteorological data (e.g. air temperature, vapor pressure) must be used (Edinger and Geyer, 1965; Ryan and Stolzenbach, 1972; and the Tennessee Valley Authority, 1972). Atmospheric radiation was measured using an Epply Precision Infrared Radiometer for this study.

\section{Back radiation}

Al1 bodies at temperatures above absolute zero emit radiation. A body which emits the maximum possible radiation is a black body. The radiation emitted by a black body is given by the Stefan-Boltzman law:

$$
\mathrm{Hbr}=\sigma(\mathrm{T}+273.16)^{4}
$$

and $\mathrm{Hbr}=$ back (water surface) radiation, $\sigma=$ Stefan-Boltzman constant $\left(1.171 \times \quad 0^{-7} \mathrm{cal} / \mathrm{cm}^{2} \mathrm{~d}^{4} \mathrm{~K}^{4}\right), \quad \mathrm{T}=$ temperature of the body in ${ }^{\circ} \mathrm{C}$, and 273.16 converts to Kelvin temperature scale.

A body which emits less that the maximum possible radiation is a gray body. The ratio of radiation emission of a gray body to that of a black body is the emissivity. The Stefan-Boltzman Law can usually be applied to gray bodies after modification to: 


$$
\mathrm{Hbr}=\epsilon \sigma(\mathrm{T}+273.16)^{4}
$$

with $\epsilon=$ the gray body emissivity (dimensionless). Water is a gray body and has an emissivity of 0.97 . Equation 3.5 is used to calculate the water surface (back) radiation of a water body.

\section{Evaporation}

Heat is transferred from a body of water to the atmosphere through evaporation of the water. Each gram of water leaving a water body of temperature $10{ }^{\circ} \mathrm{C}$ as water vapor carries its latent heat of vaporization of about 590 calories. The rate of heat loss by evaporation, He, is usually expressed in the form:

$$
\mathrm{He}=\rho \mathrm{L} \mathrm{E}
$$

where $L=$ latent heat of vaporization $(L=595.9-0.545 \mathrm{~T} \mathrm{cal} / \mathrm{g})$ and $E$ $=$ evaporation rate in $\mathrm{cm} / \mathrm{d}$. It is in the determination of $\mathrm{E}$ that problems arise.

There are many methods for estimating evaporation. All of them are basically empirical (Edinger and Geyer, 1965). Ryan and Stolzenbach (1972) give an excellent summary of the many attempts to quantify $E$. Most of these formulae are of the form:

$$
E=\psi\left(e_{0}-e_{a}\right)
$$

where $\psi=$ an empirical function of windspeed, $e_{0}=$ saturation vapor pressure of air at a temperature equal to that of the water surface, and $e_{\mathbf{a}}=$ vapor pressure of the air above the water. The value of $e_{a}$ is measured and the value of $e_{0}$ can be determined from the water temperature using the empirical equation (Jobson, 1980a)

$$
e_{0}=\exp [52.418-6788.6 /(T+273.16)-5.0016 \ln (T+273.16)] 3.8
$$

The equation to calculate heat exchange due to evaporation is thus: 


$$
\mathrm{He}=\rho \mathrm{L} \psi\left(\mathrm{e}_{\mathbf{o}}-\mathrm{e}_{\mathbf{a}}\right)
$$

The wind function is generally assumed to be of the form:

$$
\psi=\alpha+\mathrm{N} \mathrm{V}
$$

in which $\alpha$ is a constant, $\mathrm{N}$ is a mass-transfer coefficient, and $\mathrm{V}$ is the windspeed. Formulae for $\psi$ use a variety of reference heights for windspeed. In addition, most formulae have been determined from lake or reservoir evaporation studies. Jobson (1973) noted that "Unfortunately there is a dearth of information concerning the (wind) function for evaporation from rivers."

From the thermal balance of a canal in southern California, Jobson $(1980 \mathrm{~b})$ found $\alpha=0.302 \mathrm{~cm} / \mathrm{d} \mathrm{kPa}$ and $\mathrm{N}=0.113 \mathrm{~cm} / \mathrm{d}(\mathrm{m} / \mathrm{s}) \mathrm{kPa}$. Comparisons to other wind functions indicate a larger evaporation at low windspeeds than using lake evaporation formulae, but the mass-transfer coefficient is within the range of values reported. The increased value of the wind function constant may be accounted for due to the relative motion between water and air generated by flow velocity even at zero windspeed. Since the values given above for $\alpha$ and $\mathrm{N}$ are the only wind function values found in the literature for flow in an open channel, they are the values used here.

\section{Conduction/convection}

Heat exchange by conduction/convection (sensible heat transfer) has received relatively little attention because its magnitude is usually small compared to evaporation heat exchange (Jobson, 1980b). Heat can enter or leave water as turbulent sensible (dry) heat conduction (Tennessee Valley Authority, 1973). Turbulent sensible heat transfer can take place by forced convection or by free convection. In 
the first case, air movement over the water imposed by outside forces (pressure differences, etc.) entrains heat and carries it away from the surface or transports heat to the surface. In the second case, the air movement and heat entrainment is due to density differences, which may be a consequence of differences in vapor content and/or temperature. Heat transfer by conduction/convection is a function of many variables in the same way as is mass-transfer (evaporation). Similarity arguments relating heat-transfer and mass transfer have been used by Bowen (1926) to arrive at a proportionality between heat conduction and heat lost by evaporation. Assuming the eddy diffusivities of heat and mass are approximately equal, then:

$$
\mathrm{B}=\frac{\mathrm{Hc}}{\mathrm{He}}=\frac{\gamma\left(\mathrm{T}-\mathrm{T}_{\mathbf{a}}\right)}{\left(\mathbf{e}_{\mathbf{o}}-\mathbf{e}_{\mathbf{a}}\right)}
$$

where $\mathrm{B}=$ the Bowen ratio and $\gamma=$ the psychrometric constant $=0.06$ $\mathrm{kPa} /{ }^{\circ} \mathrm{C}$. Hc can be determined from 3.9 and 3.11 as:

$$
\mathrm{Hc}=\gamma \rho \mathrm{L} \psi\left(\mathrm{T}-\mathrm{T}_{\mathbf{a}}\right)
$$

and all terms have been previously defined. The air temperature used in equations 3.11 and 3.12 should be measured at the same elevation as the vapor pressure in 3.11 (Jobson, 1980b).

Methods of measuring or calculating all the terms of the complete air-water interface heat exchange equation (equation 3.1 ) have now been presented. For various reasons (to be given shortly) a simplified approach is sometimes used. This approach uses the equilibrium temperature concept, the topic of the next section. 


\section{EQUILIBRIUM TEMPERATURE CONCEPT}

From the previous discussion, it is seen that the evaluation of all the components which contribute to air-water interface heat exchange requires that a significant amount of meteorological data be collected or estimated. These data include solar and atmospheric radiation (plus reflected components of each must be measured or estimated), air temperature, windspeed, vapor pressure (or relative humidity), and cloud cover (depending on formulations used). Instrumentation required to collect these meteorological data are expensive to acquire and maintain (calibration checks, etc.). In addition, complete long term meteorological data for historic and extreme conditions simulations are not normally available. The concept of an equilibrium temperature was developed to overcome some of these deficiencies.

The equilibrium temperature of a water body is the temperature at which there is no net exchange of energy with the atmosphere. It is the temperature a water body will tend to reach for a specified set of meteorological variables and is constant when the meteorological conditions are stable. The equilibrium approach makes use of equation 1.1 , repeated here for convenience:

$$
\mathrm{H}=-\mathrm{K}\left(\mathrm{T}-\mathrm{T}_{\mathbf{e}}\right)
$$

and all terms are as previously defined.

From equation 3.13 , it is seen that a water body with a temperature below equilibrium temperature will approach equilibrium by warming, and conversely a body of water whose temperature is above equilibrium will approach equilibrium by cooling. Stated another way, a body of water that is warming up has a temperature below equilibrium and a body 
cooling down has a temperature above equilibrium. The larger the difference between the water body temperature and equilibrium temperature, the higher the rate of net heat exchange.

In order to use the simplified net surface exchange expression given in 3.13 , the surface exchange coefficient, $K$, must be determined. A complete expression for the net heat flux is (equations $3.1,3.5,3.9$, and 3.12$)$ :

$$
\mathrm{H}=\mathrm{Hn}-\epsilon \sigma(\mathrm{T}+273.16)^{4}-\rho \mathrm{L} \psi\left[\left(\mathbf{e}_{\mathbf{o}}-\mathbf{e}_{\mathbf{a}}\right)+\gamma\left(\mathrm{T}-\mathrm{T}_{\mathbf{a}}\right)\right]
$$

with $\mathrm{Hn}=$ net absorbed radiation $=\mathrm{Hs}+\mathrm{Ha}-\mathrm{Hsr}-\mathrm{Har}$. At the equilibrium temperature, $\mathrm{H}=0$ and 3.14 becomes

$$
\mathrm{Hn}=\epsilon \sigma\left(\mathrm{T}_{\mathbf{e}}+273.16\right)^{4}+\rho \mathrm{L} \psi\left[\left(\mathrm{e}_{\mathbf{o}}-\mathbf{e}_{\mathbf{a}}\right)+\gamma\left(\mathrm{T}_{\mathbf{e}}-\mathrm{T}_{\mathbf{a}}\right)\right]
$$

where $e_{0}$ is evaluated at $T_{e}$. Differentiating equations 3.13 and 3.14 with respect to water temperature and setting the slopes equal gives

$$
\begin{aligned}
\frac{\partial H}{\partial T}=-\mathrm{K}=-4 \epsilon \sigma(\mathrm{T} & +273.16)^{3}-\rho \mathrm{L} \psi\left[\frac{\partial \mathrm{e}_{\mathbf{o}}}{\partial \mathrm{T}}+\gamma\right] \\
& +0.545 \rho \psi\left[\left(\mathrm{e}_{\mathbf{o}}-\mathrm{e}_{\mathbf{a}}\right)+\left(\mathrm{T}-\mathrm{T}_{\mathbf{a}}\right)\right]
\end{aligned}
$$

the last term of which is small compared to the previous terms and can be neglected.

The exchange coefficient is determined from 3.16 as

$$
\mathrm{K}=4 \epsilon \sigma(\mathrm{T}+273.16)^{3}+\rho \mathrm{L} \psi\left[\frac{\partial \mathrm{e}_{\mathrm{o}}}{\partial \mathrm{T}}+\gamma\right]
$$

and the slope $\partial e_{o} / \partial T$ is determined from an empirical expression for the vapor pressure in $\mathrm{kPa} /{ }^{\circ} \mathrm{C}$ (Jobson, 1980a) as

$$
\left.\frac{\partial e_{0}}{\partial T}\right|_{T}=\frac{1.1532 \times 10^{11} \exp [-4271.1 /(T+242.63)]}{(T+242.63)^{2}}
$$

From equations 3.17 and 3.18 , it is observed that the only data required for the determination of $\mathrm{K}$ are water temperature and windspeed. 
Windspeed is therefore the only meteorological variable required to calculate $\mathrm{K}$.

At this point there is no justification to solve for the equilibrium temperature (solving equation 3.15 for $T$ ) since it gives no advantage to solving the complete expression in 3.14 . On the other hand, an easily obtainable estimate of the equilibrium temperature would make the use of equation 3.13 quite attractive.

Observations show that weekly or monthly average water and air temperatures relate well over time (figure 3.3). Dingman (1972, p 42) observed that if air-water interface exchange "... occurred only by conduction and convection, the equilibrium temperature would equal the air temperature near the water surface." Jobson (1980a, p 27) stated, "It is believed that air temperature can be substituted for equilibrium temperature for most practical applications to predict water temperature to within \pm 1 or $2{ }^{\circ} \mathrm{C} . "$ Jobson makes no reference to time period length however. If Jobson's proposal of using air temperature to estimate equilibrium temperature is followed, equation 3.13 becomes:

$$
\mathrm{H}=-\mathrm{K}\left(\mathrm{T}-\mathrm{T}_{\mathbf{a}}\right)
$$

and $\mathrm{T}_{\mathbf{a}}$ is the air temperature. Laenen and Hansen (1985) have used 3.19 for time period lengths of one hour with success.

Unfortunately, air temperature is not the godsend it appears upon initial examination. Dingman (1972, p 47) shows the equilibrium temperature reaches its maximum earlier in the day than air temperature. Edinger, et a1. (1968 p 1142) state the equilibrium temperature may have as much as a $50^{\circ} \mathrm{C}$ diel fluctuation, much larger than the normal air temperature diel change. In light of Laenen and Hansen's work though, 


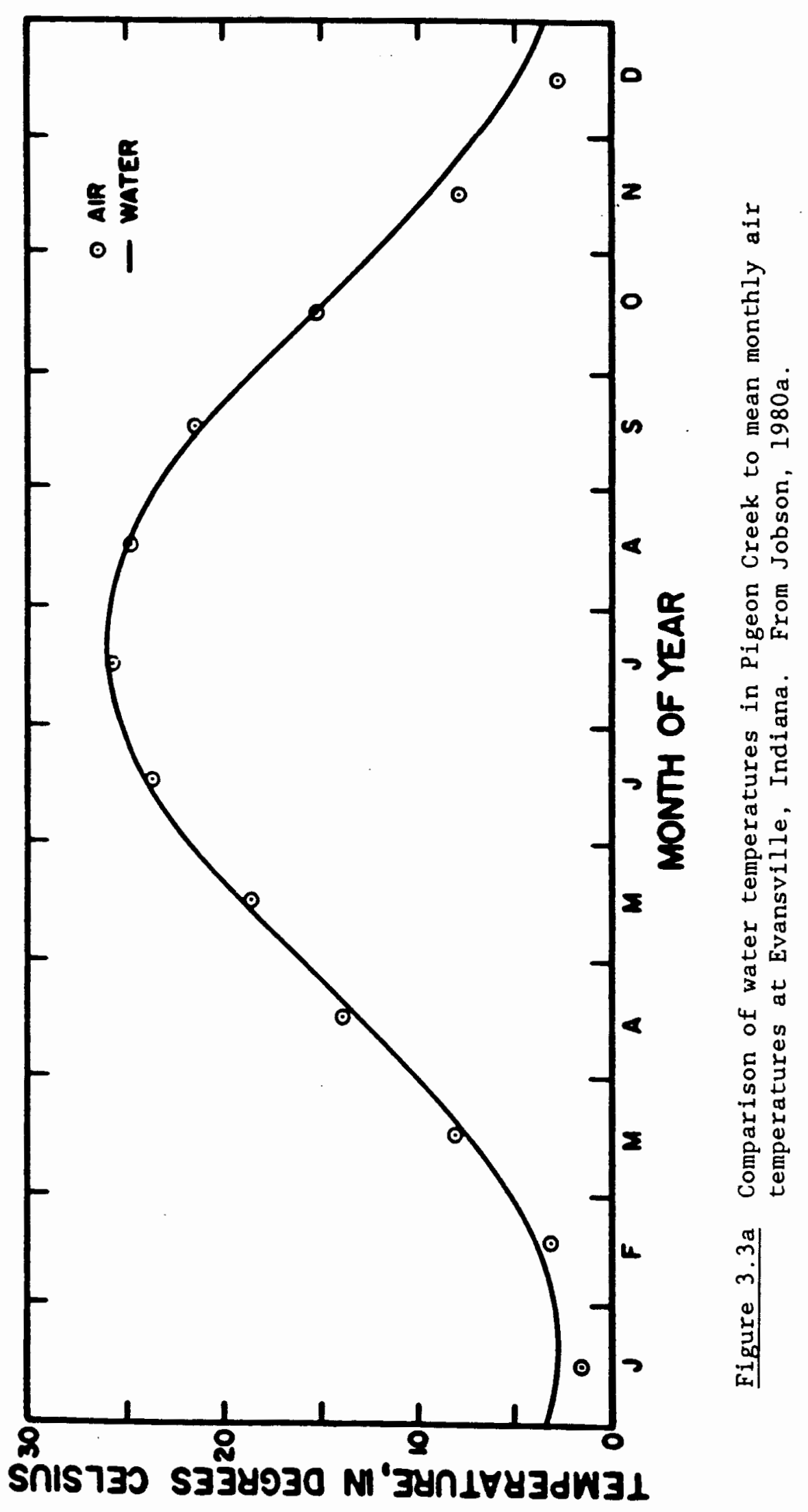




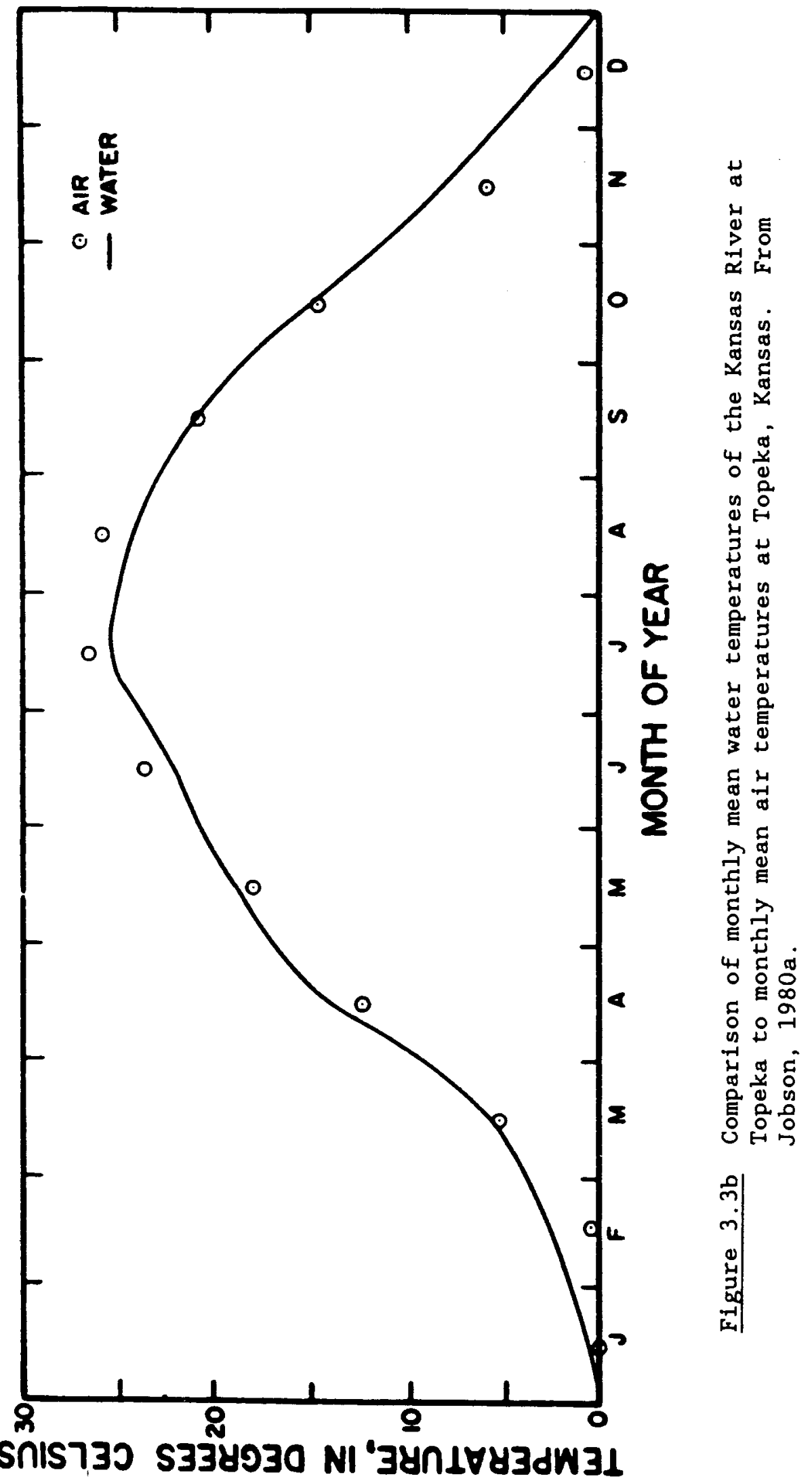


the use of air temperature as an estimate of equilibirum temperature has merit. If the actual equilibrium temperature is computed, and a relation between it and air temperature established, then the use of a modified air temperature estimate should remove some of the problems associated with using air temperature alone. This is the impetus for this study.

The equilibrium temperature approach is not without its detractors however. Yotsukura, et al (1973, p 118) state

The daily equilibrium temperature calculated from meteorological data may be used as a base as long as it does not deviate excessively from the actual water temperature. ... the shortterm equilibrium temperature has no merit as a base temperature of linearization.

Morse (1970, p 290) refers to "the elusive equilibrium temperature". His opinion is stated more clearly in a latter work (1972, p. 1031) when he cites one of three easily overcome deficiencies in water temperature modeling is moving away from

... a lingering dependency on a highly dynamic variable called the equilibrium temperature of water. In nature the heat exchange across the air-water interface is rarely, if ever, in a state of equilibrium. There remain sufficient obstacles, evaporation for example, in this overall problem without including another unnecessary one. The general objective in model building is to find, determine or develop rigorous mathematical expressions which involve a minimum number of unknown parameters.

Regardless of these admonitions, the equilibrium temperature approach is used here. Air temperature is used to estimate equilibrium temperature and compared to results using the calculated equilibrium for periods when sufficient atmospheric data are available. A relation between air temperature and equilibrium is established as warranted. 
CHAPTER IV

MODEL DESCRIPTION

The water temperature model used in this thesis was developed by Dr. Harvey Jobson of the U.S. Geological Survey. The computer program and model documentation are presented in Jobson (1980a). Some assumptions in the model version used here include: 1) the stream is completely mixed with no lateral or vertical variation in crosssectional temperature, i.e., longitudinal one dimensional representation is appropriate; 2) steady-state flow within the time period considered; 3) atmospheric heat exchange is the dominant heat transfer process, and bed conduction and biochemical reaction contributions are neglected; 4) tributary sources and diversion sinks are considered, but groundwater inflow and precipitation are neglected; 5) the equilibrium temperature approach is valid; and 6) air temperature can be used to estimate equilibrium temperature. Other minor assumptions are introduced as appropriate.

MODEL EQUATION

The model equation solved is based on the Lagrangian formulation of the convective-diffusion equation (equation 2.2). If an additional term is added to account for tributary inflow, equation 2.2 becomes:

$$
\frac{\partial T}{\partial t}=D x \frac{\partial^{2} \mathrm{~T}}{\partial \xi^{2}}+\frac{H W}{A c_{p} \rho}+\Phi
$$

and $\Phi$ is the additional heat source term. Integrating from $t_{0}$ to $t$ (the travel time) 4.1 becomes: 


$$
T=T_{0}+\int_{t_{0}}^{t} D x \frac{\partial^{2} T}{\partial \xi^{2}} d t^{\prime}+\int_{t_{0}}^{t} \frac{H W}{A c_{p} \rho} d t^{\prime}+\int_{t_{0}}^{t} \Phi d t^{\prime}
$$

where $T_{0}$ is the initial water temperature in ${ }^{\circ} \mathrm{C}$, and $\mathrm{H}$ is determined by using equation 3.13. Equation 4.2 is amenable to numerical analysis because of its integral rather than differential form. It is also useful because it allows the contribution of each term to be isolated for comparison.

The terms in equation 4.2 represent the water temperature at time $t$, the initial upstream water temperature at time $t_{0}$, the change in water temperature due to dispersion, the change in water temperature due to air-water interface heat exchange, and the change in water temperature due to other sources or sinks (tributaries or diversions in this case). Equation 4.2 is the principal equation used in Jobson's Lagrangian transport mode1 (LTM).

The dispersion coefficient, $D x$, is assumed to be a function of the shear velocity and the hydraulic radius. The function takes the form:

$$
\mathrm{Dx}=\mathrm{C} \mathrm{U}^{\prime} \mathrm{R}
$$

where $C$ is a coefficient, $U^{\prime}$ is the shear velocity, and $R$ is the hydraulic radius. Values of $\mathrm{C}$ are reported to range from 5.9 to 7500 (Jobson, 1980a). Jobson (1980b) used 250 as a value for $C$ and that is the value used here.

The dispersion term of equation 4.2 is calculated using an explicit finite difference method for each time step (Jobson, 1980a):

$$
\int_{t_{0}}^{t} \operatorname{Dx} \frac{\partial^{2} T}{\partial \xi^{2}} d t^{\prime}=\frac{D Q Q(K-1) A U \Delta t\left(T_{k-1}-T_{k}\right)+D Q Q(K) A U \Delta t\left(T_{k+1}-T_{k}\right)}{V} \quad 4.4
$$


where $\mathrm{DQQ}=\mathrm{DQ} / \mathrm{Q}=$ the ratio of the flow rate of water between parcels (DQ) to the discharge $Q, V=$ parcel volume, and $K$ is a parcel index number. DQQ is related to $\mathrm{Dx}$ by:

$$
\mathrm{DQQ}=\frac{\mathrm{Dx}}{\mathrm{U}^{2} \Delta t}
$$

The Lagrangian method establishes marked volumes of water distributed along the channel axis which are moved along the channel at the mean flow velocity. The Lagrangian grid is thus a set of moving points which represent the centers of the marked volumes. Longitudinal dispersion between volumes can then be viewed as caused by the difference in stream velocity between different points in the cross-section. The boundaries between parcels are advected through the reach at the mean stream velocity while water near the surface and center may move faster than the mean and the water near the bed and banks will move slower. Figure 4.1 is a longitudinal section schematic which demonstrates this phenomenon.

A solution for the system is constructed by solving equation 4.2 for a series of parcels. A new parcel is added with its centroid at the upstream boundary for each time step. This new fluid parcel contains all the water to flow into a reach during the time $t-\Delta t / 2$ to $t+\Delta t / 2$. The location of each water parcel is determined from equation 2.3. Thus the solution computation proceeds along advective paths (characteristic curves) defined by equation 2.3 (Jobson, 1980a).

Every model has its own set of data required for implementation and use. The data required for LTM is presented next. 

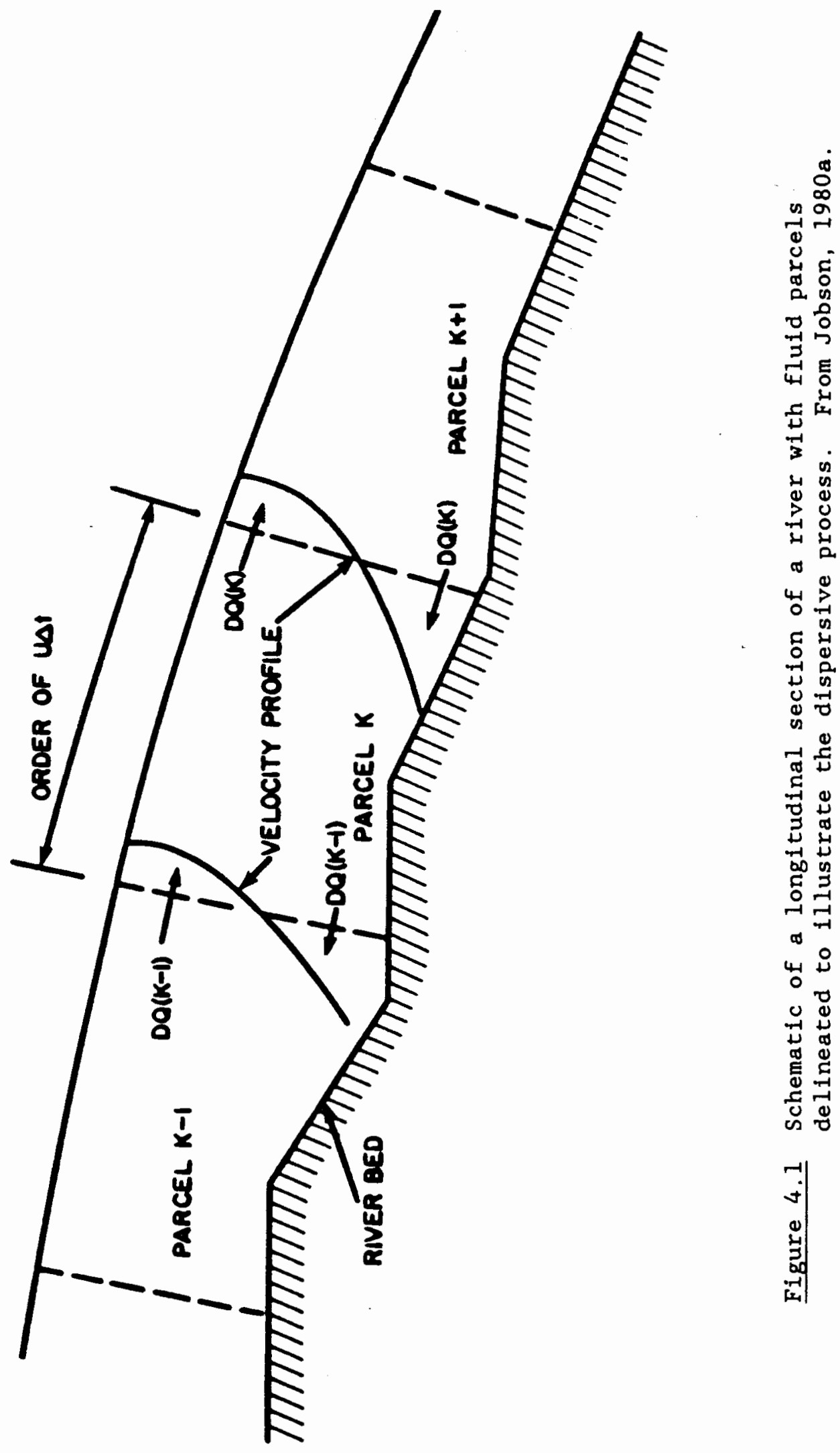

守造

吾 $\pm$

कo

동 걱

(1)

냉 웅

Uू

-1
$j$
0
$\vdots$
0
0
0.1 


\section{DATA REQUIREMENTS}

The data required to use ITM are straightforward and relatively easy to obtain. ITM requires stream horizontal cross-section inputs of topwidth and cross-sectional area at distinct grid points to define parcel characteristics. The model uses the average of consecutive grid point attributes to define the parcel between those grid points. Grid points are also used to add tributary inflow or subtract diversion outflow. River mile locations of each grid point are needed to determine longitudinal distances between grid points. Grid points are used mainly to input tributary inflow, output results for specific locations e.g. recorder sites, or define changes in channel morphology.

Other data required are the number of grid points to be used, the number of time steps the model is to be run, the time step length in hours, the initial upstream discharge in meters per second (remains constant for steady state), interior grid point for which output is desired (results of the last grid point are always given), how often output is to be printed (printed every $n$ number of time steps), the number of tributaries, the number of time steps between midnight and time zero of the model (to keep output in actual hours of the day and not relative), the value of the constant in the wind function in mm/day $\mathrm{kPa}(\alpha=3.01)$, and the mass transfer coefficient in $\mathrm{mm} /$ day $(\mathrm{m} / \mathrm{s}) \mathrm{kPa}(\mathrm{N}=1.13)$.

Following these data are the river mile location of each grid point, the cross-sectional area, and the topwidth, as mentioned above. Next, grid point number and discharge are required for each tributary used. Then the DQQ values for each grid point are input. A value of 0.13 was used for each grid point for the McKenzie River. Finally the 
initial temperature at each grid point is required. These data make up the header information.

Following the header information, boundary condition data are required for each time step. These data include the upstream water temperature, equilibrium temperature (or an estimate), windspeed, and temperature for each tributary. Figure 4.2 shows a sample input data set.

A sample of the model output is given in figure 4.3. The initial conditions are reiterated for convenience in tabular form. Then follows the output for the requested interior grid point and the final grid point. In addition to temperatures for specified time steps, output includes travel time, parcel temperature at entry, and changes in parcel temperature due to dispersion, tributary inflow and surface exchange (decay) for both grid points. During the initial period when travel time equals the elapsed time, the computed temperature is highly dependent on the initial temperature. This can be considered model "start up " time.

\section{PARAMETERS}

The literature contains various uses of the word parameter. Sometimes parameter and variable are used interchangeably. In modeling, however, each has a very distinct meaning. A variable is a quantity that may assume any of a set of values. For LTM, discharge, upstream water temperature, windspeed, and tributary temperatures are all variables. A parameter defines relations between variables. 
$\stackrel{m}{0}$

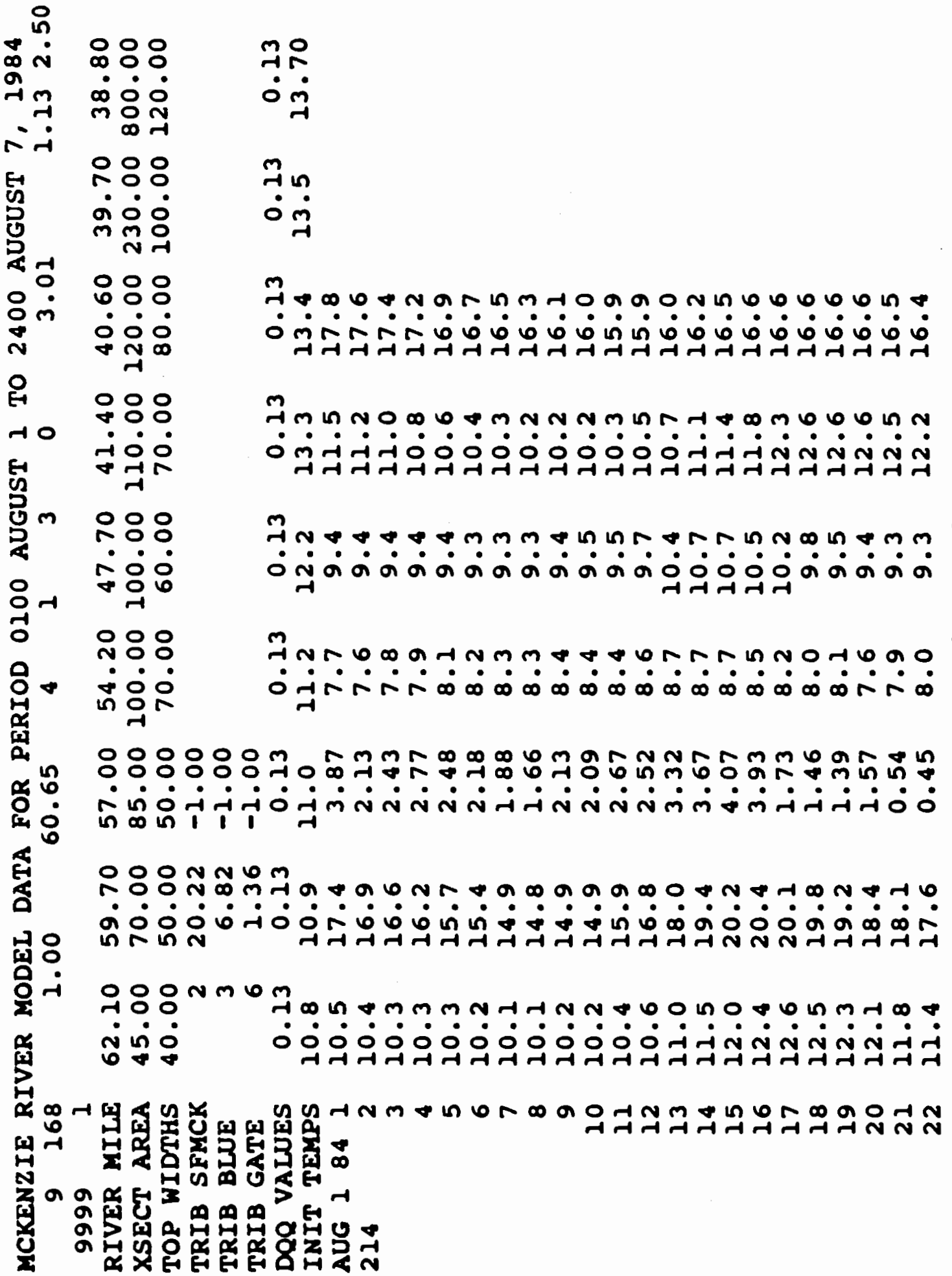




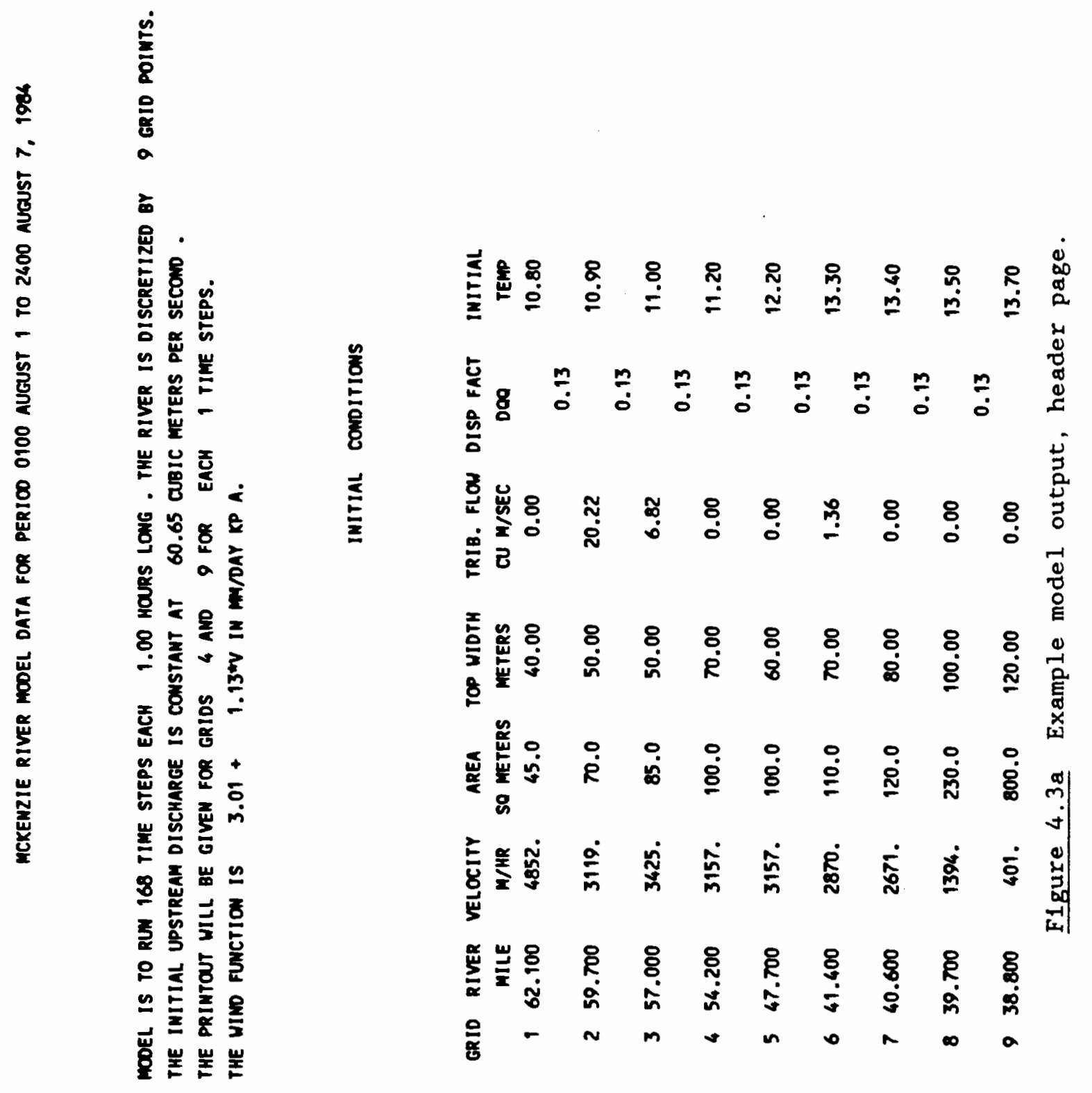




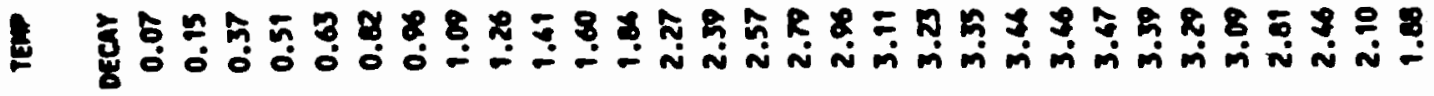

붕

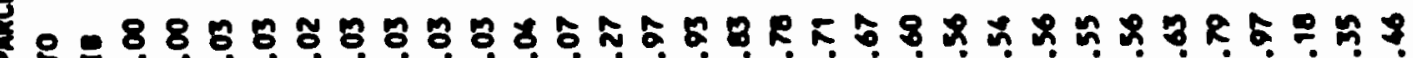
$=\mathbf{z}$

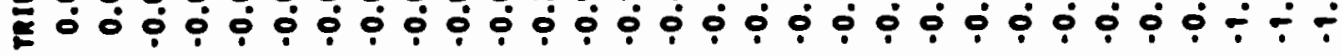

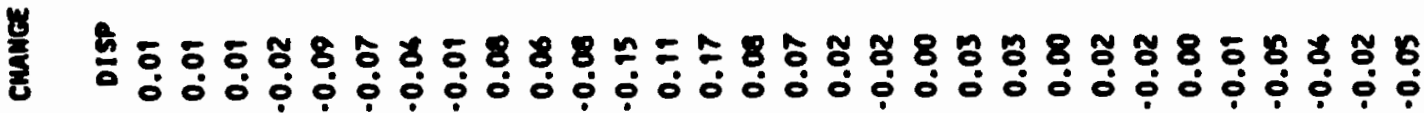

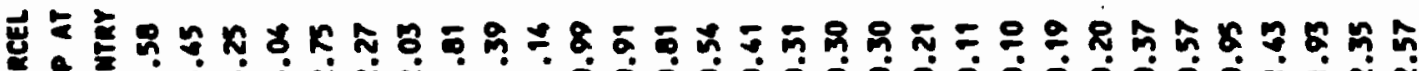

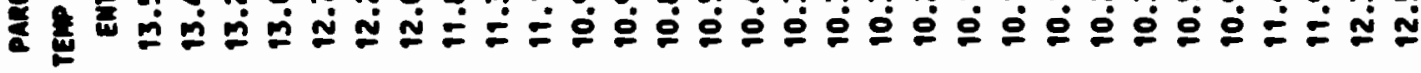

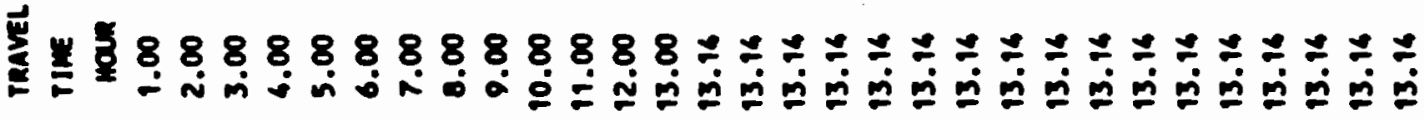

ะำร

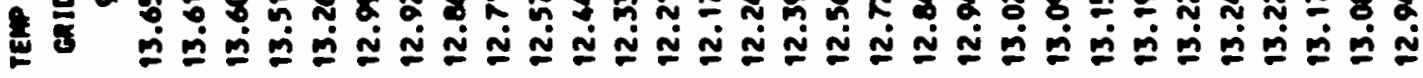

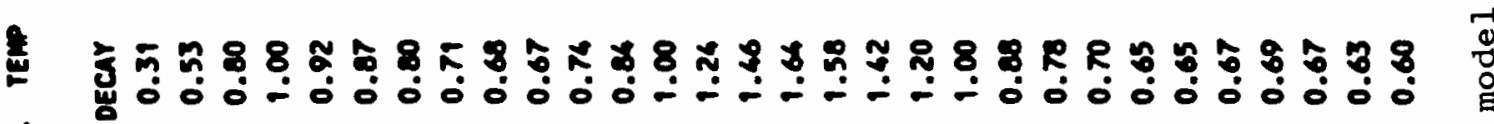
$\overrightarrow{\mathrm{z}}$

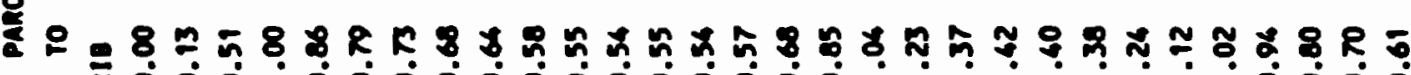
І

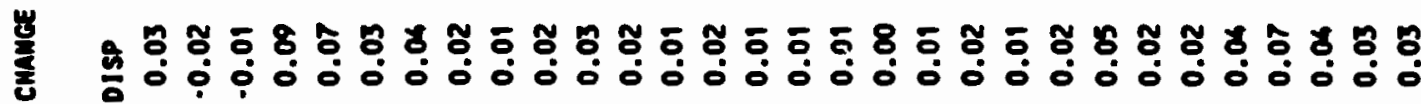

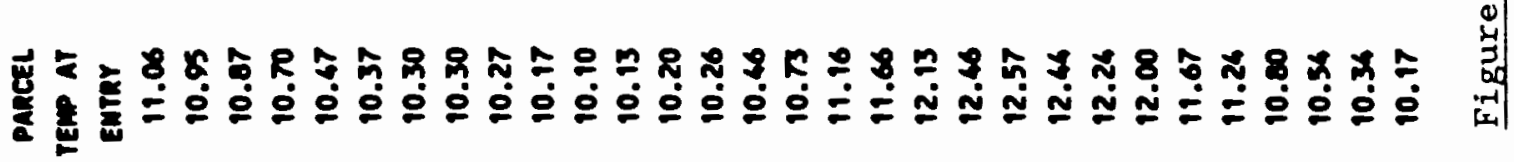

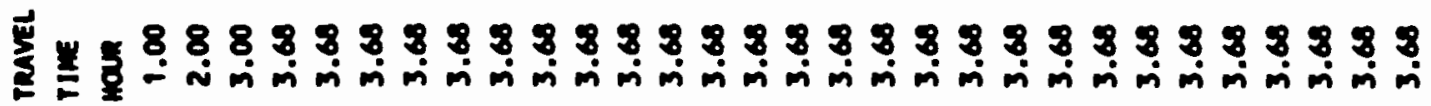

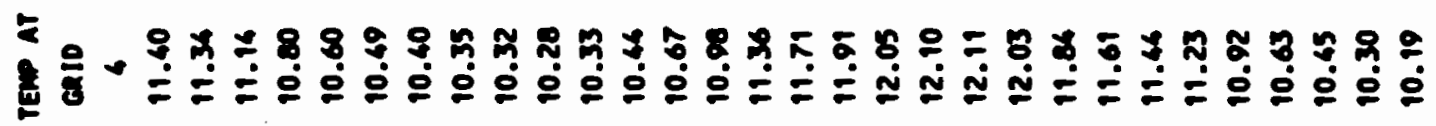

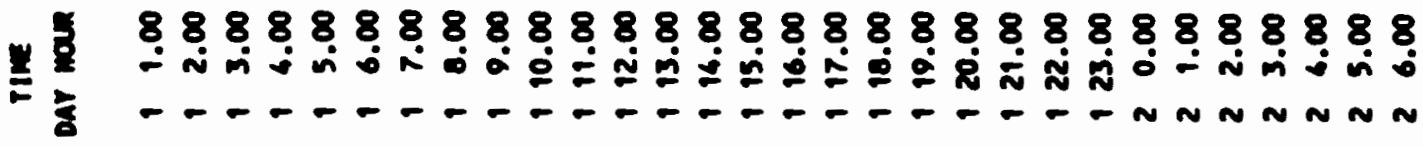


Calibration is the process of determining parameter values to provide the "best fit" between observed and modeled data. Many times however, parameters are treated as constants and not subjected to calibration.

LTM contains several parameters. The main one is equilibrium temperature. The wind function contains two parameters, $\alpha$ and $\mathrm{N}$. $\mathrm{K}$ is a parameter due to its dependence on the wind function. Dx is also a parameter. Indeed, all empirical relations contain parameters. It is the use of parameters in models that dictates the need for calibration.

The stage is now set to unveil the motive behind the preceding discussion. The temperature model described is used to determine the effects of $\mathrm{COE}$ dams and resulting reservoirs on the mainstem McKenzie River. 
CHAPTER V

APPLICATION TO THE MCKENZIE RIVER

PHYSICAL SETTING

\section{Geography/Geology}

The McKenzie River and its tributaries drain the western slopes of the Cascade Range from Three Fingered Jack to Irish Mountain (figure 5.1). This basin occupies a drainage area of about 1340 square miles. It extends westward from the Cascade Range to its confluence with the Willamette River near Eugene.

The basin is made up primarily of sedimentary, volcanic, and alluvial rock units. The oldest rocks consist of sandstone and siltstone and are exposed along the base of the Coburg Hills. Volcanic rocks form the Cascade Range and are divided into basalts and rhyolites. Alluvial deposits made up principally of coarse volcanic sand and gravel extend far up the McKenzie River valley. Porous lavas of the High Cascades store large quantities of precipitation and snowmelt and release the water gradually thus sustaining relatively high stream flows during early summer months.

The Cascade Range gives the basin a mountainous character with about 90 percent lying above the 1,000-foot contour and 70 percent above 2000 feet. Elevations range from about 350 feet above mean sea level (NGVD) at the mouth to 10,354 feet at the summit of North Sister. 


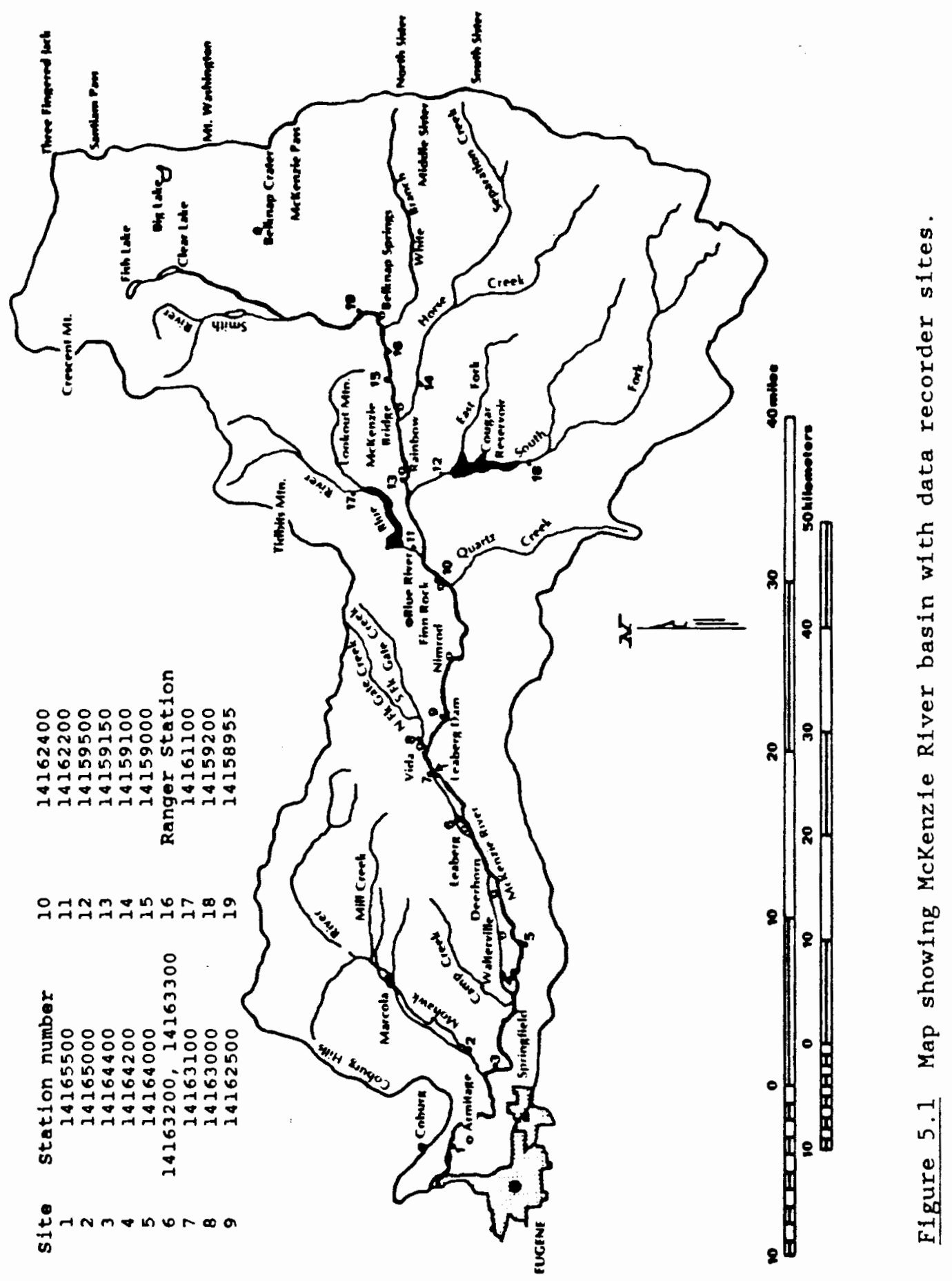


C1imate

The McKenzie River basin has a temperate, marine climate characterized by relatively wet winters and dry summers. About 80 percent of the normal precipitation falls between October and May. Mean annual rainfa11 ranges from about 40-50 inches near Eugene to about 110 inches in the headwaters of Blue River. The normal annual air temperature at Mahlon-Sweet Airport in Eugene (the nearest first-order weather station) is $52.5^{\circ} \mathrm{F}$. Normal monthly temperatures range from $40.0^{\circ} \mathrm{F}$ in January to $66.8{ }^{\circ} \mathrm{F}$ in July. Extremes range from $-12^{\circ} \mathrm{F}$ to $108^{\circ} \mathrm{F}$. The normal annual windspeed is $7.6 \mathrm{mph}$. Normal monthly windspeed ranges from 6.6 $\mathrm{mph}$ in October to $8.4 \mathrm{mph}$ in March. The maximum windspeed of at least one minute duration was 63 mph. Table I shows selected atmospheric statistics for Eugene.

\section{TABLE I}

SELECTED METEOROLOGICAL NORMALS (1951-1980), MEANS AND EXTREMES FOR EUGENE, OREGON, 1942-1984.

\begin{tabular}{|c|c|c|c|c|c|c|}
\hline Month & \multicolumn{3}{|c|}{$\begin{array}{l}\text { Monthly recorded } \\
\text { air temperatures }\left({ }^{\circ} \mathrm{F}\right)\end{array}$} & $\begin{array}{c}\text { mean } \\
\text { sky cover } \\
\text { (tenths) }\end{array}$ & $\begin{array}{l}\text { normal } \\
\text { precip. } \\
\text { (inches) }\end{array}$ & $\begin{array}{l}\text { wind } \\
\text { speed } \\
\text { (mph) }\end{array}$ \\
\hline Jan. & 40.0 & 67 & -4 & 8.6 & 8.39 & 8.1 \\
\hline Feb. & 43.5 & 71 & -3 & 8.4 & 5.12 & 7.9 \\
\hline Mar. & 45.8 & 77 & 20 & 8.0 & 5.11 & 8.4 \\
\hline Apr. & 49.6 & 86 & 27 & 7.5 & 2.76 & 7.7 \\
\hline May & 55.0 & 92 & 28 & 6.8 & 1.97 & 7.3 \\
\hline June & 61.1 & 100 & 32 & 6.3 & 1.24 & 7.4 \\
\hline July & 66.8 & 105 & 39 & 3.9 & 0.27 & 8.0 \\
\hline Aug. & 66.2 & 108 & 38 & 4.6 & 0.95 & 7.4 \\
\hline Sep. & 62.0 & 101 & 32 & 5.0 & 1.45 & 7.4 \\
\hline Oct. & 53.3 & 94 & 19 & 7.1 & 3.47 & 6.6 \\
\hline Nov. & 45.3 & 76 & 12 & 8.4 & 6.82 & 7.2 \\
\hline Dec. & 41.3 & 68 & -12 & 8.9 & 8.49 & 7.7 \\
\hline Year & 52.5 & 108 & -12 & 7.0 & 46.04 & 7.6 \\
\hline
\end{tabular}


Riverine Description

The McKenzie River has its origin at the outlet of Clear Lake in the Cascades. From there, the river flows south about 15 miles and then west for 75 miles to its confluence with the willamette River. The McKenzie River is diverted by Eugene Water and Electric Board (EWEB) below Koosah Falls (RM 87.6) from Carmen Reservoir through a diversion tunnel to the Smith River and Smith Reservoir. EWEB uses the water to generate power as it passes from Carmen-Smith reservoirs to Trail Bridge reservoir located at the natural confluence of the Smith and McKenzie Rivers. Trail Bridge reservoir is used to attenuate daily fluctuations in stream flow caused by producing power to meet peak demands. Below Trail Bridge Dam ( $R M$ 81.9), the McKenzie River flows to Belknap Hot Springs (RM 74.6). The contribution of heat and flow from this spring is quite small compared to the total flow in the McKenzie River at that point.

Lost Creek (White Branch) joins the McKenzie from the east at RM 73.6. Its source is glaciers on North and Middle Sister volcanoes. A significant portion of the flow in Lost Creek is from springs draining porous lavas. These springs provide a nearly constant flow throughout much of the year with temperatures at or near the water temperature of the McKenzie River at their confluence.

Horse Creek meets the McKenzie from the southeast at RM 67.2. Horse Creek drains glaciers on South Sister and is similar to Lost Creek in its basin hydrology. Horse Creek contributes approximately 9 percent of the annual McKenzie River basin yield from 11 percent of the total basin area. 
The McKenzie River combines with the South Fork McKenzie at RM 59.7. The South Fork McKenzie has its origins in the High Cascades and is fed by snowmelt in spring. Much of the snowmelt reaches the stream by way of porous lava beds which tend to release water at a uniform rate, naturally augmenting summer flows. South Fork contributes about $15 \%$ of the total McKenzie River basin annual yield from $16 \%$ of the total basin area. South Fork has been regulated since 1963 by Cougar Dam. Cougar Dam and the resultant Cougar Lake form one of two COE projects in the McKenzie basin.

Blue River joins the McKenzie from the north at RM 57.0. A relatively large portion of the annual yield of Blue River occurs in April and May from snowmelt. Lack of stream regulation by ground water storage is evident by low base flow in late summer. Blue River contributes $8 \%$ of the total annual basin yield from $7 \%$ of the total basin area. It has been regulated since 1969 by Blue River Dam. Blue River Dam and Blue River Lake is the second of the two COE projects in the McKenzie basin.

Gate Creek, entering from the north, has its confluence with the McKenzie at RM 41.4. Gate Creek contributes 48 of the total basin yield and has 48 of the total basin area. It has relatively little snowmelt contribution, typical of the lower McKenzie streams which deliver high winter and low summer flows to the McKenzie River.

EWEB diverts water at Leaburg Dam (RM 38.8) for power generation (Leaburg power canal). EWEB is required to leave a minimum of $500 \mathrm{cfs}$ in the mainstem below Leaburg Dam for fish habitat. The diverted flow is returned at $\mathrm{RM} 33.2$, but the traveltime through the power canal is 
faster then it would be down the main channel. EWEB diverts flow again for power generation at RM 28.5 and returns it to the river at RM 20.9 (Walterville power canal). Minimum flow requirements in the Mckenzie after diversion range from $350 \mathrm{cfs}$ from October to April to $1000 \mathrm{cfs}$ in. May (State Water Resources Board, 1961, p.125). Approximately 2200 cfs is diverted at Leaburg Dam and $2000 \mathrm{cfs}$ is diverted near Walterville (Rick Junker, EWEB, oral communication, September, 1983). EWEB also diverts water (approximately $40 \mathrm{cfs}$ ) at Hayden Bridge (RM 14.8) for use as a water supply for the city of Eugene.

Mohawk River, the last major tributary, joins the Mckenzie from the north at RM 13.7. It rises from a lower elevation than the other tributaries and has no significant snowmelt contribution. It has a low baseflow during the late summer due to less porous rocks than streams in the McKenzie Rivers headwaters. It contributes 98 of the total annual basin yield but contains 138 of the total basin area.

\section{Reservoirs}

The COE has two reservoir projects in the McKenzie basin, Cougar and Blue River. Their primary authorized purposes are flood control, irrigation, and downstream navigation improvement. Cougar also has a 25,000 kilowatt generating capacity. Secondary purposes include low flow augmentation, pollution abatement, and recreation.

Cougar Lake was formed by the completion of Cougar Dam, a 452-foot high embankment dam. It is located on the South Fork McKenzie River about 46 miles east of Eugene. Cougar Lake has a 207,000 acre-foot storage capacity and a 1,240 acre surface area at full pool. 
Blue River Dam, a 320-foot high embankment dam was completed in 1969. It is located on Blue River about 48 miles east of Eugene. Blue River Lake was formed upon completion of Blue River Dam and a 70-foot embankment dam about four miles from the main dam which closes off a low saddle between the Blue river and McKenzie River drainages. The reservoir provides 82,800 acre-feet of storage and has a surface area of 950 acres at full pool.

DATA NETWORK

Data used in this study included data from existing stream gage and temperature recording locations, data obtained at temporary collection sites, and miscellaneous field measurements. Techniques used for water temperature data collection are set forth in Stevens, et al, 1975. Figure 5.1 shows the location of existing stream gages and water temperature recorders plus temporary water temperature and atmospheric data recorders.

\section{Existing Long-term Stations}

Existing sites included U.S. Geological Survey stream-gaging stations on the McKenzie River at McKenzie Bridge (14159000) and near Vida (14162500), on the South Fork McKenzie River above Cougar Lake near Rainbow (14159200) and below Cougar Lake near Rainbow (14159500), on Blue River below Tidbits Creek near Blue River (14161100) and near Blue River (14162200), on Lookout Creek near Blue River (14161500), on Gate Creek at Vida (14163000) and on the Mohawk River near Springfield (14165000). Long-term stream discharge and water temperature have been collected at each of the above sites with the exception of the last two, 
at which water temperature was collected only for the duration of this project (April-October, 1983-84). Table II shows the period of record for each variable at each site. Hourly air temperature and windspeed data were available from the National Weather Service station at MahlonSweet Airport in Eugene.

\section{TABLE II}

PERIOD OF RECORD FOR EACH VARIABLE AT LONG-TERM STATIONS.

\begin{tabular}{|c|c|c|c|c|c|}
\hline $\begin{array}{l}\text { Station } \\
\text { Number }\end{array}$ & $\begin{array}{c}\text { Location } \\
\text { Description }\end{array}$ & $\begin{array}{l}\text { Para- } \\
\text { meter }\end{array}$ & $\begin{array}{c}\text { Statis - } \\
\text { tic } \\
\end{array}$ & Begin & End \\
\hline \multirow[t]{4}{*}{14158850} & McKenzie River & Temp & $\operatorname{Max}$ & 197611 & 198509 \\
\hline & below Trail & Temp & Min & 197611 & 198509 \\
\hline & Bridge Dam & Temp & Mean & 197710 & 198509 \\
\hline & & $\mathrm{Q}$ & Mean & 196010 & Present \\
\hline \multirow[t]{4}{*}{14159000} & McKenzie River at & Temp & $\operatorname{Max}$ & 197611 & 198509 \\
\hline & McKenzie Bridge & Temp & Min & 197611 & 198509 \\
\hline & & Temp & Mean & 197808 & 198509 \\
\hline & & $Q$ & Mean & 191008 & Present \\
\hline \multirow[t]{3}{*}{14159100} & Horse Creek nr & Temp & $\operatorname{Max}$ & 196301 & 196909 \\
\hline & McKenzie Bridge & Temp & Min & 196301 & 196909 \\
\hline & & $\mathrm{Q}$ & Mean & 196210 & 196910 \\
\hline \multirow[t]{4}{*}{14159200} & South Fork & Temp & $\operatorname{Max}$ & 195711 & Present \\
\hline & McKenzie River at & Temp & Min & 195711 & Present \\
\hline & Cougar Lake & Temp & Mean & 197808 & Present \\
\hline & & $\mathrm{Q}$ & Mean & 195710 & Present \\
\hline \multirow[t]{4}{*}{14159500} & South Fork & Temp & $\operatorname{Max}$ & 195507 & Present \\
\hline & McKenzie River $\mathrm{nr}$ & Temp & Min & 195507 & Present \\
\hline & Rainbow & Temp & Mean & 197808 & Present \\
\hline & & $Q$ & Mean & 194710 & Present \\
\hline \multirow[t]{4}{*}{14161100} & Blue River below & Temp & $\operatorname{Max}$ & 196309 & Present \\
\hline & Tidbits Creek nr & Temp & Min & 196309 & Present \\
\hline & Blue River & Temp & Mean & 197806 & Present \\
\hline & & $Q$ & Mean & 196309 & Present \\
\hline \multirow[t]{5}{*}{14161500} & Lookout Creek nr & Temp & $\operatorname{Max}$ & 195008 & 198109 \\
\hline & Blue River & Temp & Min & 195008 & 198109 \\
\hline & & Temp & Mean & 197808 & 198109 \\
\hline & & $Q$ & Mean & 194910 & 195509 \\
\hline & & Q & Mean & 196310 & Present \\
\hline
\end{tabular}


TABLE II (cont.)

PERIOD OF RECORD FOR EACH VARIABLE AT LONG-TERM STATIONS.

\begin{tabular}{|c|c|c|c|c|c|}
\hline $\begin{array}{l}\text { Station } \\
\text { Number } \\
\end{array}$ & $\begin{array}{c}\text { Location } \\
\text { Description }\end{array}$ & $\begin{array}{l}\text { Para- } \\
\text { meter }\end{array}$ & $\begin{array}{l}\text { Statis - } \\
\text { tic }\end{array}$ & Begin & End \\
\hline \multirow[t]{3}{*}{14162000} & Blue River $\mathrm{nr}$ & Temp & $\operatorname{Max}$ & 196106 & 196409 \\
\hline & Blue River & Temp & Min & 196106 & 196409 \\
\hline & & $Q$ & Mean & 193509 & 196412 \\
\hline \multirow[t]{4}{*}{14162200} & Blue River at & Temp & $\operatorname{Max}$ & 196608 & Present \\
\hline & Blue River & Temp & Min & 196608 & Present \\
\hline & & Temp & Mean & 197808 & Present \\
\hline & & $\mathrm{Q}$ & Mean & 196610 & Present \\
\hline \multirow[t]{5}{*}{14162500} & McKenzie River $\mathrm{nr}$ & Temp & $\operatorname{Max}$ & 196106 & 198509 \\
\hline & Vida & Temp & Min & 196106 & 198509 \\
\hline & & Temp & Mean & 197802 & 198509 \\
\hline & & $\mathrm{Q}$ & Mean & 191007 & 191103 \\
\hline & & $Q$ & Mean & 192409 & Present \\
\hline \multirow[t]{2}{*}{14163000} & Gate Creek nr & Q & Mean & 195110 & 195709 \\
\hline & Vida & $Q$ & Mean & 196610 & Present \\
\hline \multirow[t]{4}{*}{14165000} & Mohawk River nr & Temp & $\operatorname{Max}$ & 196310 & 196909 \\
\hline & Springfield & Temp & Min & 196310 & 196909 \\
\hline & & $Q$ & Mean & 193510 & 195709 \\
\hline & & $Q$ & Mean & 196310 & Present \\
\hline \multirow[t]{3}{*}{14165500} & McKenzie River $\mathrm{nr}$ & Temp & $\operatorname{Max}$ & 196310 & 197509 \\
\hline & Coburg & Temp & Min & 196310 & 197509 \\
\hline & & $Q$ & Mean & 194410 & 197209 \\
\hline
\end{tabular}

\section{Additional Sites}

Data were collected at several additional sites from approximately April to October 1983-1984 unless otherwise noted. Additiona1 water temperature data were collected by installing Mini-monitor temperature units with thermistor probes and Leupold-Stevens digital recorders in temporary shelters on the McKenzie River at Armitage Park near Coburg (14165500), at Hendricks Bridge near Walterville (14164000), at Leaburg (14163200)(1984 only), at Finn Rock (14162400), at Delta Campground near Rainbow (14159150), and at Frissell-Carpenter Road above Belknap Springs (14158955) (1983 on1y). Water temperature recording units of this type 
were also located on the EWEB power canal near Walterville (14164200), the EWEB power canal near Leaburg (14163300)(1984 only) and on Horse Creek near McKenzie Bridge (14159100). Data were recorded on paper tape at half-hour intervals and reduced to hourly averages.

Campbe11 CR-21 dataloggers with thermistor temperature probes and anemometers were used on the McKenzie River at Hayden Bridge near Springfield (14164400)(1984 only), at Leaburg Dam (14163100) and at the McKenzie Bridge Ranger Station near McKenzie Bridge. The ranger station site collected only air temperature and windspeed. The other two CR-21 datalogger sites collected air temperature, water temperature, and windspeed. Additional meteorological data were collected at the Leaburg Dam site from June 22 to September 24 , 1984. The additional data collected were solar radiation, atmospheric radiation, relative humidity, and vapor pressure. All CR-21 data were collected at 1-minute intervals, reduced on site to hourly averages, and then recorded on cassette tape.

\section{Field surveys}

Floating surveys were made to obtain topwidth, cross-section, and water temperature data. Top-width surveys were made July 25-29 and August 5, 1983 in the reach from Finn Rock to Armitage Park. Water temperature surveys were made August 22-24 and August 31 to September 2, 1983 in the reach from Frisse11-Carpenter Road to the mouth of the McKenzie River. An additional float survey was made August 21-22, 1984 from Leaburg Dam to Bellinger boat ramp near Springfield. A summary of the float survey data can be found in Hansen, 1986. 
During the water temperature survey, an attempt was made to float with the stream current and record water temperatures at regular intervals. The object was to follow a water parcel and observe how it heated or cooled in response to tributary inflow, stream bank canopy, stream bed character (riffle or pool), and man-made alterations.

Temperature cross-sections were made at all bridges on several occasions. The temperature cross-sections were made to determine if any horizontal and/or vertical variation in water temperature existed. A Whitney thermistor probe and sounding weight were used to measure temperature and vertical depth. Figure 5.2 shows example temperature cross-sections at selected locations. A complete set of temperature cross-section data can be found in Hansen, 1986. Since there was little variation both horizontally and vertically in any cross-section (less than $0.5^{\circ} \mathrm{C}$ ), the assumption of one-dimensional representation is valid and use of a one-dimensional model is justified.

\section{MODEL SEGMENTATION}

Jobson's model requires stream cross-section inputs of topwidth and cross-sectional area at distinct grid points to define parcel characteristics. The model uses the average of consecutive grid points to define the parcel between those grid points. Grid points are also used to add tributary inflow or subtract diversion outflow. Inputs required for each time step are: initial upstream water temperature, air temperature (or other estimate of equilibrium temperature), windspeed, and tributary inflow temperatures. Model calibration assumed steadystate flow so all discharges were input only once. 

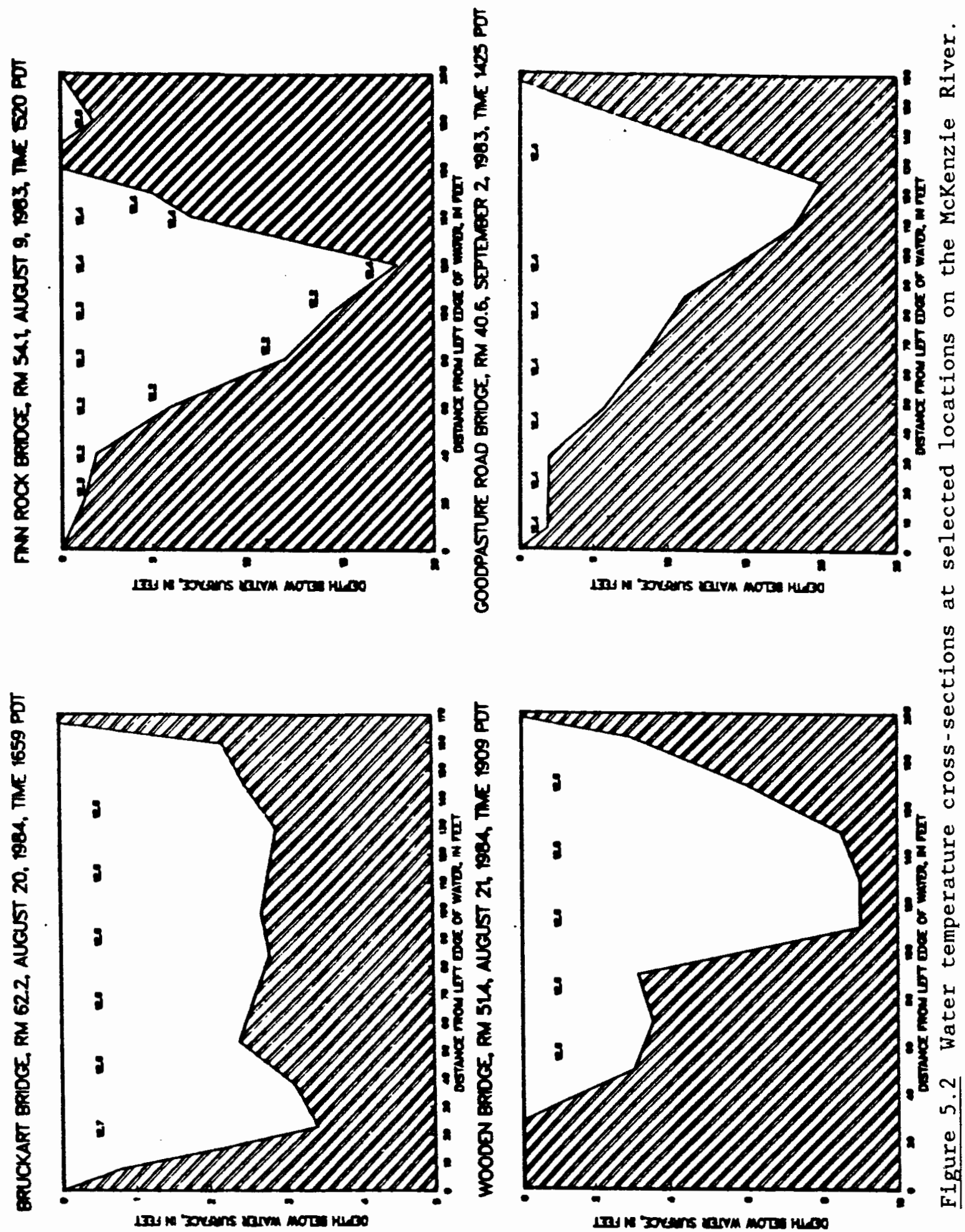
Topwidths were determined by averaging widths measured every 2000 feet along the stream length from aerial photos and checked with sporadic field measurements. Cross-sectional areas were estimated from field measurements and travel-time estimates. Upstream discharge used in model simulations was determined by subtracting the discharges from Blue River at Blue River (14162200) and South Fork McKenzie River near Rainbow (14159500) from the discharge of the McKenzie River near Vida (14162500) and assuming ungaged tributaries contributed little discharge by comparison.

The original intent of this study was to model the McKenzie River from above the confluence with the South Fork McKenzie to Armitage Park near the mouth of the McKenzie River. It was soon realized, however, that the two EWEB power canals complicated the modeling effort tremendously and would require the use of a model with branching network capabilities to properly simulate water temperatures downstream from Leaburg Dam. The EWEB power canals affect the stream temperature (see figure 5.3) by decreasing travel time and lowering the topwidth to depth ratio (thereby decreasing the surface area available for heat transfer). Even with proper modeling capabilities, separating the effects of these two EWEB facilities from the effects of COE dams may be difficult. Temperature data predating EWEB facilities (representing completely natural conditions) is virtually nonexistent. Temperature data predating COE projects but after EWEB facilities were constructed is similarly lacking. Separating the effects of EWEB and COE projects is likely but requires a much more complex temperature analysis and modeling approach. The problem of EWEB canal effects was circumvented 


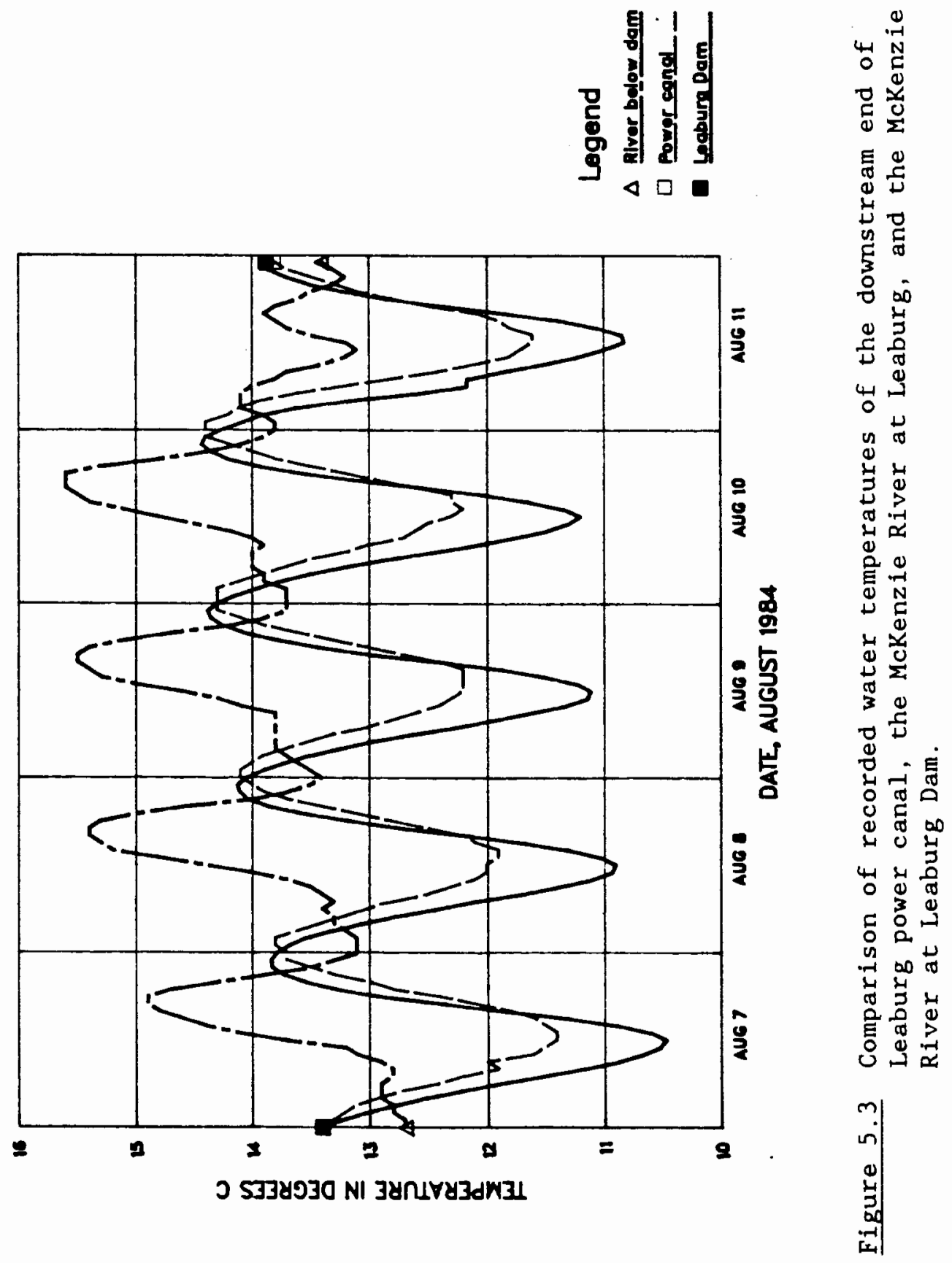


by modeling to Leaburg Dam, just above EWEB canal influence.

A temperature station was installed above Belknap Hot Springs to determine if there were any significant effects from those hot springs. Preliminary modeling and data analysis showed no effects from the hot springs and the station was discontinued after the first season.

Tributary temperatures were collected on Horse Creek to assess its influence on the McKenzie River. Stream cross-sections made at the Covered Bridge at Rainbow (RM 64.4) 2.8 miles downstream from the Horse Creek confluence showed that water temperatures were well mixed by this point and modeling could begin at Delta Park (RM 62.1). Beginning simulation at Delta Park also alleviates the need to estimate the discharge from Horse Creek.

The section of the McKenzie River selected for analysis was from Delta Park (RM 62.1) to Leaburg Dam (RM 38.8). This reach of river was delineated by 9 grid points ( 8 subreaches). See figure 5.4. The grid points are: (1) Delta Park (RM 62.1), (2) confluence with South Fork McKenzie (RM 59.7), (3) confluence with Blue River (RM 57.0), (4) Finn Rock (RM 54.2), (5) Geological Survey gage near Vida (RM 47.7), (6) confluence with Gate Creek (RM 41.4), (7) upper end of Leaburg impoundment (RM 40.6), (8) middle of Leaburg impoundment (RM 39.7), and (9) Leaburg Dam (RM 38.8).

In order to determine effects of reservoirs on daily maximum, minimum, and mean temperatures, modeling time steps must be less than one day in length. Hourly time steps were chosen more for convenience than statistical significance. 


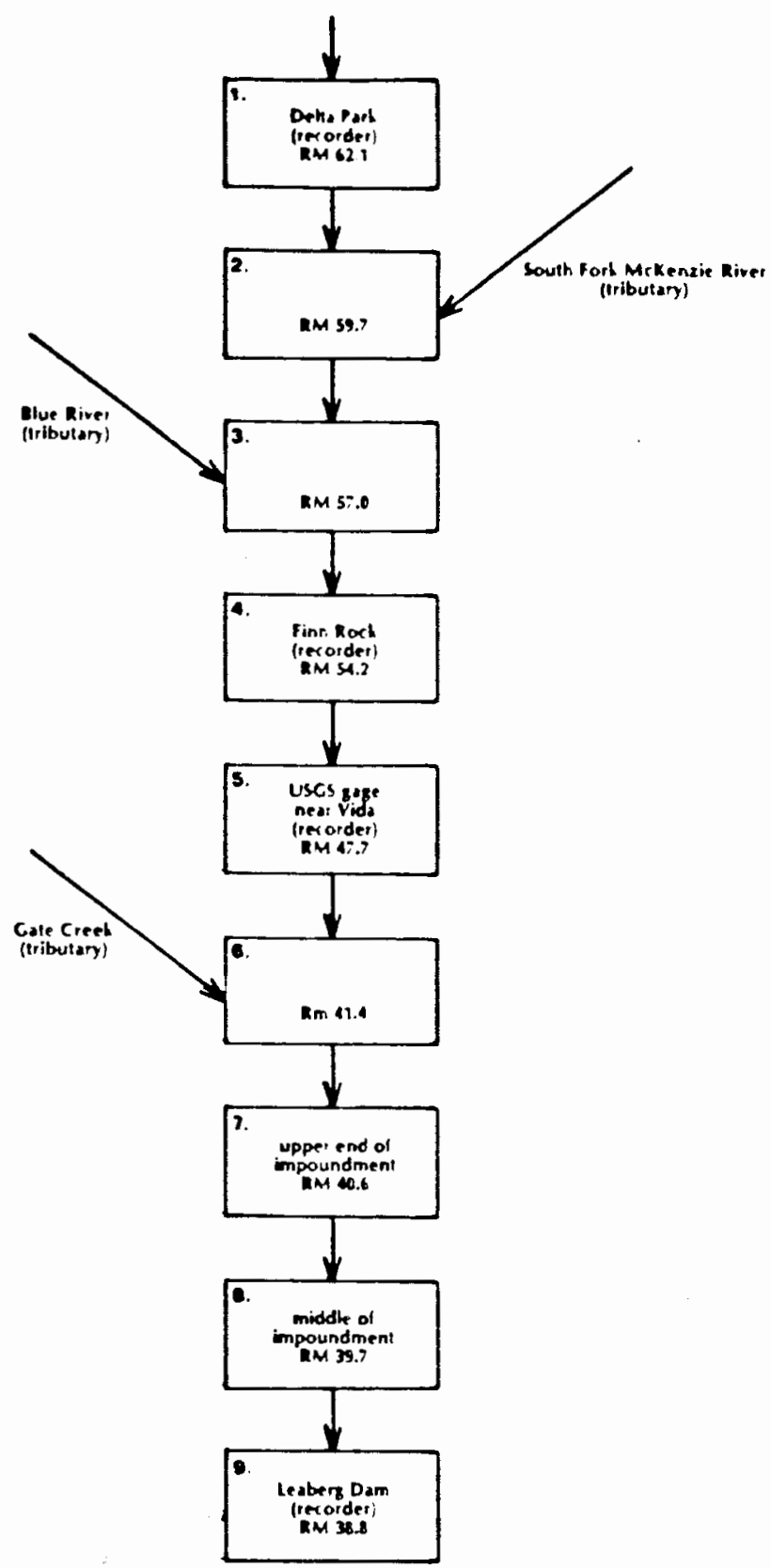

Figure 5.4 Schematic of model segmentation for the Mckenzie River. 


\section{CALIBRATION}

Calibration of the model was performed for a time step length of one hour. The period August 1 to 7, 1984 was chosen for calibration since it was about in the middle of the period when atmospheric data were collected. Air temperatures and windspeeds used were from the data collected at Leaburg Dam (14163100). Since the model was used in steady-state discharge mode, the discharge used was the mean discharge for each period modeled. Upstream discharge was calculated by subtracting discharges at South Fork McKenzie River (14159500) and Blue River (14162200) from the discharge at the Mckenzie River near Vida (14162500). This assumes that South Fork McKenzie and Blue River are the only major tributaries in the reach between Delta Park and the USGS gage near Vida or that at times when other tributaries contribute significant discharges, their water temperatures do not differ significantly from the water temperatures of the mainstem McKenzie River.

Discharges and temperatures from the South Fork McKenzie (14159500), Blue River (14162200) and Gate Creek (14163000) were used as tributary inputs. Blue River and Gate Creek gages are located within 1 mile of the confluence and thus inflow values of discharge and water temperature would be very close to the actual confluence values. The South Fork McKenzie River gage, however, is located 3.9 miles upstream from the confluence. Data values from this gage would be slightly less than actual confluence values since temperatures and discharges would 
likely increase before the actual confluence is met. At times when water is released from Cougar Lake at much warmer than normal temperatures, temperature values used would likely be higher than confluence values. Magnitudes of the differences are not known, but the existence of differences should be kept in mind.

Initial results of simulations using air temperature as an estimate of equilibrium temperature indicate the daily maximum temperature is underpredicted (model values less than observed), while daily minimum values are within a couple of tenths of a degree Celsius. Simulated results do no replicate the diel amplitudes exhibited by the observed data (figure 5.5). In addition, the occurence of the simulated daily maximum and minimum water temperatures lags the observed values, and improvement was deemed necessary.

\section{Calculated equilibrium temperature}

Atmospheric data collected at Leaburg Dam were used to calculate the equilibrium temperature from equation 3.15. The program to calculate the equilibrium temperature uses the Newton-Raphson method to find a solution. A listing of the program used is given the Appendix. The computed hourly equilibrium temperatures were then used in the temperature model in place of air temperature used previously. The results of this scenario are given in figure 5.6. Examination of figure 5.6 shows model results using the computed hourly equilibrium temperature are worse then the results using air temperature as an estimate of equilibrium temperature (figure 5.5). The only redeeming quality from using the calculated equilibrium temperature is that occurences of simulated daily maximum

and

minimum

water temperatures 


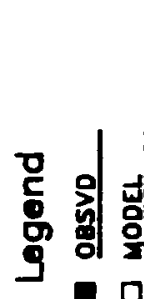

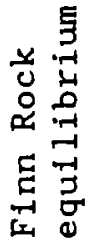

口

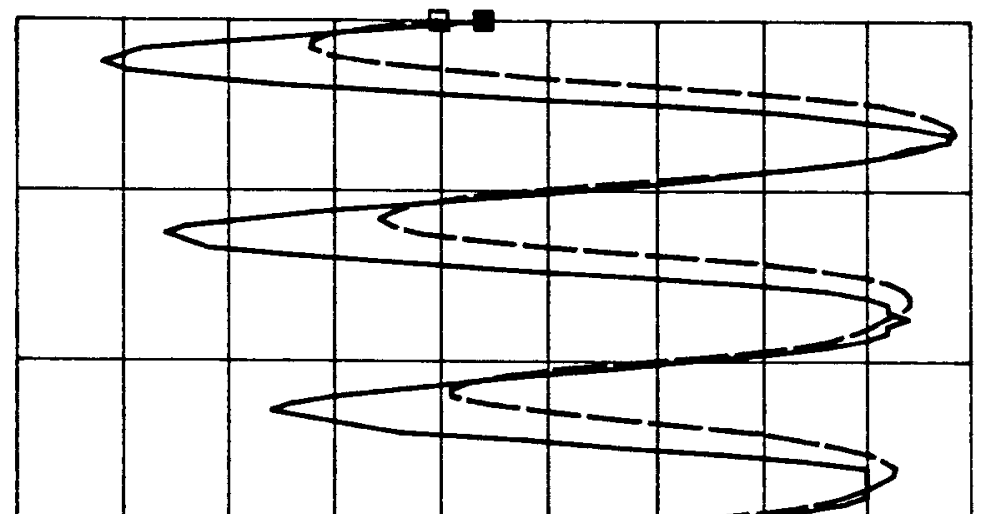

告

$+4$

थ

$\$$

站

$\pi$

过

茴

过

4

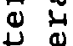

范

ช

$5 \times \quad 0$

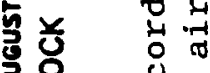

₹욜

z

占告告

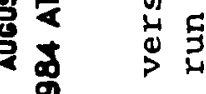

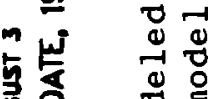

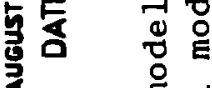
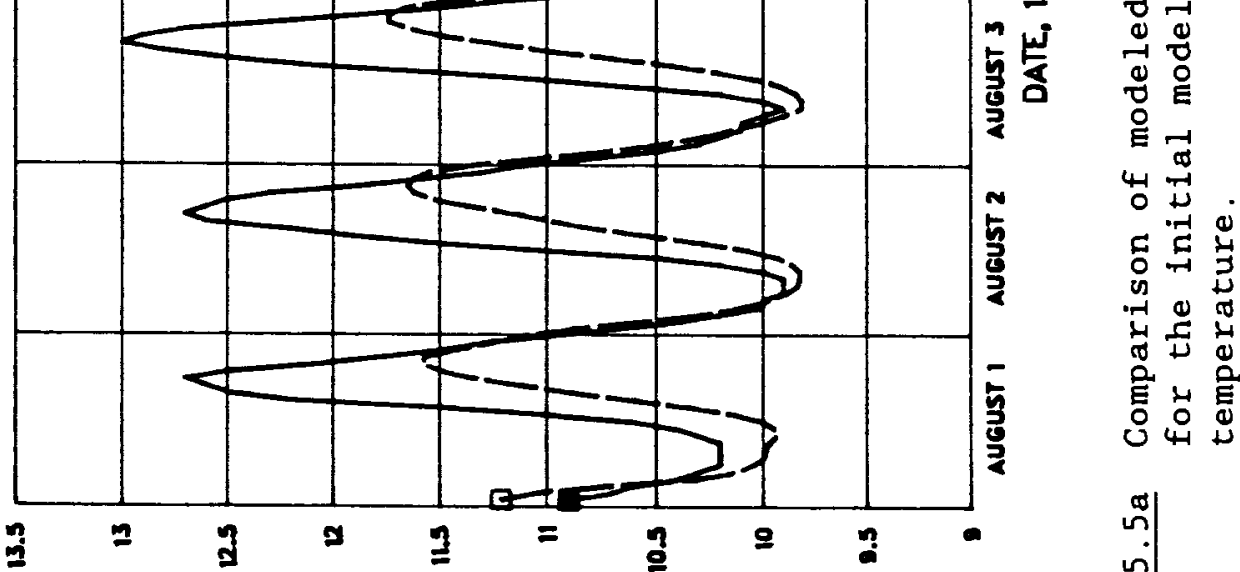

जึ| 


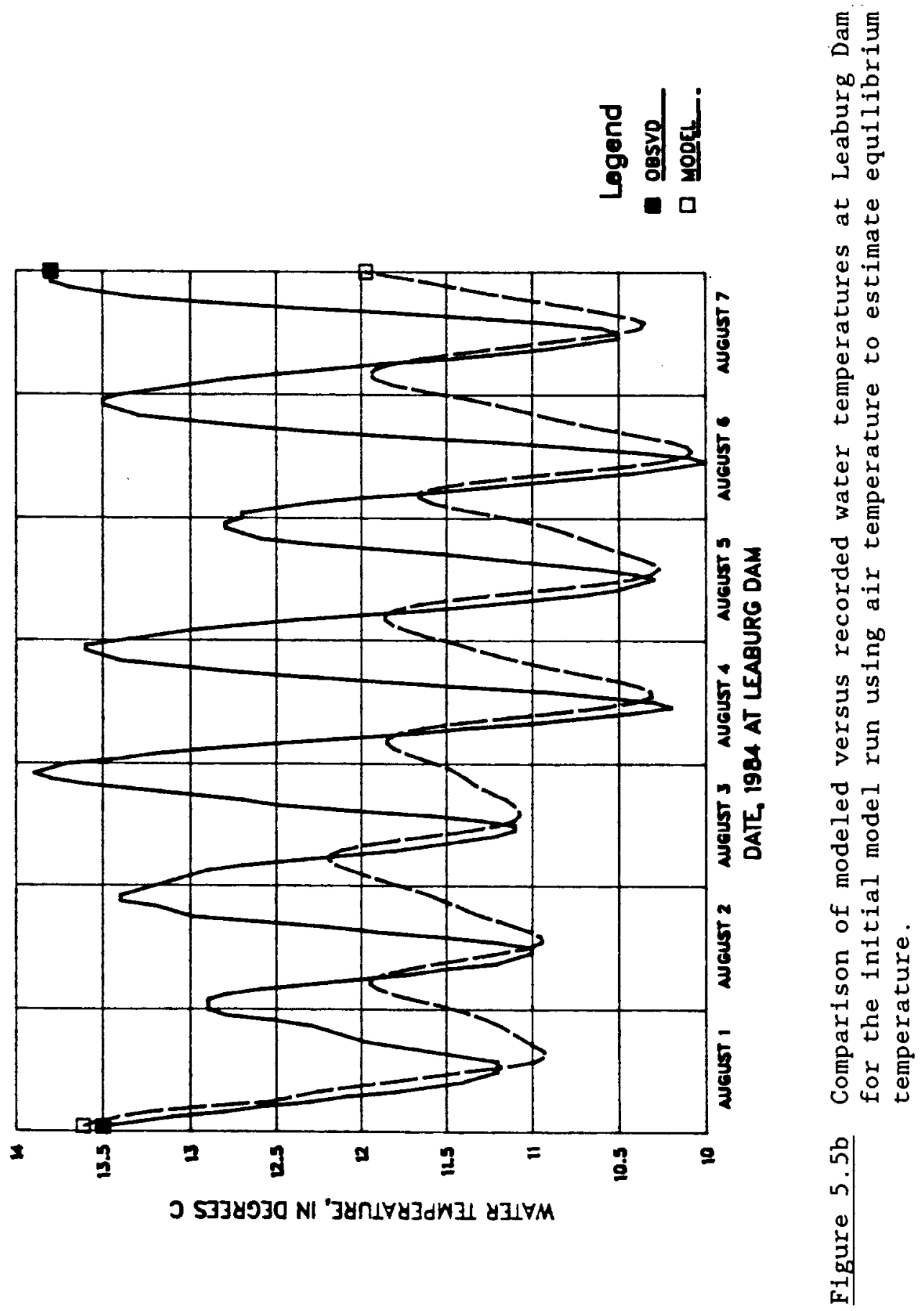




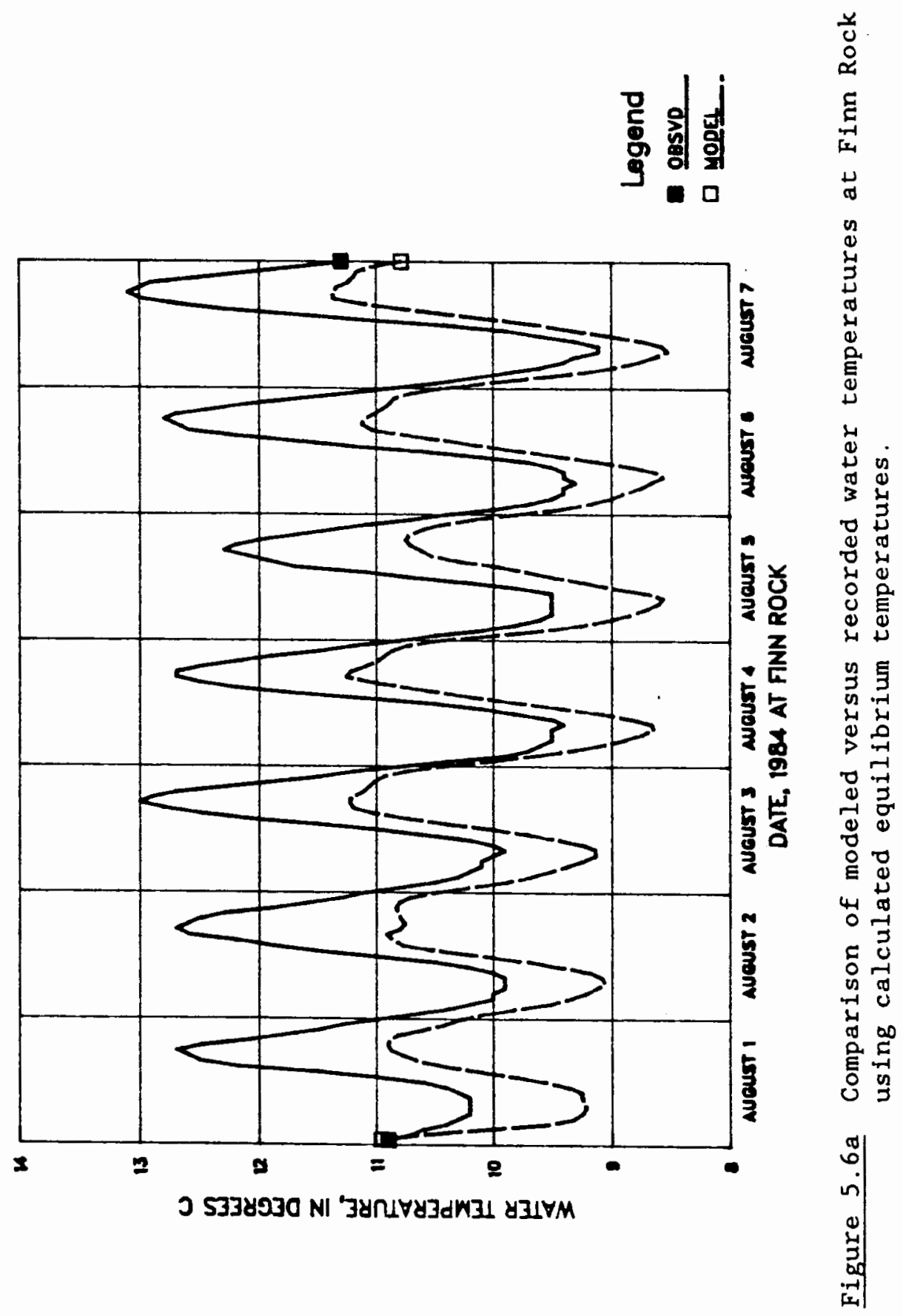




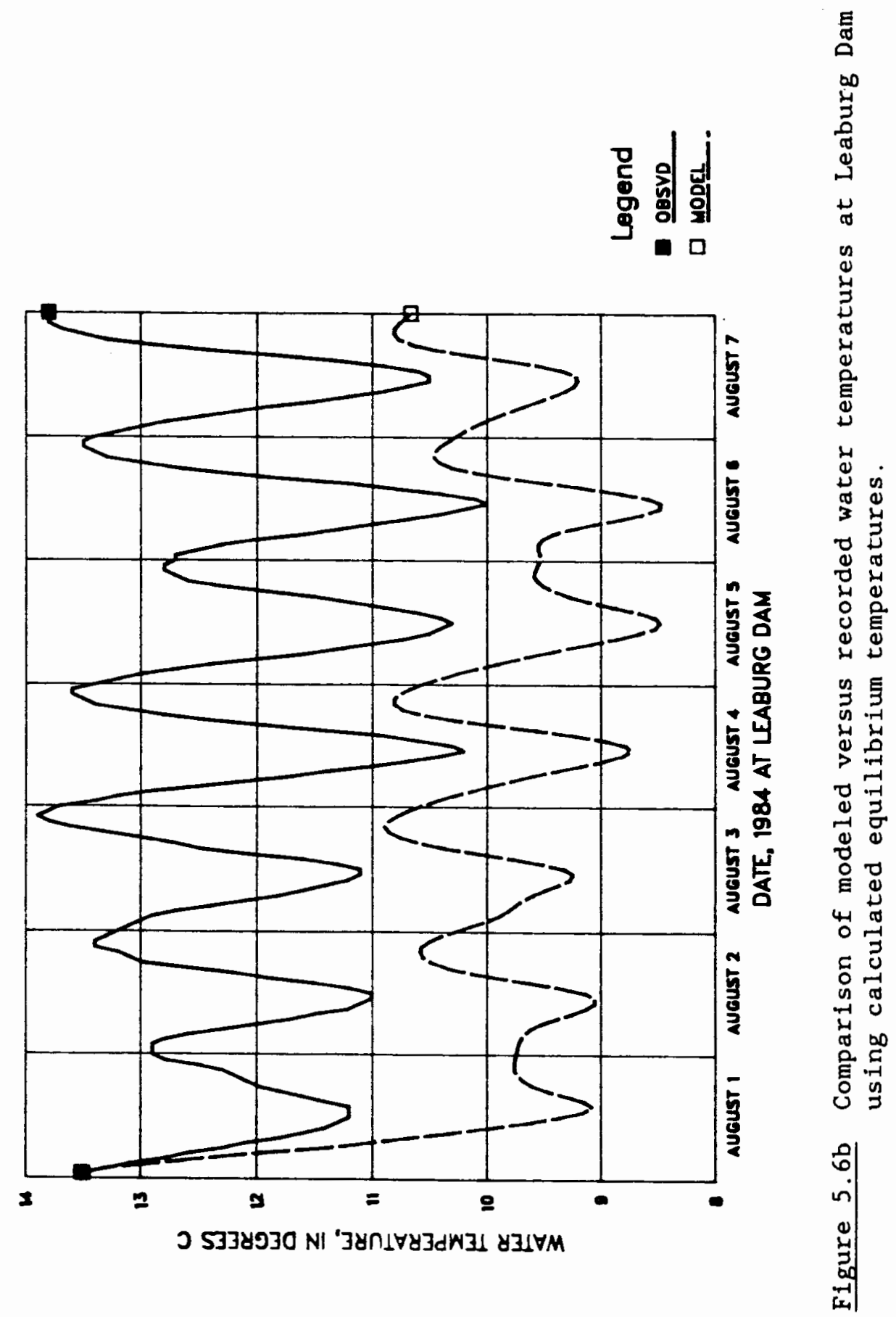


correspond with recorded data more closely when computed values of equilibrium temperature are used. The assertion by Yotsukura, et al (1973) that "the short-term equilibrium temperature has no merit as a base temperature of linearization" has been proven correct in this case. Since calculated equilibrium temperature performed poorly in modeling water temperature, no attempt was made to establish a relation between air and equilibrium temperatures.

Comparisons of results between simulations using air temperature and computed equilibrium temperature indicate that, on an hourly basis at least, use of computed equilibrium temperature is of little value. The reason computed equilibrium temperature performs so badly is that its diel variation is very large and includes temperatures well above and we11 below the water temperature. Table III shows a comparison of mean daily equilibrium, air, and water temperatures for the period June 22 , to September 24,1984 . The mean daily temperature range and extreme values are also included.

\section{TABLE III}

COMPARATIVE STATISTICS

\begin{tabular}{|c|c|c|c|}
\hline & $\begin{array}{l}\text { equilibrium } \\
\text { temperature } \\
{ }^{\circ} \mathrm{C} \\
\end{array}$ & $\begin{array}{c}\text { air } \\
\text { temperature } \\
{ }^{\circ} \mathrm{C} \\
\end{array}$ & $\begin{array}{c}\text { water } \\
\text { temperature } \\
{ }^{\circ} \mathrm{C} \\
\end{array}$ \\
\hline mean daily & 5.8 & 17.2 & 12.0 \\
\hline mean daily range & 36.0 & 13.1 & 2.9 \\
\hline maximum daily range & 44.2 & 19.5 & 4.0 \\
\hline maximum daily $\max$ & 32.2 & 31.7 & 15.5 \\
\hline minimum daily min & -21.0 & 3.3 & 8.4 \\
\hline
\end{tabular}


The maximum daily range of equilibrium temperature calculated was $44.2{ }^{\circ} \mathrm{C}$ indicating that the value of $50^{\circ} \mathrm{C}$ presented by Edinger, et a1 (1969) is plausible.

\section{Topwidth parameter}

The dilemma of how to improve the temperature model still remains. Improving model accuracy would improve the models ability to determine effects of COE reservoirs on the McKenzie. Three explanations were considered for underestimating heat input (assuming heat loss was not overestimated): 1) the reach modeled (Delta Campground RM 62.1 to Leaburg Dam RM 38.8) has many riffles, so perhaps an effective topwidth needs to be used rather than the actual field measured topwidth, 2) air temperature underestimated equilibrium temperature in this case, or 3 ) some combination of the two. Whatever the reason, the results showed the heat coming into a parcel was underestimated or the heat leaving was overestimated.

Because quantification of an effective topwidth or a better surrogate for equilibrium temperature would be a time consuming, trial and error process, a simpler solution was employed. First, an assumption was made that the estimate of heat entering the parcel at the air/water interface was not properly evaluated. Next, the initial water temperature, dispersion, and tributary inflow heat contributions were assumed to be accurate. Then, referring to equation 4.2 , if the surface exchange term (the third term on the right hand side) is multiplied by a factor greater than one, the amount of heat coming into (or leaving, depending on the sign of $\mathrm{H}$ ) the system is increased. Since both $\mathrm{H}$, the net air/water interface heat exchange term, and $W$, the width, are in the 
numerator of the surface exchange term, the two can be treated together instead of separately. Finally, a factor less than one can be used if modeling indicated temperatures were being overpredicted (modeled temperatures greater than observed temperatures). Calibration is then reduced to determining the heat exchange parameter (HEP) needed to provide the best match of modeled versus observed data.

Determination of the value of HEP needed for simulated results to more closely approximate recorded values was performed in the following manner. The HEP value was increased by increments of 0.5 until the results were deemed satisfactory. No optimization routine was employed to determine HEP more precisely. The value of HEP found in this manner was 2.5. Figure 5.7 shows the simulated results using this value.

Increases in HEP do not provide an equal increase in both daily maximum and minimum temperatures. As HEP increases, daily maximums increase by a greater amount than daily minimums. This is because the amount of heat available for transfer is larger during the warmest part of the day. HEP not only increases the simulated daily maximums and minimums, but also increases the diel fluctuation. The addition of the HEP parameter permits the simulated results to more closely represent the observed data.

In reality $\mathrm{HEP}$ is a catch all error term to compensate for inadequecies in the model approach used. HEP does have some physical basis however. Intuitively, its use to account for an "effective" topwidth appears reasonable and the results appear to support its appropriateness. 

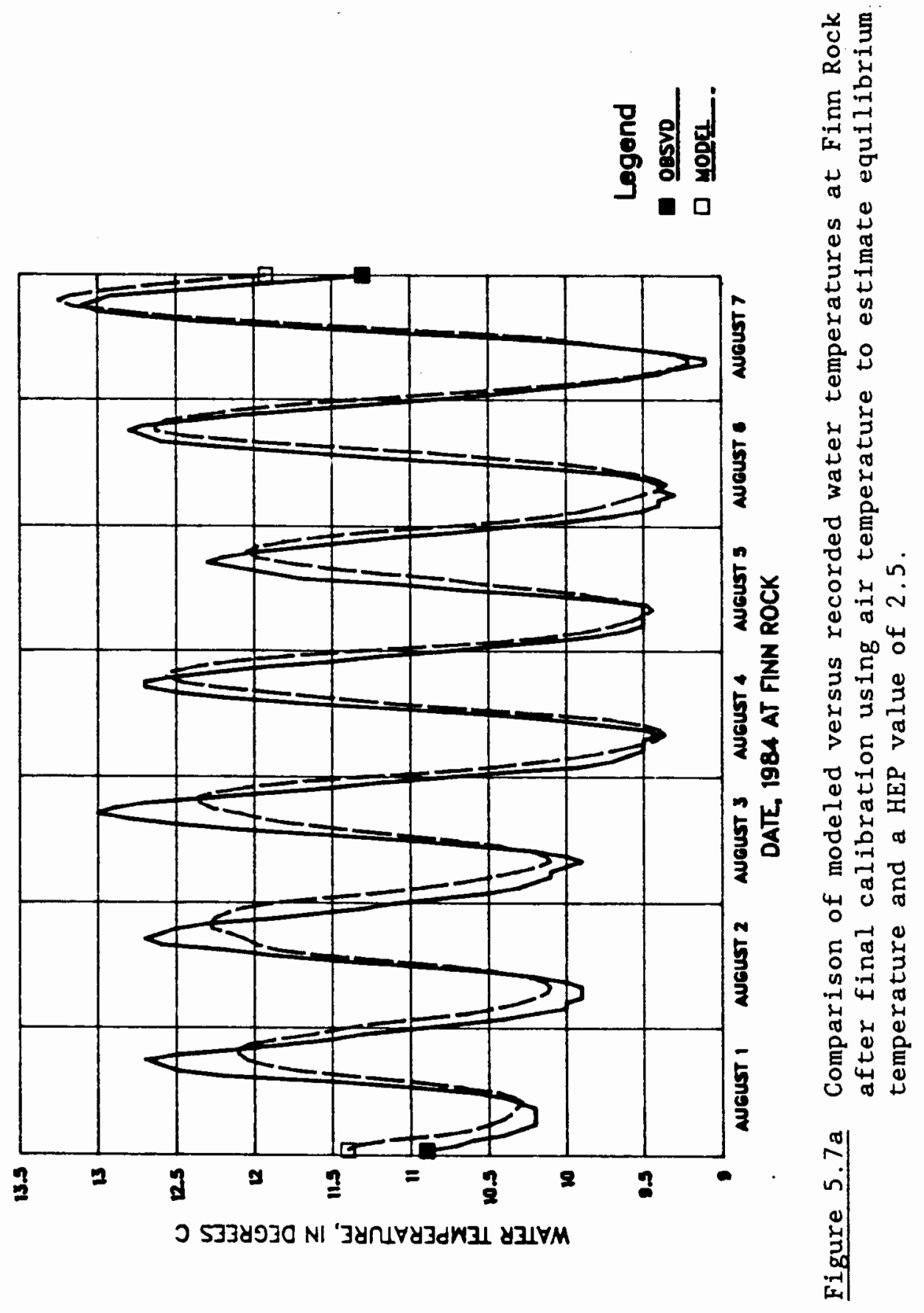


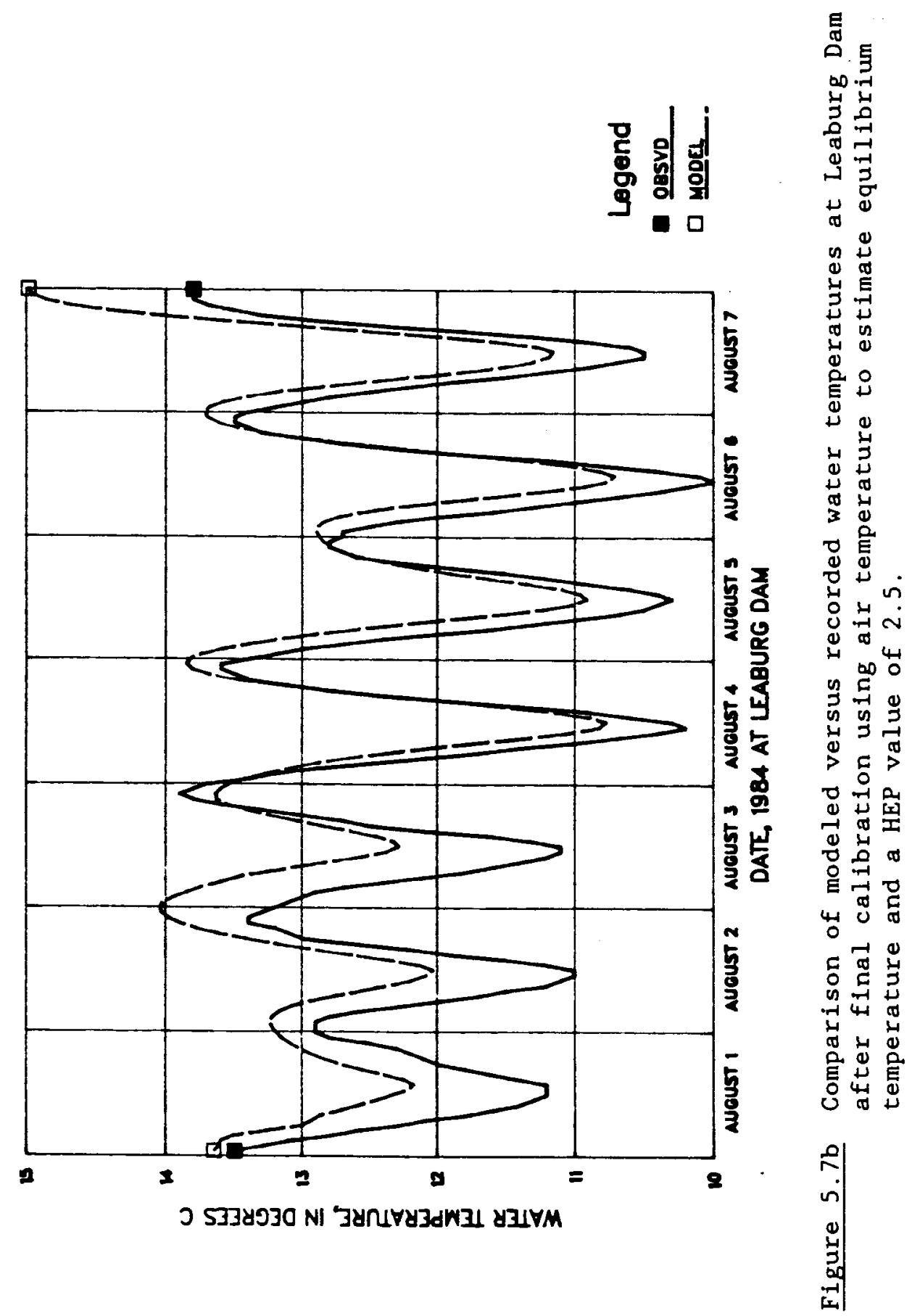




\section{VALIDATION}

Validation of the calibrated model was performed on data for the periods July 11 to 17, and September 1 to 8, 1984. Results for these two periods appear in figures 5.8 and 5.9 respectively. Inspection of these figures shows the simulated data at Finn Rock compare well with the recorded data. Comparison of simulated with recorded data at Leaburg Dam are not as good.

For both the July and September periods, there are several days when the simulated values are significantly greater than the recorded values. The closer the simulated values are to the recorded values at Finn Rock, the further off they are at Leaburg Dam. This implies that perhaps the heat input is overestimated in the subreach from Finn Rock to Leaburg Dam. The HEP values was held constant throughout the study reach, even though the frequency and violence of the riffles decreased with distance downstream from Delta Park. Perhaps the HEP values needs to be subreach specific. Further study into the relation between channel (especially stream surface) character and HEP values appears appropriate.

Another measure of the model validity is its ability to follow the diel variation at the recorder sites and especially the occurences of daily maximums and minimums at Leaburg Dam. Figure 5.10 shows that the occurence of the daily maximums and minimums at Leaburg Dam are anomalous compared to the other recorder sites. Yet simulation of the occurences of the daily maximums and minimums at Leaburg Dam is quite respectable. 

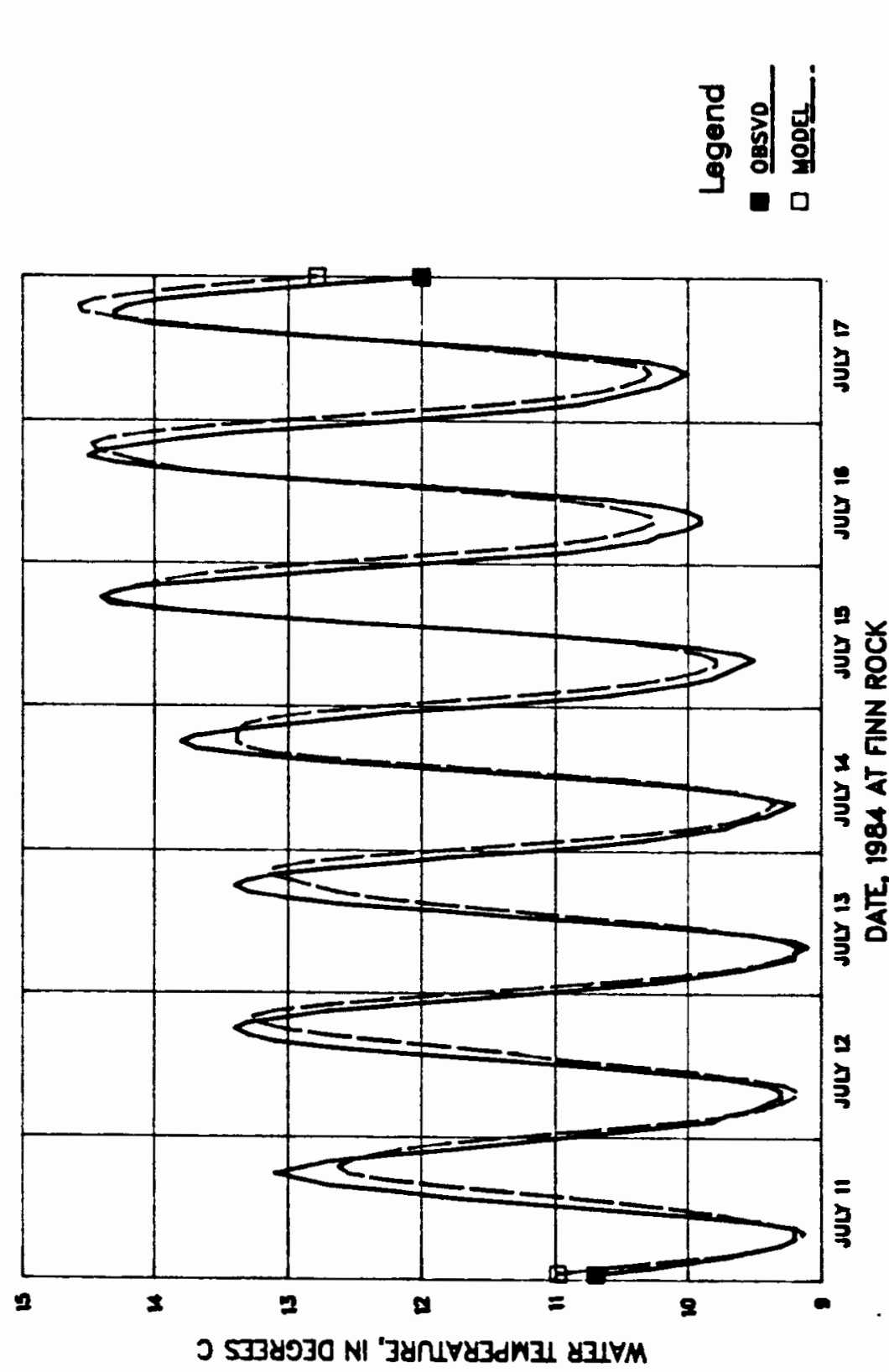

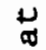

ט

5

Ð

प्र

ษ

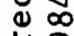

3

疋

4

$\stackrel{\infty}{>}$

강

查

ర్

点

㟔

:

岁

41
0

돈

응

것

(1)

芜吉

O․

م. 


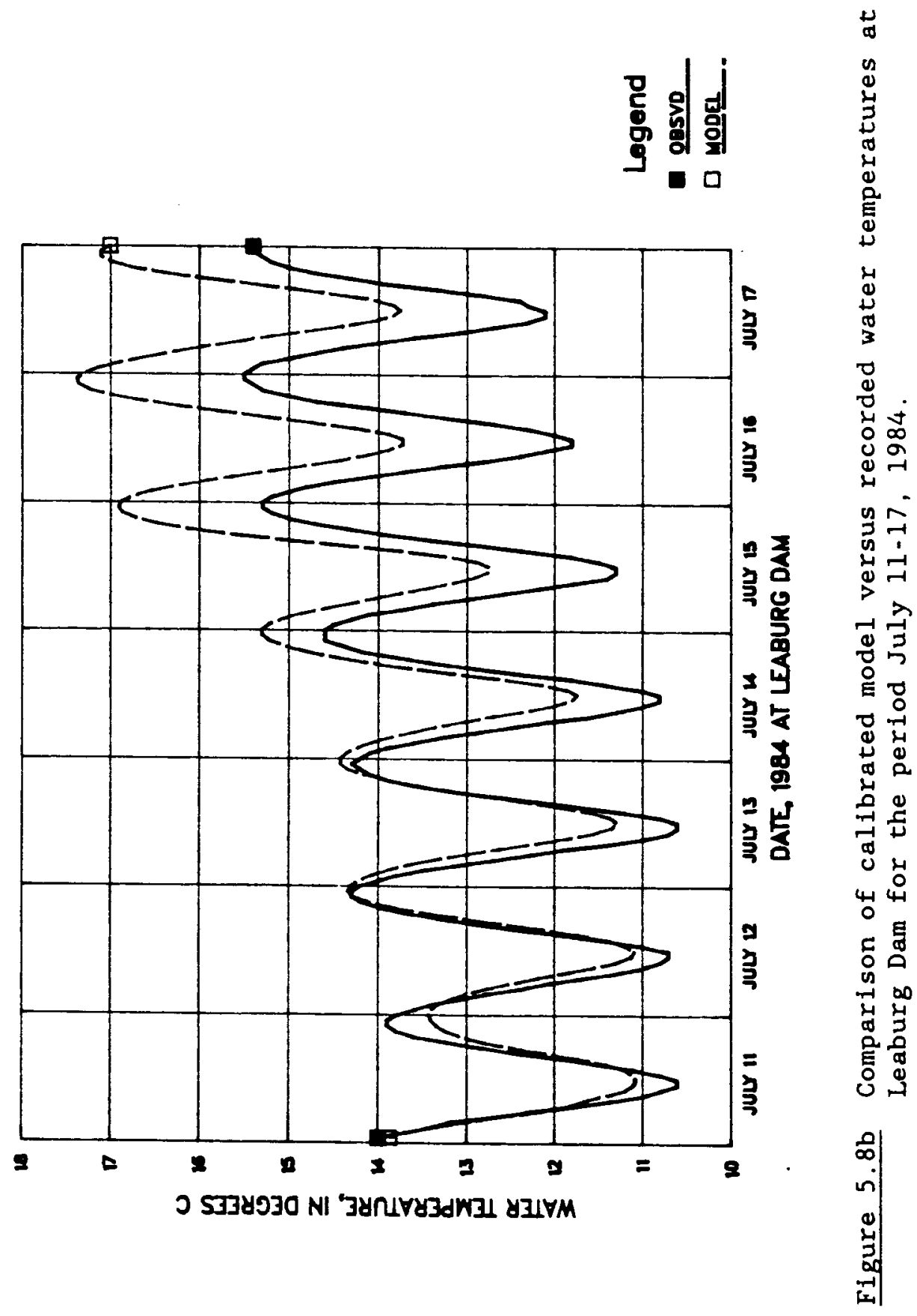



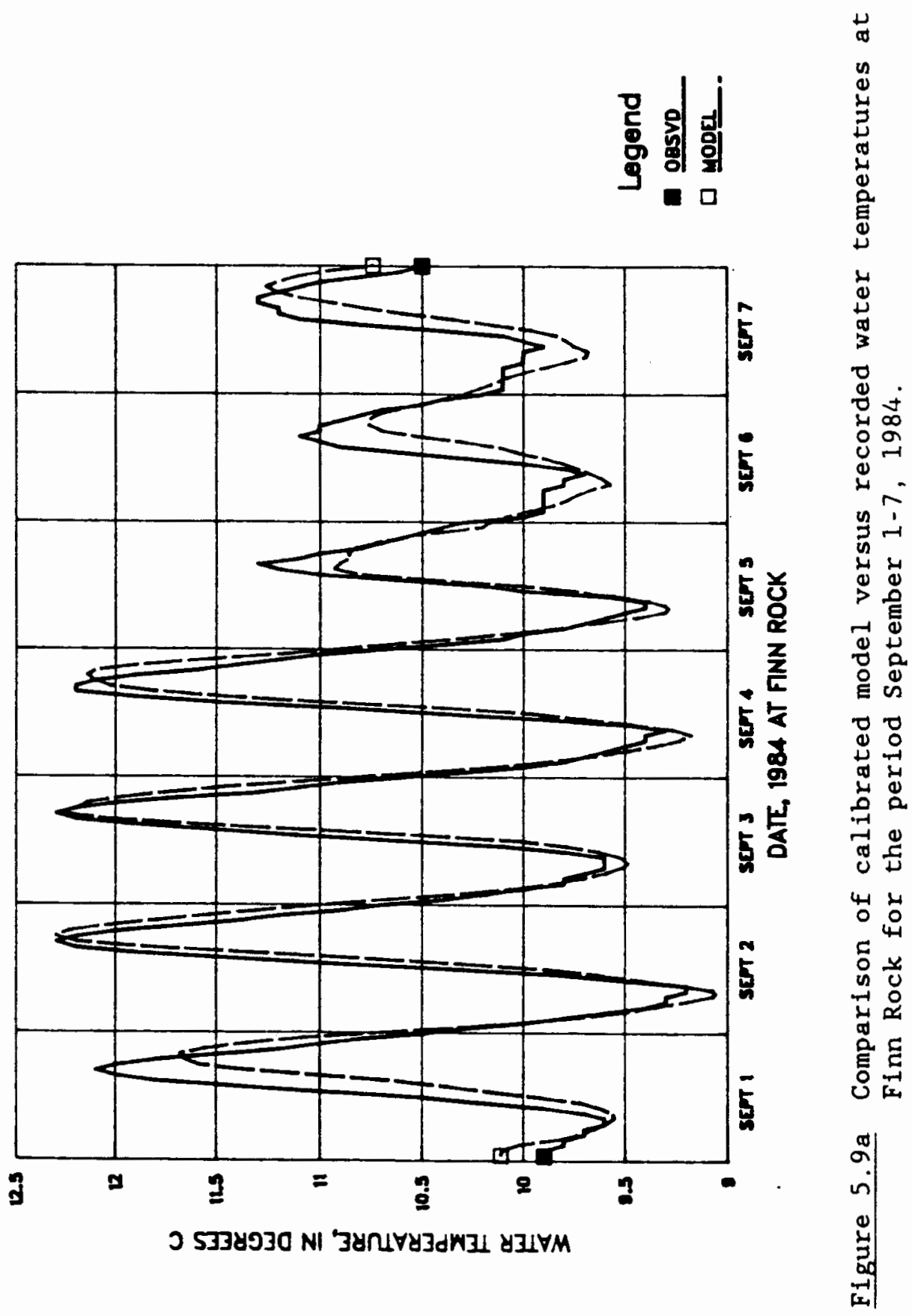


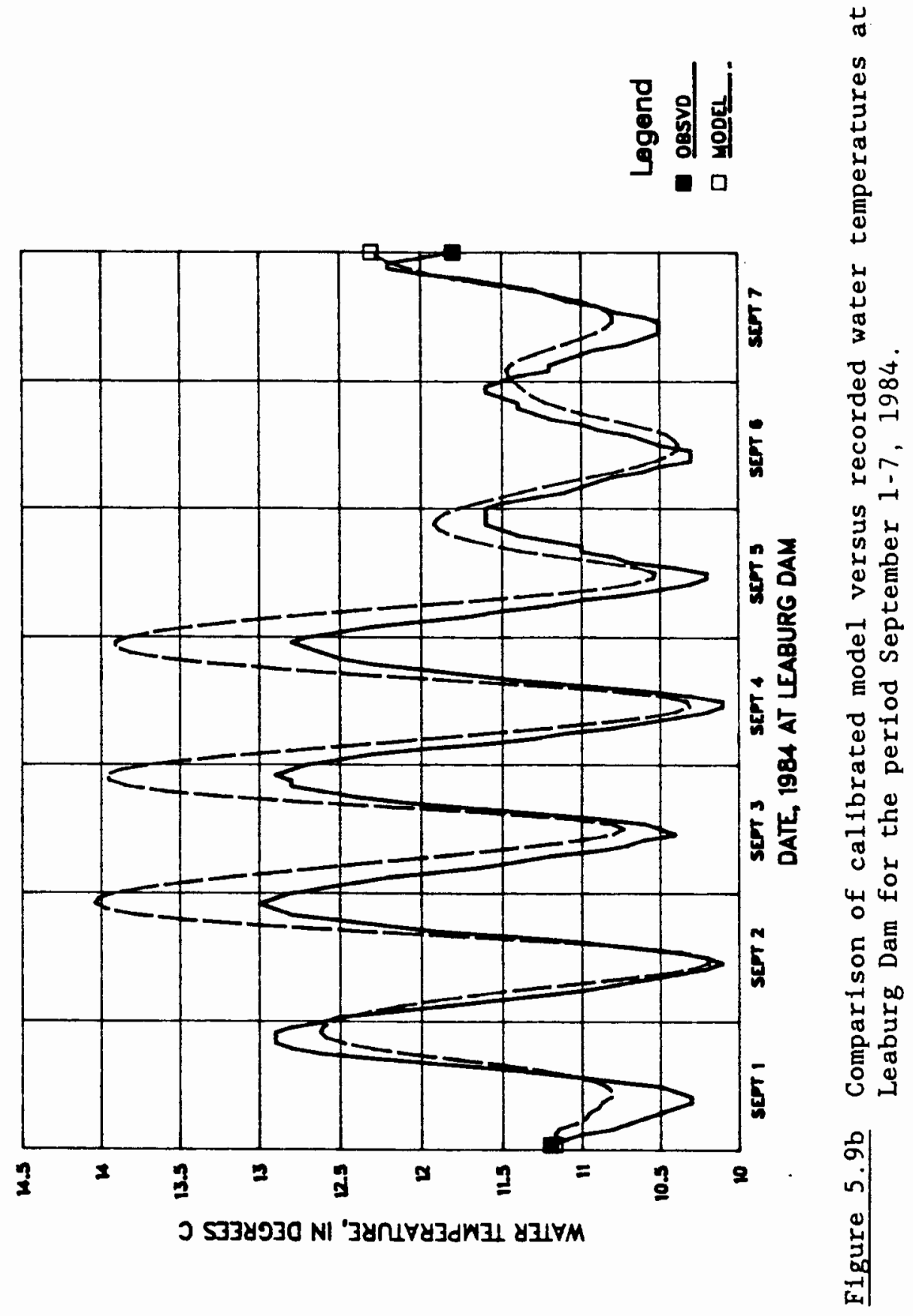




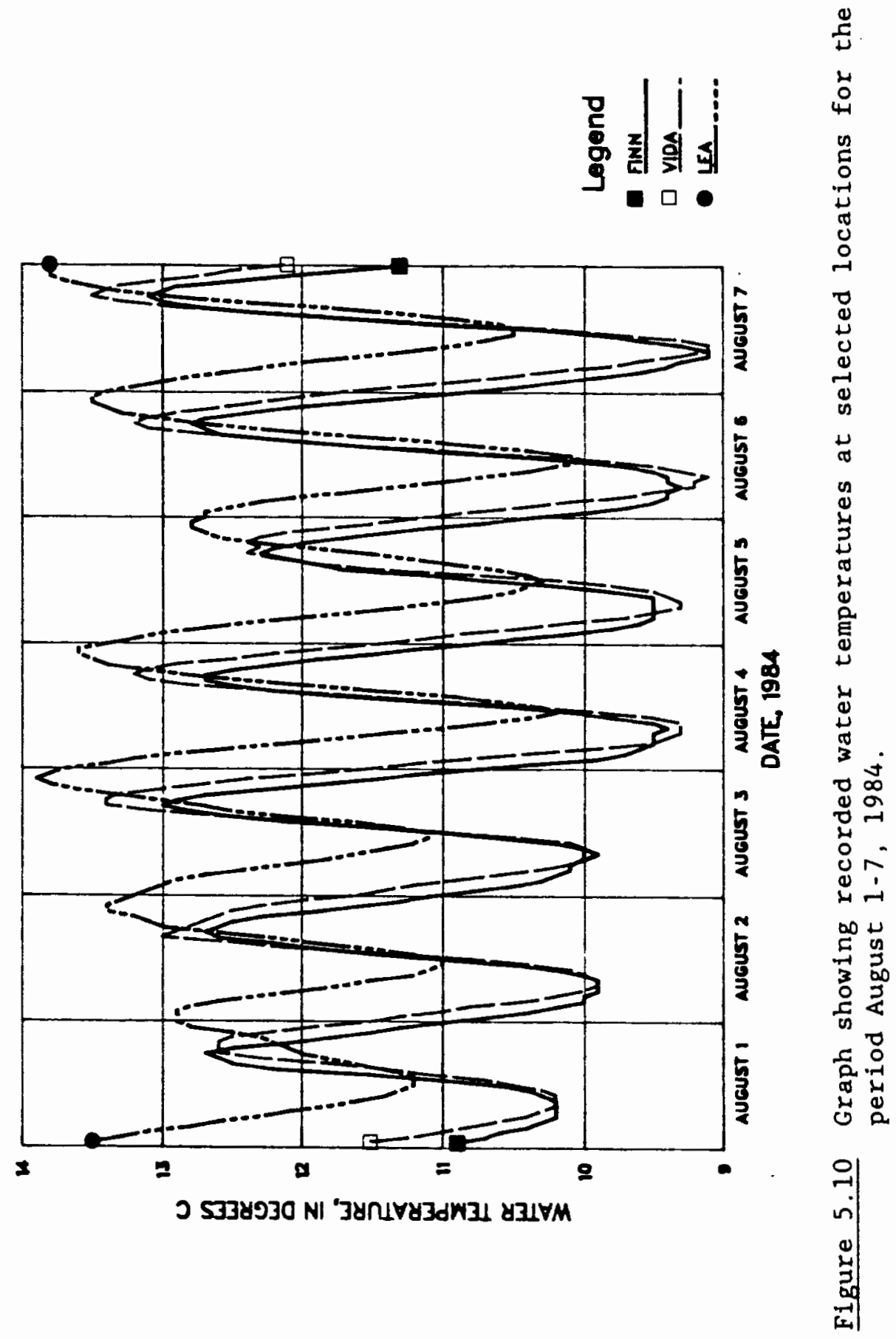




\section{SENSITIVITY}

The model was analyzed for sensitivity by varying model inputs singularly and comparing results to evaluate which inputs cause the largest changes. It should be recognized, however, that the sensitivity analysis was performed under a specific set of conditions. The results should be used as a measure of the relative sensitivity of the variables and not the absolute values of the variables sensitivity.

The sensitivity analysis was performed on the period August 1 to 7, 1984. The goal of the sensitivity analysis was to determine how errors in model data affect water temperatures downstream at Leaburg Dam. From the results of this analysis, the modeler knows what data must be collected with the greatest accuracy. This is especially helpful if project budgets constrain data collection.

The parameters evaluated were equilibrium temperature (air temperature) and HEP. The variables chosen were topwidth, crosssectional area, windspeed, upstream discharge, and tributary discharge. Each parameter or variable was tested by increasing or decreasing its value in the calibrated model by 25 percent. Table IV show the results of the sensitivity analysis.

Examination of Table IV shows air (equilibrium) temperature is by far the most important factor in driving the model. A $25 \%$ change in air temperature causes a change of over 108 in water temperature at Leaburg Dam. Air temperature is the model's principal measure of atmospheric heat input, so high model dependence on this factor is not surprising.

It is not coincidental that a 258 change in HEP or topwidth produce identical results. Recall the previous discussion on the 
rationale for the introduction of HEP and how it is applied. Since HEP is a coefficient applied to the term containing the topwidth, increases or decreases of the same magnitude in HEP or topwidth produce the same results. This helps justify the use of HEP in calibration and lends support to the hypothesis that measured topwidths for turbulent reaches are inadequate and an "effective" topwidth needs to be considered.

TABLE IV

SENSITIVITY ANALYSIS

\begin{tabular}{|c|c|c|c|c|}
\hline $\begin{array}{l}\text { Parameter or } \\
\text { variable changed }\end{array}$ & $\begin{array}{l}\text { Amount } \\
\text { changed }\end{array}$ & $\begin{array}{r}\text { Base } \\
\text { value } \\
\end{array}$ & $\begin{array}{c}\text { Mean change } \\
\text { erature at } \\
{ }^{\circ} \mathrm{C}\end{array}$ & $\begin{array}{c}\text { in water temp } \\
\text { Leaburg Dam in } \\
\text { percent }\end{array}$ \\
\hline air temperature & $\begin{array}{l}+258 \\
-258\end{array}$ & $\begin{array}{c}\text { Leaburg Dam } \\
\text { hourly }\end{array}$ & $\begin{array}{l}+1.60 \\
-1.39\end{array}$ & $\begin{array}{l}12.68 \\
10.98\end{array}$ \\
\hline HEP & $\begin{array}{l}+258 \\
-258\end{array}$ & 2.5 & $\begin{array}{l}+0.57 \\
-0.47\end{array}$ & $\begin{array}{l}4.58 \\
3.78\end{array}$ \\
\hline topwidth & $\begin{array}{l}+258 \\
-258\end{array}$ & $\underline{1} /$ & $\begin{array}{l}+0.57 \\
-0.47\end{array}$ & $\begin{array}{l}4.58 \\
3.78\end{array}$ \\
\hline $\begin{array}{c}\text { cross-sectional } \\
\text { area }\end{array}$ & $\begin{array}{l}+25 \% \\
-25 \%\end{array}$ & 1/ & $\begin{array}{l} \pm 0.39 \\
\pm 0.62\end{array}$ & $\begin{array}{l}3.18 \\
4.98\end{array}$ \\
\hline windspeed & $\begin{array}{c}+258 \\
-258 \\
\text { set }=0\end{array}$ & $\begin{array}{l}\text { Leaburg Dam } \\
\text { hourly }\end{array}$ & $\begin{array}{l}+0.25 \\
-0.13 \\
-0.71\end{array}$ & $\begin{array}{l}2.08 \\
1.08 \\
5.68\end{array}$ \\
\hline discharge & $\begin{array}{l}+25 \% \\
-25 \%\end{array}$ & $60.65 \mathrm{~m}^{3} / \mathrm{s}$ & $\begin{array}{l}-0.19 \\
+0.38\end{array}$ & $\begin{array}{l}1.58 \\
3.08\end{array}$ \\
\hline $\begin{array}{l}\text { tributary } \\
\text { discharge }\end{array}$ & $\begin{array}{l}+258 \\
-258\end{array}$ & $\underline{1} /$ & $\begin{array}{l}-0.14 \\
+0.30\end{array}$ & $\begin{array}{l}1.18 \\
2.48\end{array}$ \\
\hline
\end{tabular}

1/ See figure 4.1 for base values.

Changing cross-sectional area had a moderate effect on water temperature at Leaburg Dam. Perhaps the most significant observation, however, is that while all other factors examined had either a positive 
or negative effect when changed, cross-sectional area had both positive and negative effects when changed by either $\pm 25 \%$. Cross-sectional area determines the velocity and hence the travel time for a given discharge. It also determines the depth for a given topwidth since rectangular cross-sections are assumed. Refering again to equation 4.2 , temperature changes due to surface exchange are inversely proportional to crosssectional area. But since cross-sectional area also affects velocity (and thus travel and exposure time), the effect of cross-sectional area on temperature is not a simple relation.

Windspeed had a minor effect when changed by \pm 258 . But when windspeed was set to zero (to remove its effect altogether), its effect became pronounced. This indicates windspeed needs to be used in the model, but use of a daily average may be sufficient if hourly averages are not available.

Discharge gives the volume of water per unit time that must be heated or cooled. The larger the volume, the smaller the temperature increase for a given heat input and duration. Thus, it is reasonable that a decrease in upstream discharge of 258 provided a greater change in water temperature than an increase in upstream discharge.

Increasing or decreasing tributary inflow discharge from south Fork McKenzie River, Blue River, and Gate Creek by 258 showed changes similar to altering upstream discharge, but not as large. This is due in part to a lower total discharge from the three tributaries than is in the McKenzie River before the tributaries enter. A complicating factor in altering tributary inflow is that tributaries affect total river 
volume and temperature depending on the water temperature of the tributaries.

It bears repeating that this sensitivity analysis represents effects under a specific set of conditions. If any of these conditions were vastly different, the results might differ. The goal in this sensitivity analysis is to get a feel for relative importance of the different factors and how errors in their measurement would affect results.

\section{ACCURACY}

Stream temperature model accuracy is highly dependent on how well the equations used to estimate the energy exchanged between water and its surrounding media approximate the actual physical processes. But even the most complex mathematical expressions representing every conceivable physical process can yield misleading results if used with inaccurate data. Thus, accuracy of model results is a reflection of both process modeling accuracy and input data accuracy.

Accuracy was measured by computing the mean of the difference between modeled and recorded water temperatures and using two different methods to calculate the scatter about that mean. The mean gives a measure of how well the model did overall for a period. The deviations about the mean indicate the error to be expected in any given hourly modeled value. The first method to measure dispersion about the mean was to compute the standard deviation of the difference between modeled and observed hourly values. The second method was to compute the mean absolute deviation (MAD) between modeled and observed hourly values. 
The MAD is calculated by taking the absolute value of the difference between modeled and observed values, totalling the absolute values, and dividing by the number of values compared.

Accuracy was further divided into two data sets. The first data set uses the calibration period (August 1 to 7,1984 ), and the second data set uses the validation periods (July 11 to 17 and September 1 to 7, 1984). Table $\mathrm{V}$ contains a summary of model accuracies at Finn Rock and Leaburg Dam.

\section{TABLE V}

MODEL ACCURACY

\begin{tabular}{|c|c|c|c|c|}
\hline Location & period & $\begin{array}{c}\text { Mean } \\
{ }^{\circ} \mathrm{C}\end{array}$ & $\begin{array}{r}\mathrm{MAD} \\
{ }^{\circ} \mathrm{C}\end{array}$ & $\begin{array}{c}\text { Std dev } \\
{ }^{\circ} \mathrm{C}\end{array}$ \\
\hline$\overline{\text { Finn Rock }}$ & $\begin{array}{l}\text { calibration } \\
\text { validation }\end{array}$ & $\begin{array}{r}\overline{0.02} \\
-0.01\end{array}$ & $\begin{array}{l}0 . \overline{36} \\
0.29\end{array}$ & $\begin{array}{l}0.42 \\
0.37\end{array}$ \\
\hline $\begin{array}{l}\text { Leaburg } \\
\text { Dam }\end{array}$ & $\begin{array}{l}\text { calibration } \\
\text { validation }\end{array}$ & $\begin{array}{l}0.59 \\
0.60\end{array}$ & $\begin{array}{l}0.61 \\
0.68\end{array}$ & $\begin{array}{l}0.38 \\
0.60\end{array}$ \\
\hline
\end{tabular}

Table $V$ shows the accuracy at Finn Rock is quite good. Since the mean difference between modeled and recorded values is near zero, the model has no overall tendency to overpredict or under predict results. The calibration proved successful in that the validation error is actually less than the calibration error. By comparison, the instrumentation is considered accurate to within $\pm 0.5^{\circ} \mathrm{C}$, and the USGS publishes data to the nearest half degree celsius.

The simulation results at Leaburg Dam are less accurate, however. A definite bias was introduced in the simulations since overall modeled 
results were about $+0.6^{\circ} \mathrm{C}$ above recorded values. Results of calibration and verification are similar and calibration can be considered a success here as well.

Since there was no bias at Finn Rock and an over prediction bias at Leaburg Dam, it appears the HEP value used is too large for the subreaches below Finn Rock. Calibration using a sub-reach specific HEP value should help reduce the bias and improve accuracy in the lower reaches of the McKenzie River below Finn Rock. Nevertheless, the accuracy is considered adequate to examine the effects of releases of water from COE reservoirs on downstream water temperatures.

\section{ANALYSIS OF EFFECTS}

The model has now been shown to be able to replicate hourly water temperatures of the McKenzie River to within $0.4^{\circ} \mathrm{C}$ at Finn Rock and 0.7 ${ }^{\circ} \mathrm{C}$ at Leaburg Dam. By altering input variables to the model, simulations of other conditions can be analyzed. Any departure greater than model error at a location is considered to be significant.

Simulations of the water temperature regime with and without COE reservoirs are compared to determine the effects of the COE projects on the mainstem McKenzie River. Reservoirs have the potential for measureable effects when 1) the difference between reservoir inflow and outflow discharges is significant, or 2) the difference between reservoir inflow and outflow temperatures is significant. The potential for reservoirs to have their greatest measurable effect occurs when significant differences between inflow and outflow discharge and temperature occur simultaneously, e.g. low reservoir inflow at high temperature and high reservoir outflow at low temperature. 
The calibrated model is used to simulate the temperature regime in the Mckenzie River without Cougar and Blue Lakes by using reservoir inflow water temperatures and discharges instead of reservoir outflow water temperature and discharges as tributary inputs to the model. This approach does not take into account changes in flow or temperature for the reach from the above reservoir stations to the below reservoir stations, a distance of 6.5 miles on the South Fork McKenzie River and 7.6 miles on Blue River. Inflow temperature and discharge utilized data from the USGS station for the South Fork McKenzie River above Cougar Lake, near Rainbow, OR (14159200). Inflow discharge to Blue River Lake used the sum of discharges at USGS stations for Blue River below Tidbits Creek, near Blue River, OR (14161100), and Lookout Creek, near Blue River, OR (14161500). The inflow water temperature used was obtained from the Blue River below Tidbits Creek site. Results generated in this manner represent minimum effects since both water temperature and flow would likely increase by the time the confluence with the McKenzie River was reached.

The periods used to examine reservoir effects were July 11 to 17 , August 1 to 7, and September 1 to 7, 1984. During the period July 11 to 17, reservoir inflow and outflow discharges are nearly equal but reservoir inflow temperatures exceeded outflow temperatures. This period represents an example of reservoir conservation holding, when reservoir levels are maintained for storage purposes.

During the period August 1 to 7 , total reservoir outflow discharge 
exceeded inflow by almost threefold. Inflow temperatures exceeded outflow temperatures by an average of over $4^{\circ} \mathrm{C}$. This period is an example of low flow augmentation reservoir operation.

During the period September 1 to 7 , total reservoir outflow exceeded inflow by over fourfold. Reservoir inflow temperatures continued to exceed reservoir outflow temperatures, but the margin was less than in the August period. This period is an example of reservoir drafting operation, when reservoir levels are lowered in preparation for winter flood control. Drafting continues into November. Low flow augmentation is a secondary benefit of this operation.

Figures $5.11,5.12,5.13$ show comparisons of with and without reservoir simulations for the selected periods in July, August, and September, respectively. Table VI gives a summary of the average daily maximum, minimum, and mean water temperatures for the with and without reservoir simulations, as well as the difference between the two simulations.

For the July period, COE reservoirs had a cooling effect at Finn Rock. Daily maximum, minimum, and mean water temperatures are all affected by amounts greater than model accuracy. The difference is not equal for each statistic, indicating effects on each statistic are different. One of the results of these effects is a decrease in diel variation at Finn Rock.

Since the differences between with and without reservoir simulations is less than model accuracy at Leaburg Dam for July, it is concluded COE reservoirs have no measurable affect on water temperatures by the time Leaburg Dam is reached. The diel variation was slightly 

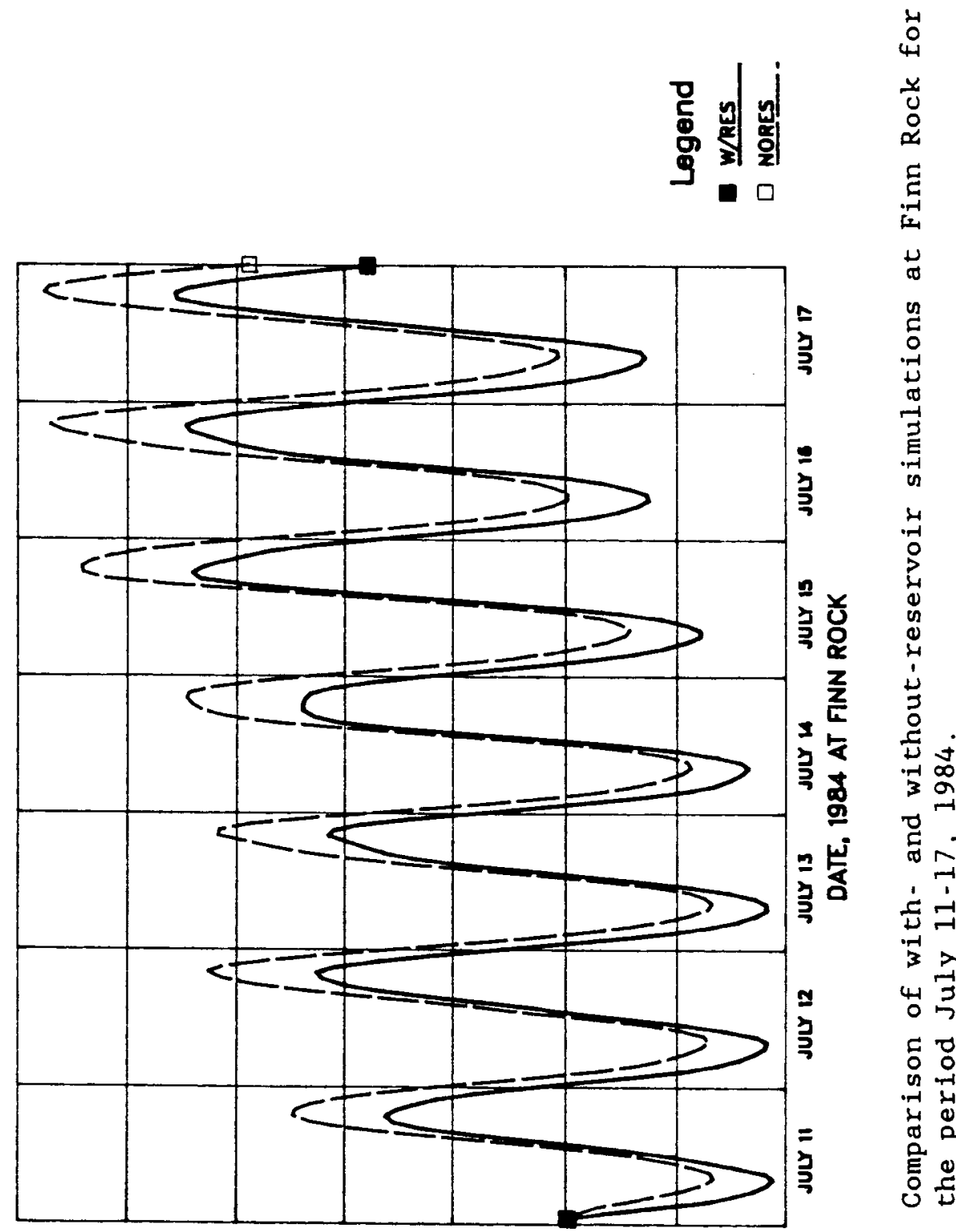

0
-1
0
0
4
5
0
0.1
0 


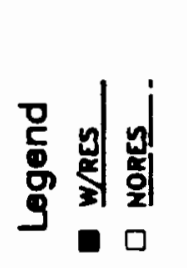

㻤

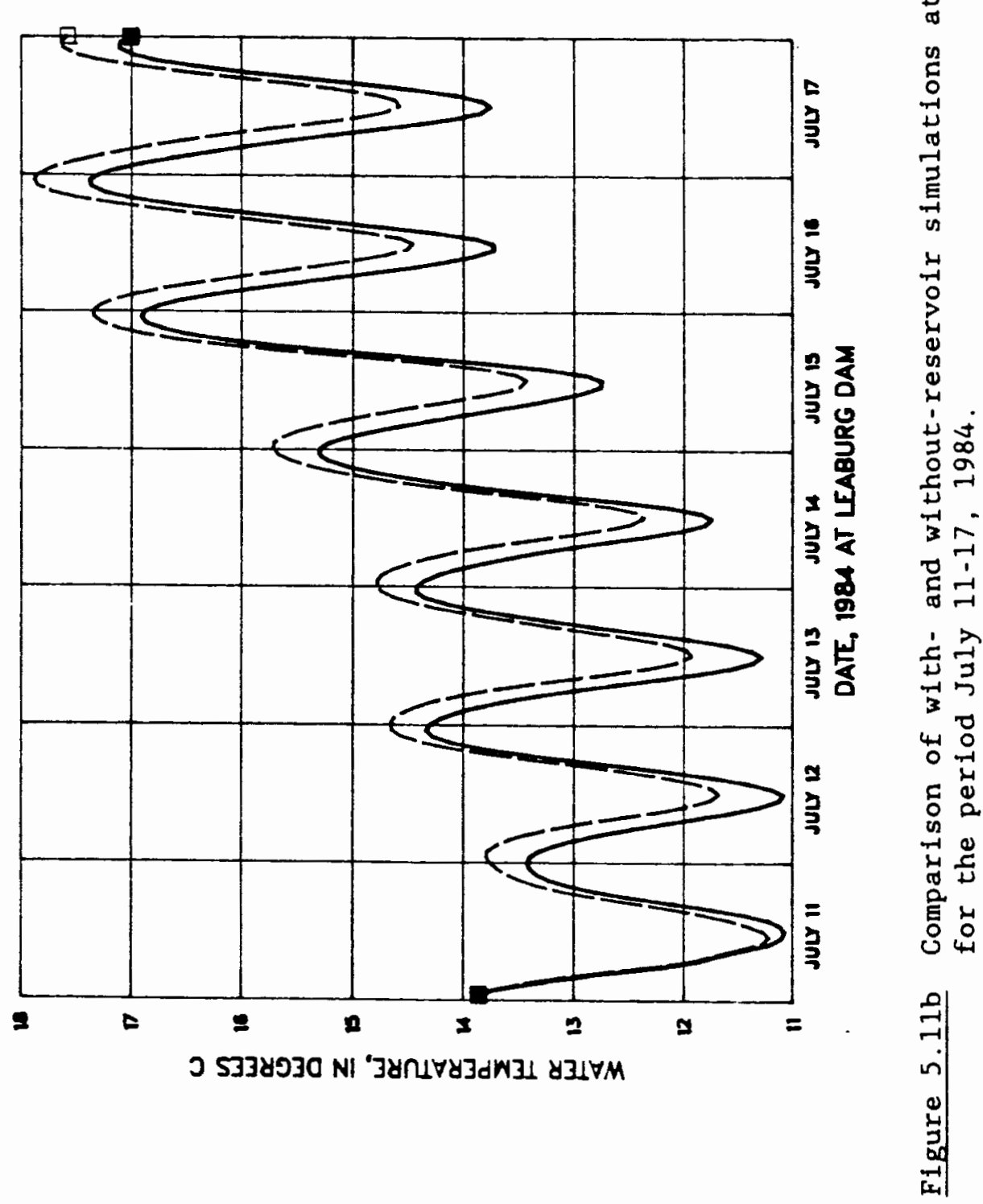



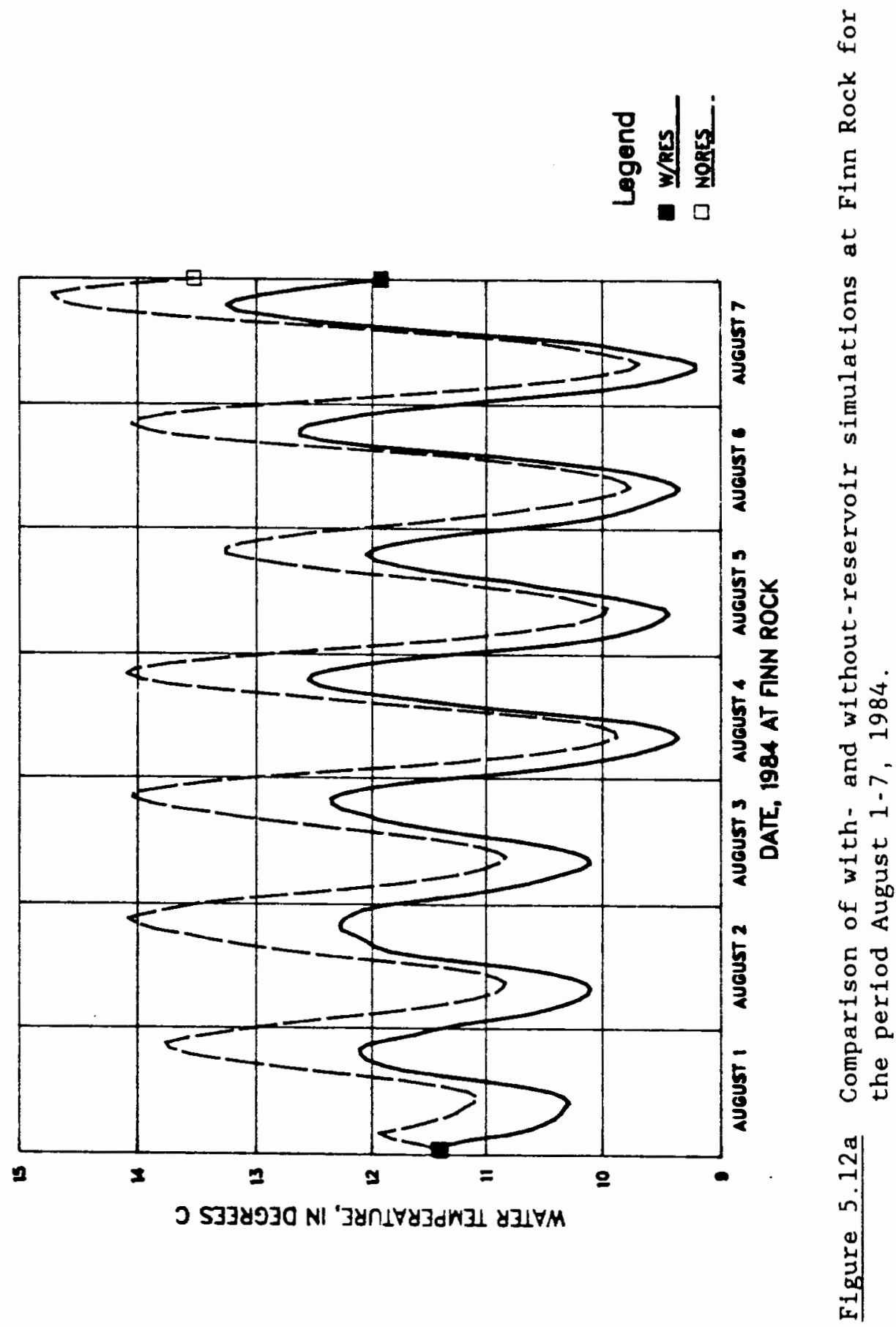


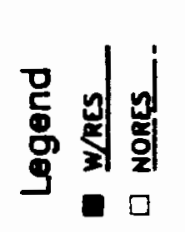

हี

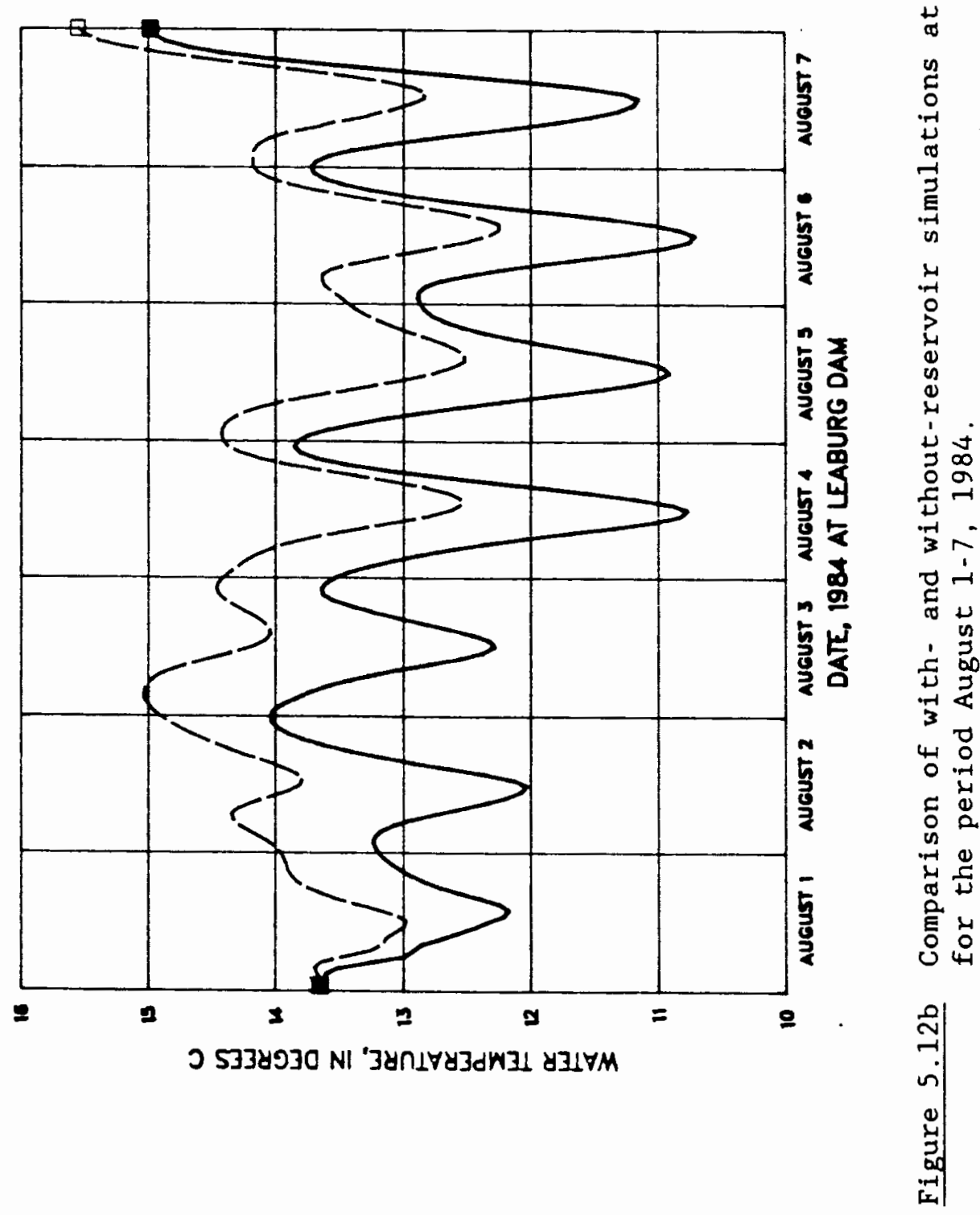




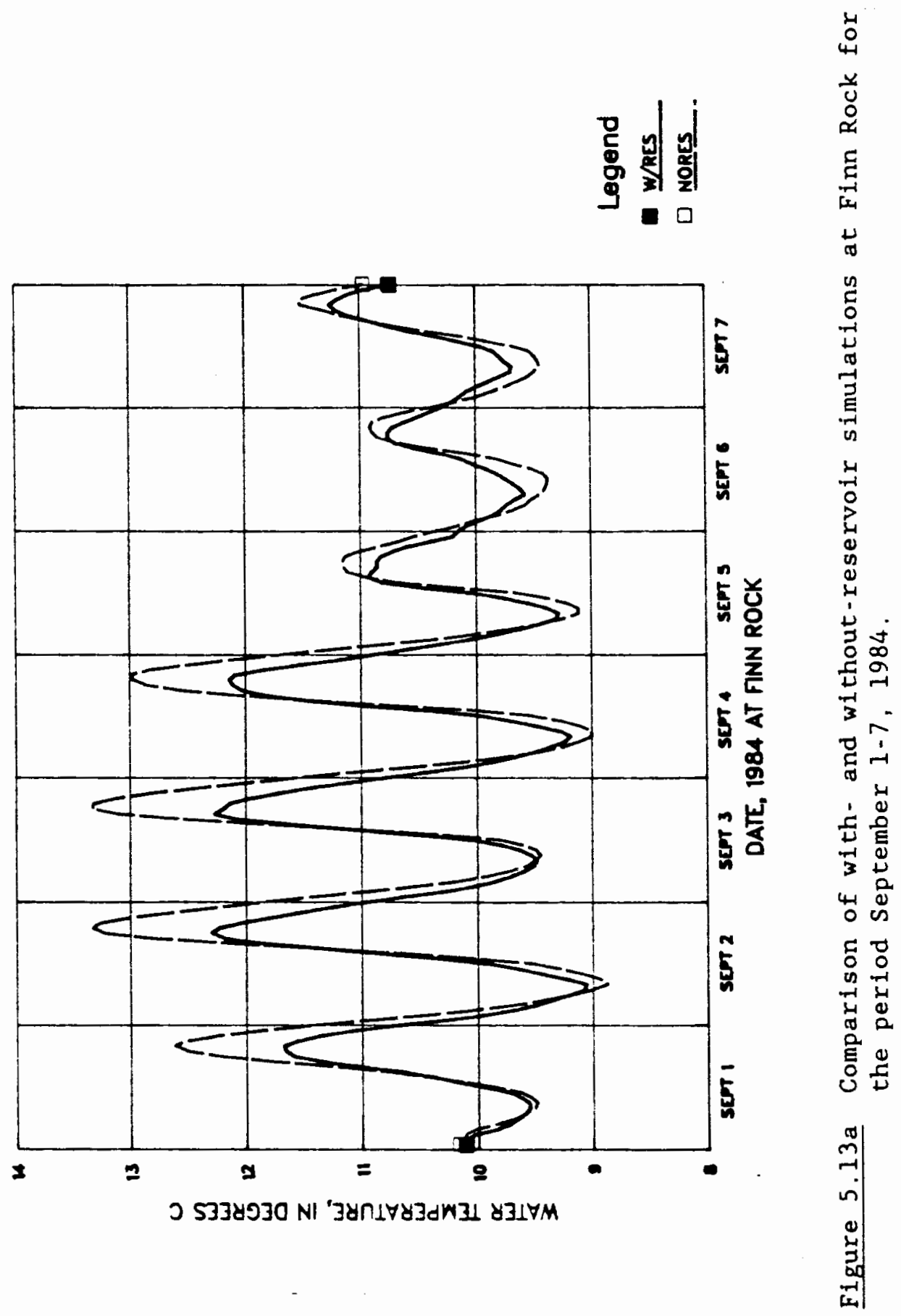




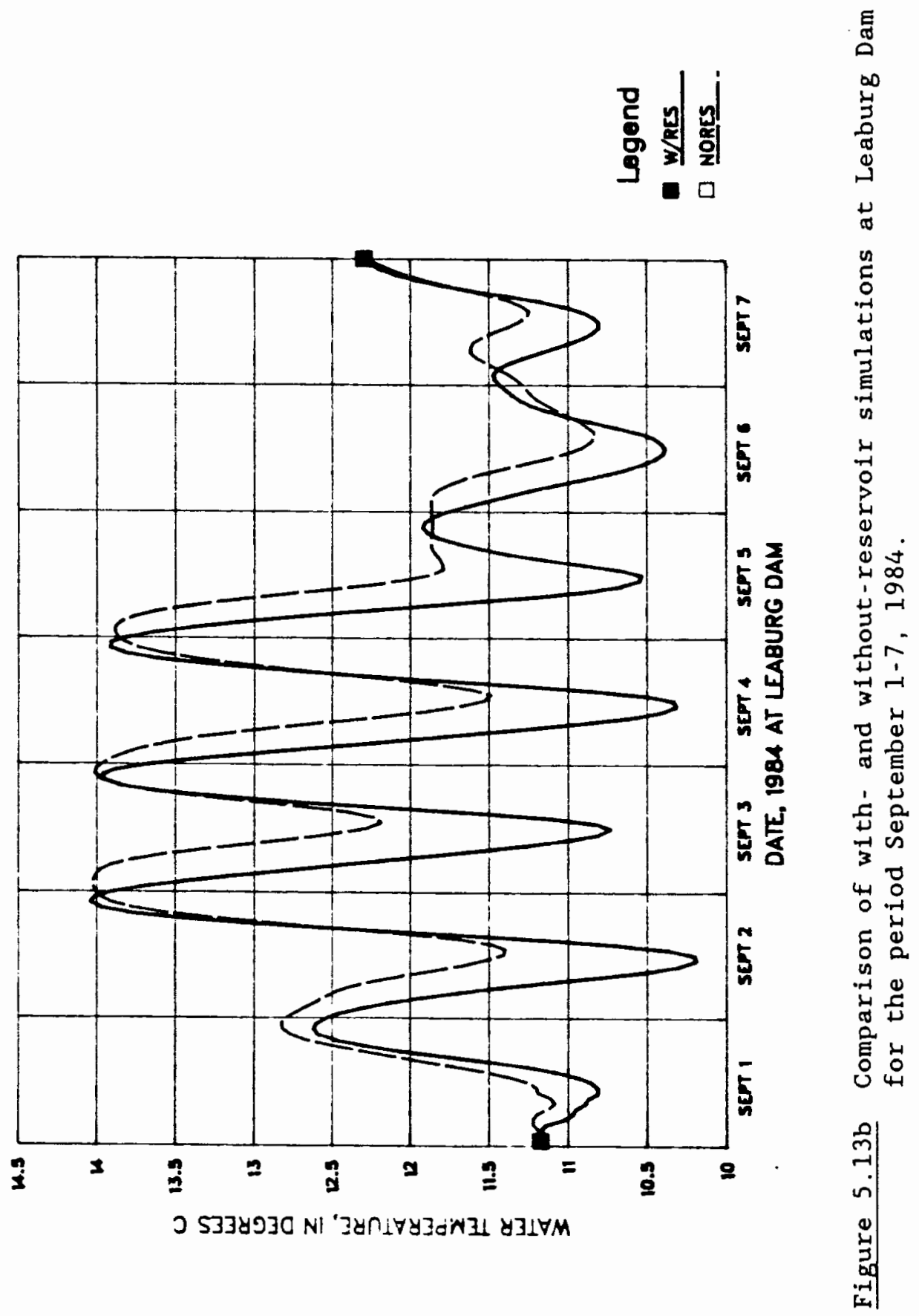


larger for the with reservoir scenario, though it too was below model accuracy .

\section{TABLE VI}

WITH AND WITHOUT RESERVOIR COMPARISONS

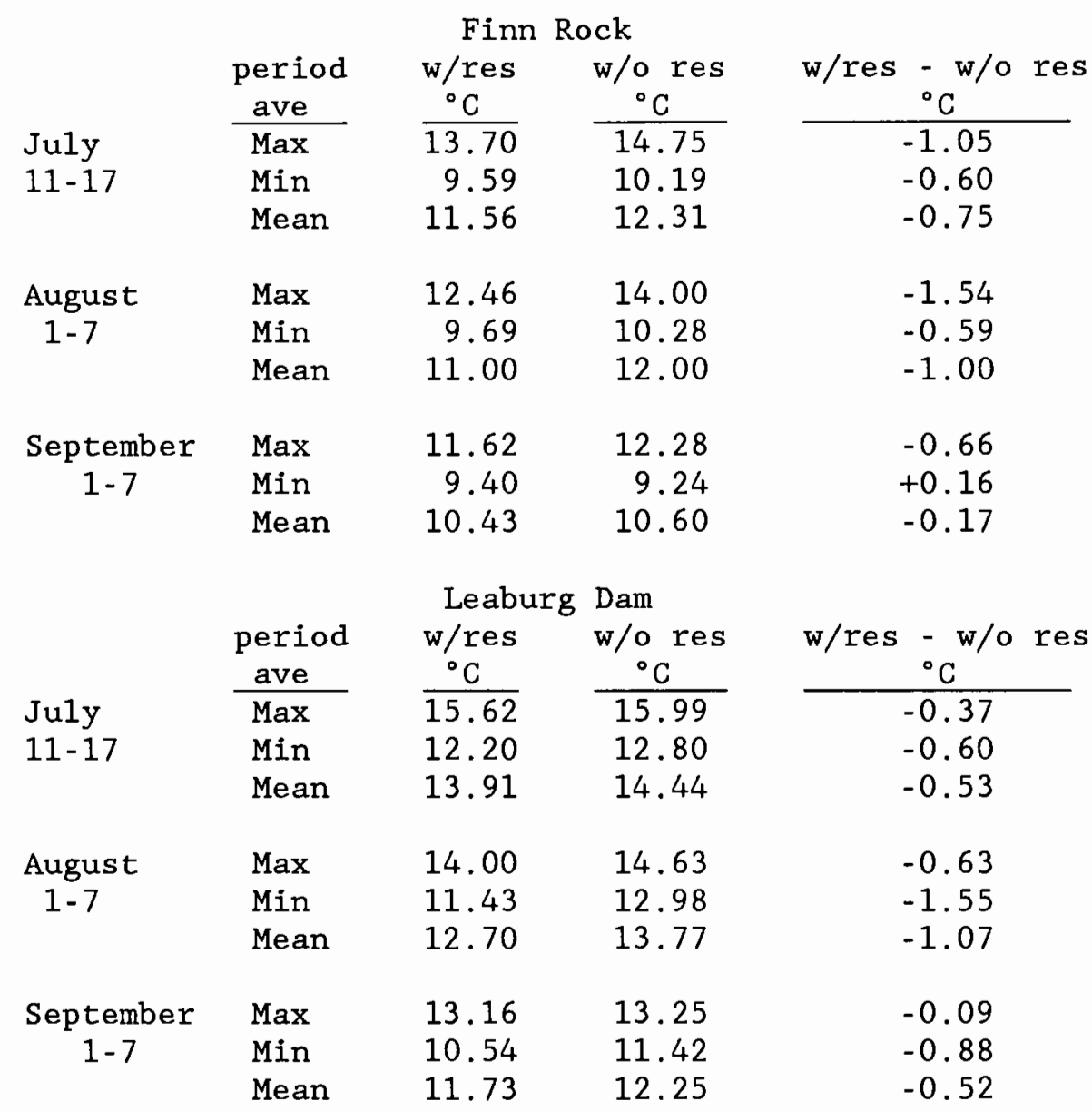

The August period exhibited the greatest cooling effect at Finn Rock. A decrease of over $1.5^{\circ} \mathrm{C}$ in daily maximum and $1.0^{\circ} \mathrm{C}$ in daily mean water temperature occurred due to the release of larger volume of water at colder temperatures than inflows to the reservoirs. A decrease in diel fluctuation of almost $1^{\circ} \mathrm{C}$ also occurred. 
At Leaburg Dam, the change in daily maximum temperature was close to model accuracy, but changes in daily minimum and mean water temperature indicate the cooling effect on these statistics extended to this point downstream. Unlike at Finn Rock, the diel fluctuation increased due to COE reservoirs.

During the September period at Finn Rock, only maximum water temperature showed a change larger than model accuracy. A decrease in diel variation still occurred, however.

Only daily minimum water temperature exhibited a change greater than model error at Leaburg Dam. An increase in diel variation continued to occur.

From the above discussion, the following conclusions are drawn. COE reservoirs have a cooling or no effect at Finn Rock and Leaburg Dam for all the periods examined. These periods do not begin to exhaust the range of hydrologic and meteorologic conditions possible on the Mckenzie River. Wide ranging generalities from the results of these three comparisons are not appropriate.

COE reservoirs had their greatest effects when the combination of high reservoir discharge at low temperature with low reservoir inflow at high temperature occurred. The most significant combination of this type occurred in August.

Comparisons of with and without reservoir simulations show $\mathrm{COE}$ reservoirs appear to cause an initial decrease and then an increase in daily diel fluctuation. The effects of the Leaburg Dam impoundment on daily diel fluctuations are not examined, but their presence is indicated in figure 5.10. The initial decrease in diel fluctuation is plausible due to the addition of larger volumes of colder water entering 
the McKenzie from reservoir releases than would occur under natural conditions. The apparent increase in diel fluctuation at Leaburg Dam due to reservoir releases may be the result of decreased residence time in the Leaburg Dam impoundment due to the larger discharge so Leaburg Dam has less of an effect, or simply model errors compounding in the wrong direction. 
CHAPTER VI

SUMMARY, CONCLUSIONS, AND RECOMMENDATIONS

SUMMARY

A one-dimensional, unsteady temperature, steady state flow model developed by Jobson (1980a), was used to simulate hourly water temperatures of the McKenzie River from Delta Park (RM 62.1) to Leaburg Dam (RM 38.8). Water temperatures were determined using the equilibrium temperature approach with air temperature as an estimate of equilibrium temperature. Hourly equilibrium temperatures were computed and also used to drive the model. Results obtained using the computed equilibrium temperature were less satisfactory than results obtained using air temperature as an estimate of equilibrium temperature.

During calibration, a heat exchange parameter, HEP, was introduced to account for the effective topwidth of a stream created by a multitude of riffles. Use of this parameter improved model results by increasing daily maximums and diel fluctuations. Calibration produced a HEP value of 2.5 for the McKenzie River.

The calibrated model was verified for two different one-week periods. Model accuracy for the calibration and validation periods was nearly identical, indicating successful calibration of a representative time period. The model had a mean error of near zero with a MAD of less than $0.4{ }^{\circ} \mathrm{C}$ at Finn Rock (RM 54.2). A mean error of $0.6{ }^{\circ} \mathrm{C}$ and MAD of over $0.6{ }^{\circ} \mathrm{C}$ at Leaburg Dam (RM 38.8) indicated that model accuracy 
decreased downstream from Finn Rock. Since water surface characteristics differ above and below Finn Rock, use of a sub-reach specific HEP value rather than a single value appears warranted.

The calibrated model was used to determine effects of COE reservoirs located on tributaries to the McKenzie River on the water temperature of the mainstem McKenzie River. A one-week period in each of the months of July, August, and September was examined. COE reservoirs were found to have cooling effects at Finn Rock during all three periods. Cooling effects were observed at Leaburg Dam during August and September with no effects found in July. Cooling effects were not uniform on each of daily maximum, minimum, and mean statistics. The greatest changes took place in the daily maximum temperature at Finn Rock and the daily minimum temperature at Leaburg Dam. The overall result of $\mathrm{COE}$ reservoirs was a decrease in water temperatures in general, and a decrease in diel fluctuation at Finn Rock but an increase in diel fluctuation at Leaburg Dam.

\section{CONCLUSIONS}

The equilibrium temperature approach is valid for modeling water temperatures on an hourly basis if air temperature is used to estimate hourly equilibrium temperature. The use of a factor to account for the increased air-water interface heat exchange caused by the turbulence of riffles is justified. This factor, HEP, increases the measured topwidth to approximate an effective topwidth. Its value is determined through calibration. From model calibration of water temperatures on the McKenzie River, a HEP value of 2.5 was found for a reach containing many riffles. 
Once the mode1 is calibrated, examination of various conditions can be analyzed by altering model input variables. Comparisons of simulations of riverine conditions for with and without COE reservoirs showed reservoir effects are greatest when reservoir outflow discharge greatly exceeds inflow discharges and inflow water temperatures exceed outflow temperatures. When reservoir outflow discharge exceed inflow discharges, cooling effects were seen as far downstream as Leaburg Dam, 18.2 miles downstream.

\section{RECOMMENDATIONS}

It is not unusual for a thesis to generate more questions than the thesis answers. That is the case here. There is often not enough time to examine all the aspects of the problem one is investigating. Here are a few recommendations for further investigation:

1) The results of the calibrated model should be compared to the results of a model that uses the complete air-water interface heat exchange equations (e.g. Jobson's Complete Model, Jobson (1980a)). This will show the accuracy gained (or lost) by using the additional atmospheric data necessary for the complete equation.

2) Calculate the windspeed function parameters and compare with Jobson's values.

3) Evaluate use of computed equilibrium temperature for daily timestep computations and compare with the use of mean daily air temperature. This is similar to what was done here on hourly time steps.

4) Validate the model over a wider range of hydrologic and meteorologic conditions. 
5) Calibrate the model by subreach using different HEP values to correspond with the subreach water surface characteristics. 


\section{REFERENCES CITED}

Anderson, E.R., 1954, Energy-budget studies in Lake Hefner Studies technical report: U.S. Geological Survey Professional Paper 269, pp 71-119.

Bowen, I.S., 1926, The ratio of heat losses by conduction and evaporation from any water surface: Physical Review, v. 27, no.6, p. $770-787$.

Brocard, D.N., and Harleman, D.R.F., 1976, One-dimensional temperature predictions in unsteady flows: Journal of the Hydraulics Division, ASCE, v. 102, no. HY3, p 227-240.

Brown, G.W., 1969, Predicting temperature of sma11 streams: Water Resources Research, v. 5, no 1, p 68-75.

Dingman, S.L., Weeks, W.F., and Yen, Y.C., 1968, Effects of therma1 pollution on river ice conditions: Water Resources Research, v. 4, no. 2 , p $349-362$.

Dingman, S.L., 1972, Equilibrium temperatures of water surfaces as related to air temperature and solar radiation: Water Resources Research, v. 8, no 1, p 42-49.

Edinger, J.E., 1970, Vertical temperature structure and water surface heat exchange: Water Resources Research, v. 6, no. 5, p 1392-1395.

Edinger, J.E., and Geyer, J.C., 1965, Heat exchange in the environment: EEI Publication No. 65-902, Edison Electric Institute, New York, $259 \mathrm{p}$.

Edinger, J.E., Duttweiler, D.W., and Geyer, J.C., 1968, The response of water temperature to meteorlogical conditions: Water Resources Research, v. 4, no 5, p. 1137-1143.

Fritschen, L.J., and Gay, L.W., 1979, Environmental Instrumentation: New York, Springer-Verlag Inc., $216 \mathrm{p}$.

Hansen, R.P., 1986, Determination of the effects of selected reservoirs on the water temperature of the McKenzie River, Oregon: U.S.

Geological Survey Water-Resources Investigation Report, in press.

Hi11s, R.G., and Viskanta, R., 1976, Modeling of unsteady temperature distribution in rivers with thermal discharges: Water Resources Research, v. 12, no. 4, p 712-722.

Jackman, A.P. and Yotsukura, N., 1977, Thermal loading of natural streams: U.S. Geological Survey Professional Paper 991, 39 p. 
Jobson, H.E., 1973, The dissipation of excess heat from water systems: Journal of the Power Division, ASCE, v. 99, no. P01, p 89-103.

Jobson, H.E., 1980a, Temperature and solute-transport simulation in streamflow using a Lagrangian reference frame: U.S. Geologica1 Survey Water-Resources Investigations 81-2, 165 p.

Jobson, H.E., 1980b, Thermal modeling of the San Diego Aqueduct, California, and its relation to evaporation: U.S. Geological Survey Professional Paper 1122, 24 p.

Jobson, H.E., 1980c, Comment on "A new collocation method for the solution of the convetion-dominated transport equation" by George E. Pinder and Allen Shapiro: Water Resources Research, v. 16, no. $6, \mathrm{p}$ 1135-1136.

Jobson, H.E., and Keefer, T.N., 1979, Modeling highly transient flow, mass and heat transport in the Chattahoochee River near Atlanta, Georgia: U.S. Geological Survey Professional Paper 1136, 41p.

Kothandaraman, V., 1971, Analysis of water temperature variations in large rivers: Journal of the Sanitary Division, ASCE, v. 97, no. SA1, pp 19-31.

Laenen, A., and Hansen, R.P., 1985, Preliminary study of the watertemperature regime of the North Santiam River downstream from Detroit and Big Cliff Dams, Oregon: U.S. Geological Survey WaterResources Investigations Report 84-4105, 45 p.

McMichael, F.C., and Hunter, J.S., 1972, Stochastic modeling of temperature and flow in rivers: Water Resources Research, v. 8, no. $1, \mathrm{p}$ 87-98.

Moore, A.M., 1967, Correlation and analysis of water-temperature data for Oregon streams: U.S. Geological Survey Water-Supply Paper $1819-\mathrm{K}, 53 \mathrm{p}$.

Morse, W.L., 1970, Stream temperature prediction mode1: Water Resources Research, v. 6, no. 1, p 290-302.

Morse, W.L., 1972, Stream temperature prediction under reduced flow: Journal of the Hydraulic Division, ASCE, v. 98, no. HY6, p 10311047.

Noble, R.D., 1981, Comparison of two surface heat exchange models: Journa1 of the Hydraulics Division, ASCE, v. 107, no. HY3, p 361366 .

Paily, P.P., Macagno, E.0., and Kennedy, J.F., 1974, Winter-regime thermal response of heated streams: Journal of the Hydraulics Division, ASCE, v. 100, no. HY4, p 531-551. 
Pinder, G.E., and Shapiro, A., 1979, A new collocation method for the solution of the convection-dominated transport equation: Water Resources Research, v.15, no. 5, p 1177-1182.

Ryan, P.J., and Stolzenbach, K.D., 1972, Environmental heat transfer, in Engineering Aspects of Heat Disposal from Power Generation:, Massachusetts Institute of Technology, Cambridge, Ralph M. Parsons Laboratory for Water Resources and Hydrodynamics, summer session, $75 \mathrm{p}$.

Stang, 0., 1982, On the heat exchange between rivers and atmosphere: Nordic Hydrology, v. 13, p 65-78.

State Water Resources Board, 1961, Upper Willamette River Basin: Oregon State Water Resources Board Publication, 186 p.

Stevens, H.H. Jr, Ficke, J.F., and Smoot, G.F., 1975, Water Temperature - influential factors, field measurement, and data presentation: U.S. Geological Survey Techniques of Water-Resources Investigations, Book 1, Chapter D1, $65 \mathrm{p}$.

Tennessee Valley Authority, 1972, Heat and mass transfer between a water surface and the atmosphere: Water Resources Research Laboratory Report No. 14, Norris, Tennessee, April, 166 p.

Yotsukura, N., Jackman, A.P., and Faust, C.R., 1973, Approximation of heat exchange at the air-water interface: Water Resources Research, v. 9, no. 1, p 118-128. 
APPENDIX

PROGRAM TO COMPUTE EQUILIBRIUM TEMPERATURES

BY R. PEDER HANSEN JANUARY, 1985

CONSTANTS

ALPHA $=$ CONSTANT IN WIND FCN $=.302 \mathrm{CM} / \mathrm{D} \mathrm{kPa}$

EMIS $=$ EMISSIVITY OF WATER $=0.97$ UNITLESS

GAM = PSYCHROMETRIC CONSTANT $=0.06 \mathrm{kPa} /{ }^{\prime} \mathrm{C}$

RHO = DENSITY OF WATER $=1 \mathrm{G} / \mathrm{CM}^{\wedge} 3$

$\mathrm{SBC}=$ STEFAN-BOLTZMAN CONSTANT $=1.171 \times 10^{\wedge}-7 \mathrm{CAL} / \mathrm{CM}^{\wedge} 2 \mathrm{D} \mathrm{K} 4$

$\mathrm{XMTC}=$ MASS TRANSFER COEFF $=.113 \mathrm{CM} / \mathrm{D} \mathrm{kPa} \mathrm{M} / \mathrm{S}$

VARIABLES

$\mathrm{AR}=$ ATMOSPHERIC RADIATION $=\mathrm{CAL} / \mathrm{CM}^{\wedge} 2 / \mathrm{HR}$

$\mathrm{HB}=$ BACK RADIATION

$\mathrm{HC}=$ CONDUCTION

HE $\quad=$ EVAPORATION

HN $=$ NET INCOMING RADIATION

JDAY = JULIAN DAY

PASR = PERCENTAGE ABSORBED SOLAR RADIATION

SVPA = SATURATION VAPOR PRESSURE OF AIR AT Te, kPa

$\mathrm{SR}=$ SOLAR RADIATION $=\mathrm{CAL} / \mathrm{CM}^{\wedge} 2 / \mathrm{HR}$

$\mathrm{TA}=\mathrm{AIR}$ TEMPERATURE $={ }^{\prime} \mathrm{C}$

$\mathrm{TE}=$ EQUILIBRIUM TEMPERATURE $={ }^{\prime} \mathrm{C}$

$\mathrm{VP}=\mathrm{VAPOR}$ PRESSURE $=\mathrm{kPa}$

WS $\quad=$ WINDSPEED $\mathrm{M} / \mathrm{S}$

XLHV = LATENT HEAT OF VAPORIZATION

CHARACTER ADFN*32, HEADER $* 32$

REAL JDAY

EMIS $=0.97$

$\mathrm{SBC}=(1.171 \mathrm{E}-7) / 24 . \quad / *$ CONVERT TO HOURLY $* /$

$\mathrm{RHO}=1.0$

$\mathrm{GAM}=0.06$

ALPHA $=.302 / 24 . \quad / *$ CONVERT TO HOURLY $* /$

XMTC $=.113 / 24 . \quad / *$ CONVERT TO HOURLY $* /$

WRITE $(1, *)$ 'INPUT ATMOSPHERIC DATA FILENAME'

$\operatorname{READ}(1,10)$ ADFN

OPEN (UNIT $=5$, FILE=ADFN, STATUS $=$ 'OLD')

$\operatorname{READ}(5,10)$ HEADER

11 CONTINUE

DO $25 \mathrm{I}=1,24$

$\operatorname{READ}(5,30, \mathrm{END}=99) \mathrm{JDAY}, \mathrm{HR}, \mathrm{TW}, \mathrm{TA}, \mathrm{WS}, \mathrm{SR}, \mathrm{AR}, \mathrm{VP}$

$\mathrm{HR}=\mathrm{HR} / 100.0$

C $\quad V P=V P * 0.90$

IF (WS. LT . 0.475) WS $=0.0$

/ * THRESHOLD VELOCITY */

CALL REFLECT (JDAY, HR, PASR)

$\mathrm{HN}=\mathrm{PASR} * \mathrm{SR}+.97 * \mathrm{AR}$

C $\mathrm{HN}=\mathrm{SR}+\mathrm{AR}$

C TE $=\mathrm{TA}$ 


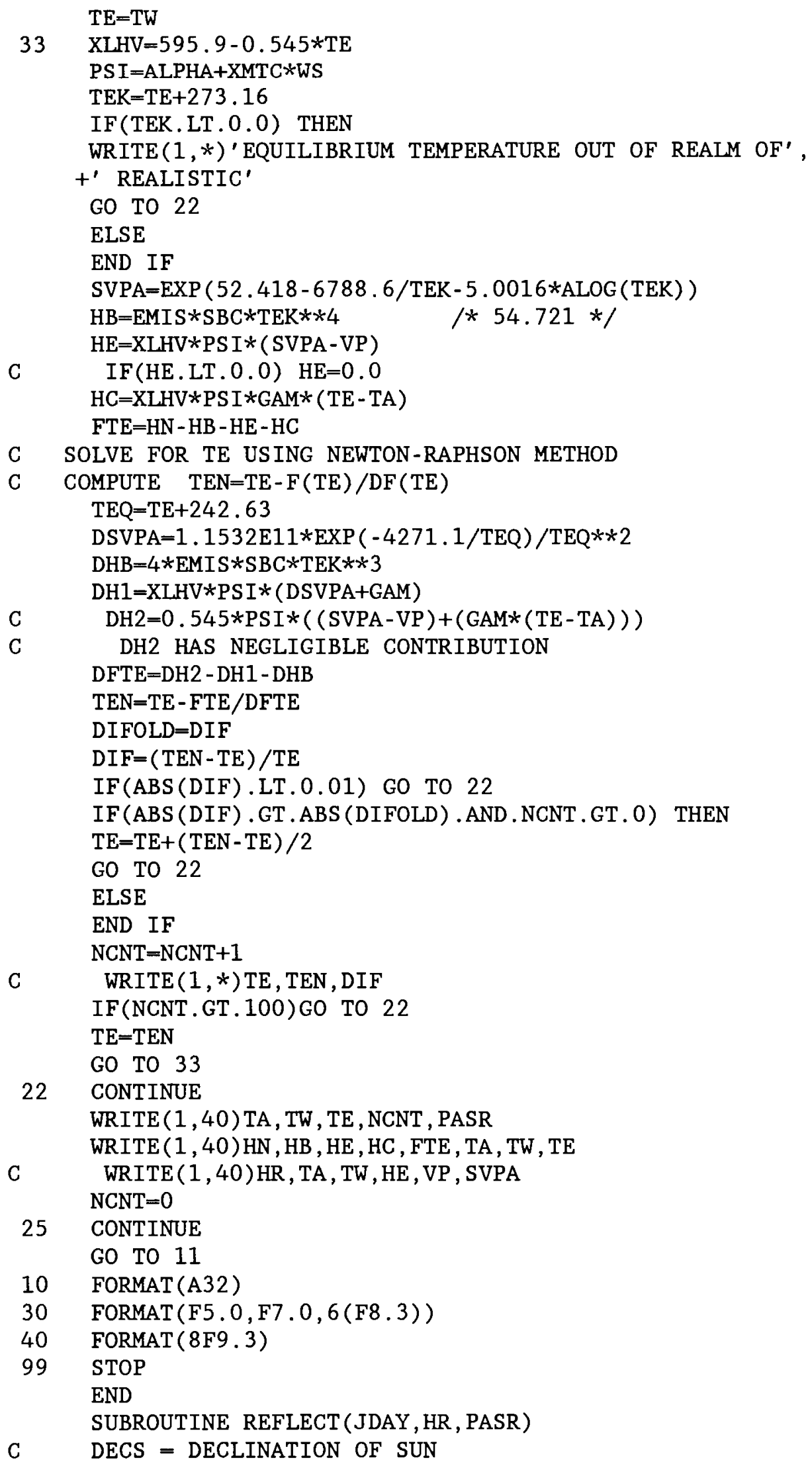


C HA $=$ HOUR ANGLE

C $\quad 6.2832=2 * \mathrm{PI}$

C $23.45=$ COEFFICIENT IN SOLAR DECLINATION EQUATION

C

$\mathrm{DR}=3.14159 / 180.0 / *$ DEGREE TO RADIAN CONV

$\mathrm{PHI}=44.0 * \mathrm{DR}$

* LATITUDE OF RIVER

ALON $=122.0$

$/ *$ LONGITUDE OF RIVER

$\mathrm{TZM}=120.0$

$/ *$ MERIDIAN OF TIME ZONE

$\mathrm{DECS}=\mathrm{DR} * 23.45 * \mathrm{COS}(6.2832 *(172.0-\mathrm{JDAY}) / 365.0)$

$* /$

$\mathrm{HA}=((180.0+\mathrm{ALON}-\mathrm{TZM})-15.0 * \mathrm{HR}) * \mathrm{DR}$

ELEV1 $=S I N(D E C S) * S I N(P H I)$

$\mathrm{ELEV} 2=\operatorname{COS}(\mathrm{DECS}) * \operatorname{COS}(\mathrm{PHI}) * \operatorname{COS}(\mathrm{HA})$

$\mathrm{ELEV}=($ ASIN $($ ELEV1+ELEV2 $)) / \mathrm{DR}$

IF (ELEV.LE.1.5) THEN

PASR $=0.2$

ELSE

PASR $=1.0-1.18 /$ ELEV $* *(0.77)$

END IF

RETURN

END 